

\section{California Agriculture}

Peer-reviewed research and news published by University of California Agriculture and Natural Resources

Director of Publishing, Executive Editor: Jim Downing

Managing Editor: Deborah Thompson

Senior Editor: Hazel White

Senior Writer and Editor: Lucien Crowder

Art Director: Will Suckow

\section{ASSOCIATE EDITORS}

Animal, Avian, Aquaculture \& Veterinary Sciences: John Angelos, Maurice Pitesky

Economics \& Public Policy: Rachael Goodhue, Mark Lubell Kurt Schwabe

Food \& Nutrition: Amy Block Joy, Lorrene Ritchie

Human \& Community Development: Rob Bennaton, Martin Smith

Land, Air \& Water Sciences: Hoori Ajami, Khaled Bali, Yufang Jin, Sanjai Parikh

Natural Resources: Ted Grantham, William C. Stewart

Pest Management: Kent Daane, Neil McRoberts,

James Stapleton

It is the policy of the (UC) and the UC Division ure and Natura Resources (UC ANR) not to engage in discrimination against or harassment of any person in any of its programs or activities (Complete nondiscrimination policy found at http://ucanr.edu/sites/ anrstaff/files/187680.pdf)

Inquiries regarding the University's equa employment opportunity policies may be directed to: Affirmative Action Contact and Title IX Officer, University of California, Agriculture and Natural Resources, 280 Second Street, Davis, CA 95618, (530) 750-1397. Email: titleixdiscrimination@ucanr. edu. Website: http://ucanr. edu/sites/anrstaff/Diversity/ Affirmative_Action/.

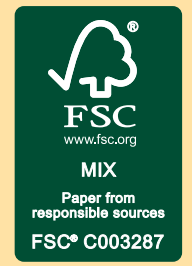

Editor's note: California Agriculture is printed on paper certified by the Forest Stewardship Council ${ }^{\bullet}$ as sourced from well-managed forests, with $10 \%$ recycled elemental chlorine. See www. fsc.org for more information.
Plant Sciences and Agronomy: Kevin R. Day, Matthew Gilbert, Stephen Kaffka, Rachael F. Long

\section{ORDERS AND SUBSCRIPTIONS}

2801 Second Street, Room 181A; Davis, CA 95618-7779

Phone: (530) 750-1223; Fax: (530) 756-1079; calag@ucanr.edu

\section{EDITORIAL}

2801 Second Street, Room 184; Davis, CA 95618-7779

(530) 750-1223; calag.ucanr.edu

California Agriculture (ISSN 0008-0845, print, linking; ISSN 2160-8091, online) is published quarterly. Postmaster: Send change of address "Form $3579 "$ to California Agriculture at the address above.

(02018 The Regents of the University of California

California Agriculture is a quarterly, open-access, peerreviewed research journal. It has been published continuously since 1946 by University of California Agriculture and Natural Resources (ANR). There are about 10,000 print subscribers.

Mission and audience. California Agriculture publishes original research and news in a form accessible to an educated but non-specialist audience. In the last readership survey, $33 \%$ of subscribers worked in agriculture, $31 \%$ were university faculty or research scientists and 19\%

Electronic version of record. In July 2011, the electronic journal (calag.ucanr.edu) became the version of record. Since then, some research article are published online only. All articles published since 1946 are freely available in the online archive, calag.ucanr.edu/Archive/. worked in government.
Indexing. The journal provides article metadata to major indexing services, including Thomson (Web of Science), AGRICOLA, the Directory of Open Access Journals and EBSCO (Academic Search Complete), and has high visibility on Google Scholar. All articles are posted to eScholarship, UC's open-access repository. In the 2017 Thomson JCR, the journal's impact factor was 1.2.

Authors. Most authors (75\%) are among the roughly 1,000 academics affiliated with ANR, including UC Cooperative Extension specialists, advisors and academic coordinators; and faculty in the following UC colleges: UC Berkeley College of Natural Resources, UC Davis College of Agriculture and Environmental Sciences, UC Davis School of Veterinary Medicine, and UC Riverside College of Natural and Agricultural Sciences. Submissions are welcome from researchers based at government agencies and at other campuses and research institutes.

Article submission and review. Guidelines for authors are here: calag.ucanr.edu/submitarticles/. The journal uses a double-blind peer-review process described at calag.ucanr.edu/About/. Roughly $50 \%$ of all submissions are rejected by the editors without peer review due to a mismatch with the journal's scope or clear weaknesses in the research. Of the subset of submissions that enter the peer-review process, roughly $60 \%$ are ultimately accepted. All accepted manuscripts are edited to ensure readability for a non-specialist audience.

Letters. The editorial staff welcomes letters, comments and suggestions. Please write to us at the address below, providing your contact information.

Print subscriptions. These are free within the United States and \$24 per year abroad. Go to: calag.ucanr.edu/ subscribe/ or write or call.

Permissions. Material in California Agriculture, excluding photographs, is licensed under the Creative Commons CC BY-NC-ND 4.0 license. Please credit California Agriculture, University of California, citing volume, number and page numbers. Indicate $\odot[y e a r]$ The Regents of the University of California.

To request permission to reprint a photograph published in California Agriculture, please complete the UC ANR Permissions Request Form (http://ucanr.edu/survey/ survey.cfm?surveynumber=5147). In general, photos may be reprinted for non-commercial purposes.

UNIVERSITY
OF
CALIFORNIA

\section{University of California}

Agriculture and Natural Resources 


\section{Contents}

\section{News and opinion}

\section{OUTLOOK}

148 Proactive biological control: A cost-effective management option for invasive pests

Hoddle et al.

Proactive biocontrol could accelerate responses to invasive pests in urban areas - where pesticide use may be unpopular - before they spread to agricultural areas.

151 Groundwater sustainability in the San Joaquin Valley: Multiple benefits if agricultural lands are retired and restored strategically

Kelsey et al.

Restoring habitat in retired farmland could reduce water demand and provide ecosystem services for farmers and local communities.

155 Possible impacts of rising $\mathrm{CO}_{2}$ on crop water use efficiency and food security

Scavo et al.

Understanding the mechanisms involved in plants' response to rising $\mathrm{CO}_{2}$ levels may lead to the development of crop plant varieties better adapted to future drought conditions.

\section{RESEARCH NEWS}

\section{Research highlights}

Downing and Crowder

Briefs on recent articles on grafted tomatoes, avocado ripening, fresh produce in low-income neighborhoods, a dystopic novel and more.

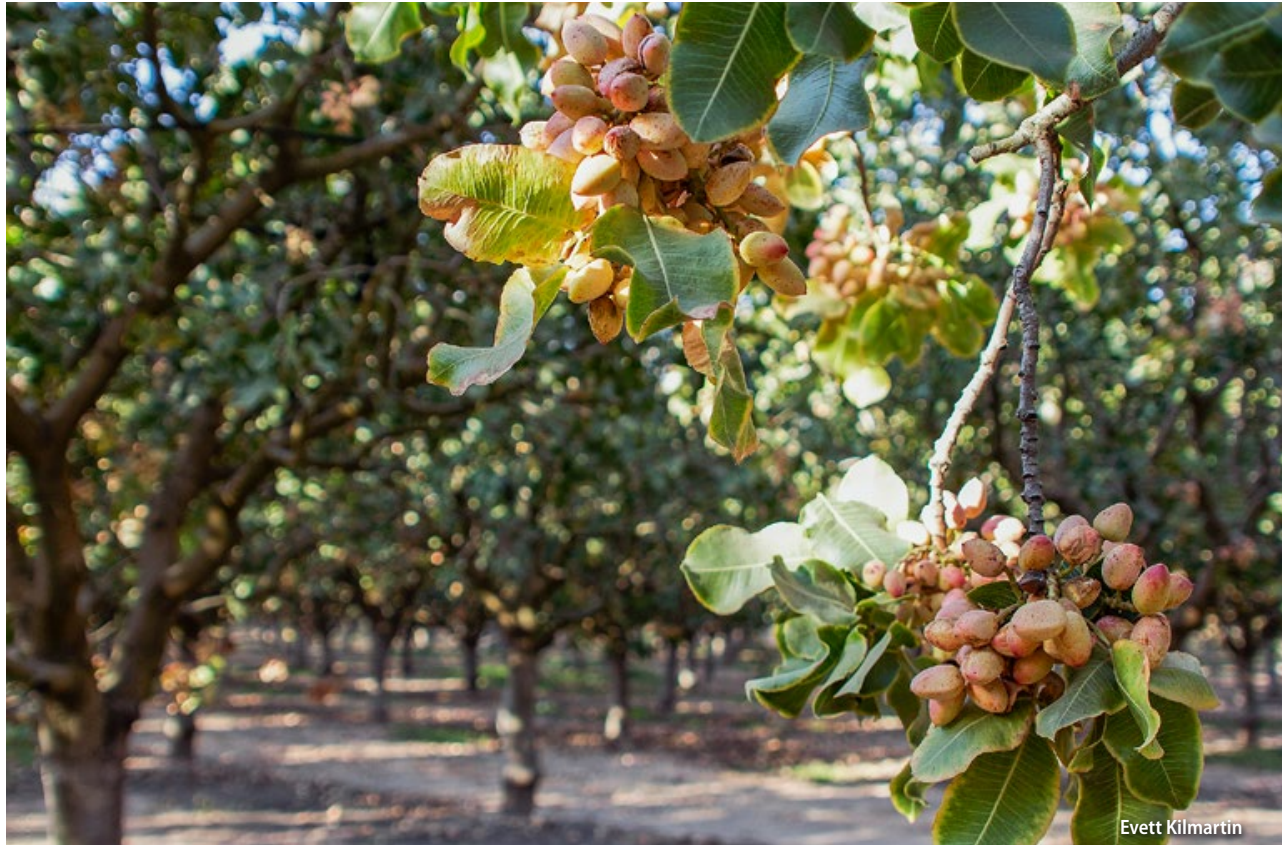

\section{Research and review articles}

162 Streamflow availability ratings identify surface water sources for groundwater recharge in the Central Valley

Dahlke and Kocis

The STARR web tool estimates how much and when surplus surface water occurs in each watershed in the three Central Valley basins, to help water planners expand groundwater banking.

170 Survey of the pathogen of Alternaria late blight reveals different levels of carboxamide fungicide resistance in the main pistachio producing regions of California

Lichtemberg et al.

Resistance was greatest in counties at the northern and southern ends of the Central Valley, where weather conditions are conducive to pathogen infection.

179 Modeled soil erosion potential is low across California's annual rangelands

Salls et al.

The authors used the Revised Universal Soil Loss Equation computer model to evaluate how high, medium and low levels of residual forage dry matter affect soil erosion potential across California rangelands. 


\title{
Proactive biological control: A cost-effective management option for invasive pests
}

\author{
Proactive biocontrol could accelerate responses to invasive pests in urban areas — where pesticide \\ use may be unpopular — before they spread to agricultural areas.
}

\begin{abstract}
Mark S. Hoddle, UC Cooperative Extension Specialist, Department of Entomology, and Director, Center for Invasive Species Research, UC Riverside Kevi Mace, Senior Environmental Scientist, Office of Pesticide Consultation and Analysis, California Department of Food and Agriculture, and Research Associate, UC Davis Department of Agricultural and Resource Economics
\end{abstract}

John Steggall, Senior Environmental Scientist, Office of Pesticide Consultation and Analysis, California Department of Food and Agriculture, and Research Associate, UC Davis Department of Land, Air and Water Resources

nvasive pests regularly threaten California agriculture as well as the state's diverse urban and wilder-

ness areas. Approximately nine nonnative species of invertebrates (i.e., insects, mites, spiders, etc.) establish in the state each year, of which about three become pests (Dowell et al. 2016). These invasive species move globally through trade and tourism. Biological control programs are typically implemented as part of an integrated pest management (IPM) approach for some invasive species infestations in California. However, a proactive approach would be to screen a pest's natural enemies and approve them for release ahead of time, before the pest establishes in California. Such a project is just getting underway.

California's agricultural enterprises are vast (valued at $\$ 46$ billion in 2015), and the state is a world leader in the

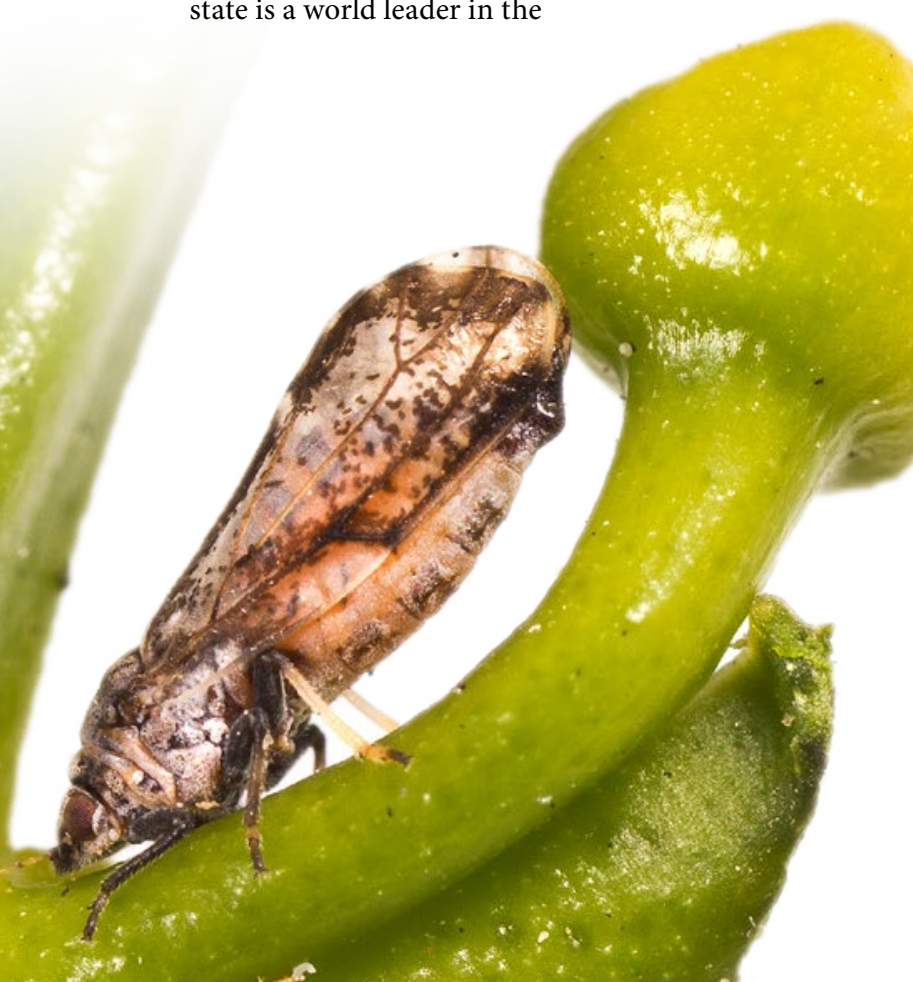

development of science-based pest management solutions. Biological control and IPM originated here. IPM is a comprehensive approach to managing pests and combines plant and pest management practices, of which biological control is one, to reduce pest pressure, crop damage and pesticide use. Biological control is the intentional use of a pest's natural enemies for suppressing population densities to less damaging levels. When a nonnative species is introduced into a new area, its population may grow and spread rapidly because predators, parasitoids or pathogens that limited population growth in the native area are not present. Classical biological control programs import, screen for safety and establish safe natural enemy species from the invader's native area for pest control.

Biological control programs in California began

125 years ago, with numerous achievements over the years in agricultural crops (e.g., citrus, olives, grapes, alfalfa) and urban areas (e.g., ash and eucalyptus). In several cases, imported natural enemies have suppressed invasive pest populations so that they no longer require management, and in many instances they have contributed significantly to IPM programs by reducing the need to spray pesticides. When a new invasive pest becomes established, IPM programs that carefully manage insecticide use may be disrupted as spraying increases in response to pressure from the new pest. In urban areas, which can be hot spots for invasive species that threaten agriculture, pesticide use to eradicate or control an invasive pest can cause public resistance, which sometimes results in legal actions and the termination of pest control programs.

With a proactive biological control approach, natural enemies would be selected, screened and pre-approved for release before an anticipated pest invasion. That way, natural enemies could be released against a target pest at a much earlier point in the emerging

Asian citrus psyllid is arguably the most serious threat California citrus growers face, because it vectors a citrus-killing bacterium. 
management program. Natural enemies could, in some cases, significantly reduce pest densities and slow rates of spread, which would lower the economic or environmental damage associated with the pest.

\section{If biocontrol agents had been approved prior to ACP establishment}

Asian citrus psyllid (ACP), a citrus pest that vectors a citrus-killing bacterium (CLas), is a highprofile example that can be used to illustrate the potential advantages of forwardplanning. ACP-CLas has severely impacted citrus production in Florida, Texas and Mexico. In 2008, ACP was found infesting backyard citrus in San Diego County (Milosavljević et al. 2017). Control attempts using pesticides were expensive and ultimately did not prevent the geographic expansion of ACP in Southern California.

In 2010, a biological control program was initiated against ACP in Southern California. Exploration for ACP natural enemies was conducted in Pakistan and resulted in federal approval of two natural enemy species for release in California. Exploration, evaluation and approval steps took several years to complete (Milosavljević et al. 2017). With appropriate funding and forward-planning, these steps could have been completed before the anticipated establishment of ACP in California. Release of ACP biological control agents could have been made concurrent with ACP establishment rather than years later, and could have been used as a component of an IPM program to reduce ACP populations in the early stages of the urban invasion.

\section{Choosing pests for proactive biological control}

Identifying pests for proactive biological control is a multi-step process that is part of a larger statewide pest management system. Several factors may be considered, from the likelihood of an invasion, to the feasibility of developing a biological control program.

\section{Pests established in other states or Baja California}

Dowell et al. (2016) noted that around $46 \%$ of nonnative invertebrates that establish in California come from established populations in the United States.
Consider ACP, which established in Florida-grown citrus around 1995 and in California in 2008; brown marmorated stink bug, which established in Pennsylvania around 1998 and probably established in California around 2005; and South American palm weevil, which was known to be in Tijuana, Mexico, since 2010, and was detected in southern San Diego County in 2011 and likely established there around 2014.

\section{Pests associated with produce imports}

Another avenue for selecting potential target pests for proactive biological control is to work with other government agencies to continually assess the risk associated with imports of agricultural produce. Consider avocados, an iconic California crop worth around $\$ 300$ million per year. The California avocado industry has no significant fruit-feeding pests to manage. However, there's a risk of a pest invasion from the millions of pounds of avocados imported into California from countries where native fruit-feeding moths and weevils are notorious avocado pests. These pests could be proactively screened for natural enemies for potential rapid importation and release into California. This approach could reduce the enormous turmoil of a pest invasion as avocado growers adapt to managing the new pests and existing IPM programs are re-engineered to accommodate them.
Brown marmorated stink bug is a highly polyphagous pest that has caused unprecedented problems in stone fruit, pome and row crops in the eastern United States. 


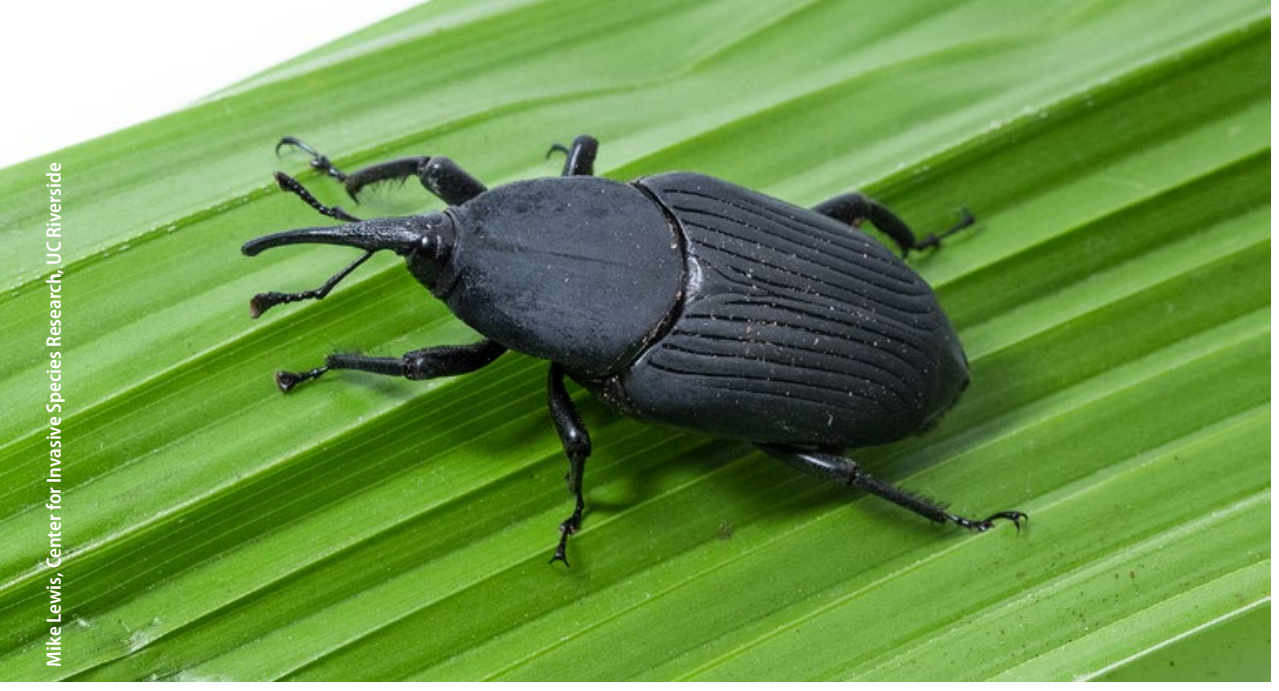

South American palm weevil is killing ornamental Canary Islands date palms in Southern California and poses a serious threat for edible date producers in the Coachella Valley.

\section{Easily controlled pests, borrowed programs, unique threats}

Not all pests are suitable targets for biological control programs. Thrips, for example, are very important agricultural pests but typically don't have specialist natural enemies that effectively regulate population growth. Invasive thrips therefore would not be good targets for proactive biological control. On the other hand, some pest groups have natural enemies capable of exerting strong population control. Some species of whiteflies, scales, leafhoppers and mealybugs have natural enemies capable of controlling them, and these pests have been successfully suppressed in California with biocontrol agents.

Some pests likely to invade California may already be the target of biological control in other parts of the United States or the world. In these situations, scientists can borrow from these programs and proactively screen the natural enemies for use in California. Alternatively, a unique pest threat may be identified, one that has not been targeted for biological control because it is new to science, or little is known about its population ecology in the native range. Should such a pest be recognized in advance of its arrival in California, scientists would need to identify natural enemies from foreign exploration efforts and assess their potential for use in California.

\section{References}

Charles J. 2012. Assessing the non-target impacts of classical biological control agents: Is host testing always necessary? BioControl 57:619-26. https://doi.org/10.1007/s10526-012-9449-z

Dowell RV, Gill RJ, Jeske DR, Hoddle MS. 2016. Exotic terrestrial macro-invertebrate invaders in California from 1700 to 2015: An analysis of records. Proc Calif Acad Sci 63:63-157.

Grandgirard J, Hoddle MS, Petit JN, et al. 2009. Classical biological control of the glassy-winged sharpshooter, Homalodisca vitripennis, by the egg parasitoid Gonatocerus ashmeadi in the Society, Marquesas, and Austral archipelagos of French Polynesia. Biol Control 48:155-63. https://doi.org/10.1016/j. biocontrol.2008.10.005

Hoddle MS, Hoddle CD. 2008. Bioecology of Stenoma catenifer (Lepidoptera: Elachistidae) and associated larval parasitoids reared from Hass avocados in Guatemala. J Econ Entomol 101:692-8. https://doi. org/10.1093/jee/101.3.692

Lara JR, Pickett C, Ingels C, et al. 2016. Biological control program is being developed for brown marmorated stink bug. Calif Agr 70:15-23. https://doi.org/10.3733/ca.v070n01p15

Milosavljević I, Schall K, Hoddle C, et al. 2017. Biocontrol program targets Asian citrus psyllid in California's urban areas. Calif Agr 71:169-77. https://doi.org/10.3733/ca.2017a0027

Pilkington LJ, Irvin NA, Boyd EA, et al. 2005. Introduced parasitic wasps could control glassy-winged sharpshooter. Calif Agr 59:223-8. https://doi.org/10.3733/ca.v059n04p223

\section{Proactive biological control in New Zealand}

The most aggressive adopter of proactive biological control is New Zealand, which has suffered tremendous ecological and economic damage from nonnative pests and is renowned for its strict biosecurity laws. New Zealand scientists identified two pests as targets for proactive biological control, the glassy-winged sharpshooter (GWSS), Homalodisca vitripennis, and brown marmorated stink bug (BMSB), Halyomorpha halys (Gonzalo Avila, Applied Entomology-Bioprotection Group, Plant and Food Research, Auckland, personal communication).

GWSS was identified as a significant invasion threat because it established in multiple island nations of the South Pacific and is a potentially severe problem for the New Zealand wine industry. GWSS has been the target of a very successful biocontrol program in the South Pacific with an egg parasitoid, Cosmocomoidea (formerly Gonatocerus) ashmeadi, (Grandgirard et al. 2009; Pilkington et al. 2005). New Zealand scientists have identified this parasitoid for use there (Charles 2012).

BMSB was identified as a significant threat because it is regularly intercepted at New Zealand ports in cargo that originates from the United States and poses an enormous threat to New Zealand's horticultural industries, especially apples and kiwifruit. BMSB is the target of a biological control program in the United States and California with an egg parasitoid, Trissolcus japonicus (Lara et al. 2016). New Zealand scientists have proactively screened $T$. japonicus in advance of presumed BMSB establishment.

\section{What can California do?}

The first attempt in California at proactive biological control focused on larval parasitoids of the avocado seed moth, Stenoma catenifer, a highly damaging pest that lives inside avocado fruit, and one identified as posing a significant invasion threat to California avocado growers (Hoddle and Hoddle 2008). In 2018, the California Department of Food and Agriculture (CDFA) initiated a new program to continue such forward-leaning work to protect California from invasive pest threats. The CDFA program will take advantage of the state's existing expertise and resources for developing proactive biological control programs. After a list of pest targets is developed, the program will fund researchers to find and evaluate candidate natural enemy species, and develop a library of U.S. Department of Agriculture Animal and Plant Health Inspection Service (USDA-APHIS) release permits that are renewed as necessary. This proactive biological control program will allow California growers, whose businesses are so significant to the economic well-being of the state, to potentially respond more rapidly and cost effectively to new invasive pest threats. CA 


\title{
Groundwater sustainability in the San Joaquin Valley: Multiple benefits if agricultural lands are retired and restored strategically
}

\author{
Restoring habitat in retired farmland could reduce water demand and provide ecosystem services \\ for farmers and local communities.
}

Rodd Kelsey, Lead Scientist, Land Program, The Nature Conservancy

Abby Hart, Project Director, Land Networks Program, The Nature Conservancy

H. Scott Butterfield, Senior Scientist, Land Program, The Nature Conservancy

Dan Vink, Executive Director, South Valley Water Association

A pistachio orchard in Tulare County next to the dry bed of Deer Creek. Implementation of the Sustainable Groundwater Management Act in California is going to have a significant impact on farming, particularly in the southern San Joaquin Valley, where farmers are highly dependent on groundwater for irrigation.

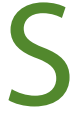
ustaining the remarkable scale of agriculture in the San Joaquin Valley has required large imports of surface water and an average annual groundwater overdraft of 2 million acre-feet (Hanak et al. 2017). This level of water demand is unsustainable and is now forcing changes that will have profound social and economic consequences for San Joaquin Valley farmers and communities. Land will have to come out of agricultural production in some areas. Yet, the emerging changes also provide an important opportunity to strike a new balance between a vibrant agricultural economy and maintenance of natural ecosystems that provide a host of public benefits - if the land is retired and restored strategically.

Once characterized by widespread artesian wells, the San Joaquin Valley now averages groundwater depths of over 150 feet below the surface, exceeding 250 feet in many areas. Decades of groundwater withdrawals have led to the declining reliability and quality of groundwater (Hanak et al. 2015; Harter et al. 2012), widespread land subsidence exceeding 25 feet in some areas (CADWR 2014; Farr et al. 2017) and degradation of groundwater-dependent ecosystems (The
Nature Conservancy 2014). The 2011-2016 drought exacerbated the situation. Severely constrained surface water supplies resulted in a near doubling of average annual land fallowing (Melton et al. 2015) and a rapid increase in groundwater depletion. In response, during the drought in 2014, California passed the Sustainable Groundwater Management Act (SGMA).

SGMA requires communities - through newly established groundwater sustainability agencies (GSAs) - to bring their groundwater basins into balance by 2040 through implementation of groundwater sustainability plans (GSPs). When implemented, the plans are meant to stabilize groundwater levels, decrease water quality degradation and halt land subsidence. Implementation of SGMA in California is going to have a significant impact on farming, particularly in the southern San Joaquin Valley, where farmers are highly dependent on groundwater for irrigation.

In some areas, it is likely that large amounts of agricultural land will need to come out of production; some predictions suggest that as many as 500,000 acres will need to be retired over the next 10 to 20 years to achieve basin sustainability (Hanak et al. 2017).

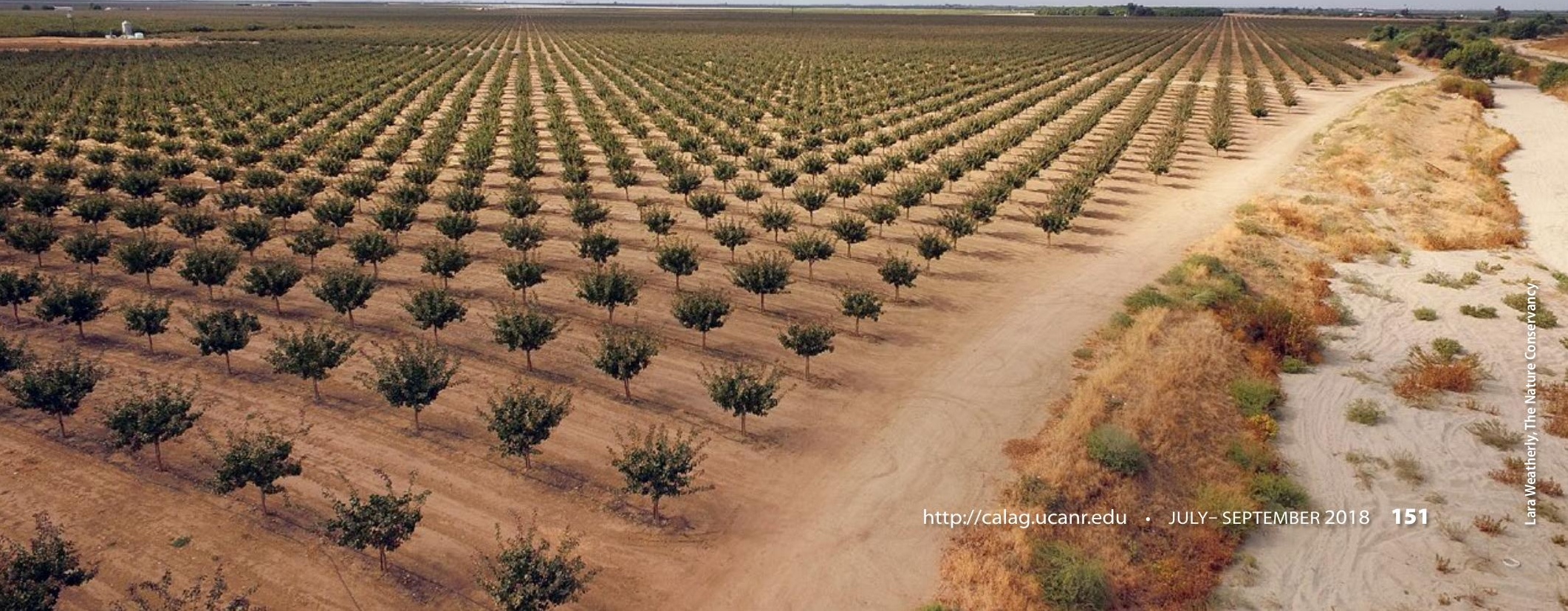




\section{Conservation land use options}

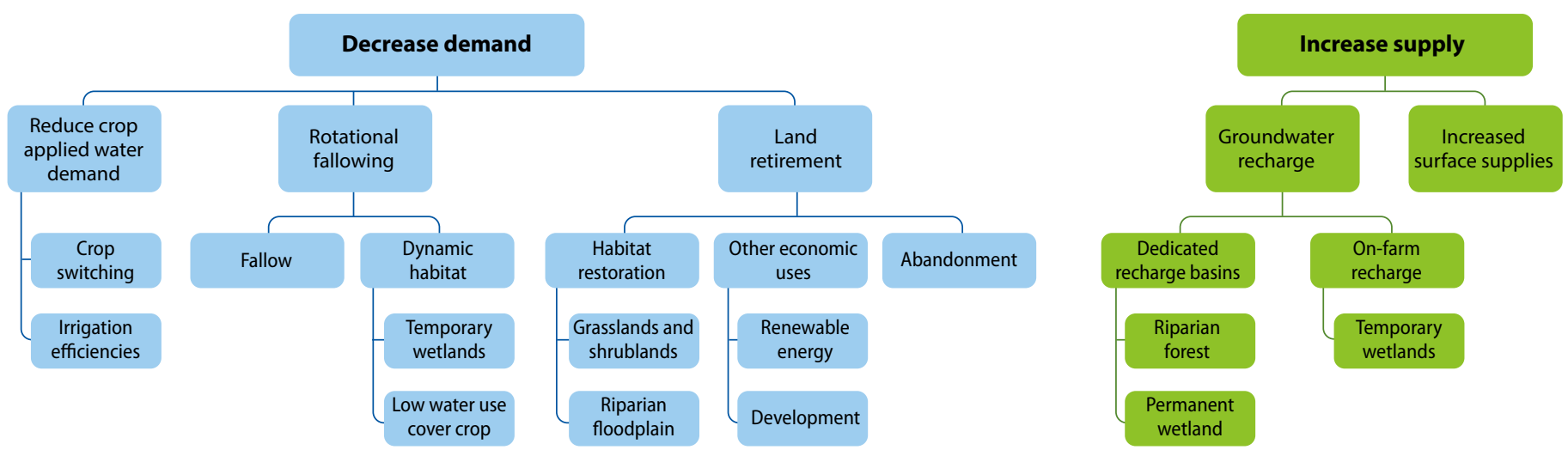

FIG. 1. Groundwater sustainability agencies (GSAs) have many strategies to balance groundwater use in local basins. Some GSAs will be more able than others to find new surface water supplies. Agencies in areas with chronic overdraft problems will need to decrease demand. Strategies are available that would provide multiple benefits to the environment.
A major opportunity lies in that scale of land use change. If portions of those retired lands are restored as a connected network of natural lands, multiple benefits could be created for farmers and San Joaquin Valley communities, in addition to helping meet groundwater sustainability. Realizing those benefits without exacerbating the impacts of the changes to this large agricultural economy is important. It will require spatially optimizing retirement and restoration of lands based on their productivity, access to water and ecosystem potential.

\section{Options to achieve sustainability}

GSAs are choosing strategies from among a palette of options to achieve groundwater sustainability (fig. 1). Increasing surface water supplies and recharging groundwater from dedicated recharge basins or temporary wetlands on fallowed fields will be valuable options in some basins. However, for areas with little or no surface water in many years, supply-side solutions will only address a small proportion of the deficit (Hanak et al. 2017). These parts of the San Joaquin Valley are where reducing demand will be necessary.

Options for reducing demand like crop switching and increasing water use efficiency through infrastructure improvements or soil management practices like those supported by the USDA-NRCS Environmental Quality Incentive Program (fig. 1) will be essential but also fail to fully close the deficit in the most critically overdrafted basins. In those basins, rotational fallowing and permanent retirement of some agricultural lands will be necessary.

\section{Multiple benefits from retiring or restoring land}

Areas that come out of production provide a range of opportunities, from habitat restoration to renewable energy (fig. 1). On lands where both agricultural productivity and potential habitat values are low, renewable energy may be among the best options (Butterfield et al. 2013; Pearce et al. 2016). On lands where the potential habitat value for natural communities is high, restoration is an important option (Butterfield et al. 2017; Lortie et al. 2018) and offers multiple other benefits. As GSAs design their plans, they might intentionally adopt strategies that secure some of these opportunities instead of leaving the lands fallow and unused or converting them to houses or industrial uses.

Converting the valley to irrigated agriculture resulted in one of the highest losses of natural diversity anywhere. The San Joaquin Valley has one of the highest concentrations of endangered species in the United States (Williams et al. 1998). Retiring and restoring parts of the farming landscape to natural habitats could significantly change the potential for recovery of dozens of endangered species in the valley (Stewart et al. 2018). The current San Joaquin Valley recovery plan for threatened and endangered upland species estimates that approximately 80,300 acres (Williams et al. 1998) of protected natural lands will be needed to recover and delist 11 species. With carefully planned restoration of some agricultural lands in the right places and in large enough, connected blocks, recovery becomes a much more realistic possibility. Species recovery, in turn, may contribute, eventually, to reducing constraints on water availability that currently protect endangered species.

Permanently restoring upland habitats that have been lost from the valley could also reduce water demand and generate other benefits for people and nature. Restored lands can provide tangible services for farmers, such as providing a reservoir of abundant native pollinators needed for crop production (Klein et al. 2012; Kremen et al. 2002) and natural enemies of agricultural pests that can reduce the pest burden in many crops (Bianchi et al. 2006).

Reducing the agricultural footprint may also help reduce air quality problems that are contributing to chronic human health issues in the valley (Almaraz et al. 2018; Keet et al. 2017). It will create the possibility, over time, of reducing overall nitrate loading in groundwater, which currently affects rural communities and contributes to higher rates of birth defects than state averages (Brender et al. 2013; Community Water Center 2013). Further, it could significantly contribute 
to helping the state meet its 2030-2050 targets for reducing greenhouse gas emissions (Cameron et al. 2018). These and other benefits, such as creating recreational opportunities for valley residents, may be the basis for public and private investments that help defray the economic costs of lost agricultural production and land restoration.

\section{Strategic retirement and restoration}

The San Joaquin Valley is an agricultural powerhouse. California is the largest food producer in the nation and exports food around the world. Seven of the state's top 10 counties for food production are in the San Joaquin Valley; in 2016, those seven counties generated over $\$ 30$ billion in agricultural revenue, $67 \%$ of the state total (CDFA 2017). Ask any San Joaquin Valley farmer, many of them fourth- or fifth-generation farmers, and they are justifiably proud of their legacy and the important role they play in growing food. The benefits of retiring land from agricultural use are clear, but it will come with very real costs to individual landowners, the broader community that relies on this agricultural economy and the reliability of a locally produced food supply. Thus, retirement and restoration need to be done strategically.

The Nature Conservancy and other organizations are developing and testing approaches to strategic land retirement and restoration (SLRR), whereby lands would be targeted for retirement and restoration where habitat, ecosystem service and human benefits can be best achieved with minimal additional impact to the agricultural economy and food production. The idea of land use planning to balance human needs and environmental health is not new (DeFries et al. 2004; Kennedy et al. 2016). A variety of technical tools are available to model and plan for optimizing land use to get the most benefit and minimize trade-offs (Beyer et al. 2016). For the San Joaquin Valley, these approaches can be used for spatially targeting land retirement in order to redesign the landscape in ways that offer the greatest ecosystem service benefit for local communities (e.g., open space for recreation and improved air quality) and for farmers (e.g., water reliability and pollination services).

The opportunity for SLRR will depend in part on the flexibility GSAs build into their GSPs for water trading and other mechanisms for basinwide water management. Consolidating retired and restored lands into the most optimal locations will be most effective when paired with water-trading options that allow landowners to support retirement of land in other GSAs or basins in exchange for water use rights on highly productive farmland kept in production.

\section{Incorporating land retirement and restoration into GSPs}

Without coordinated planning, land retirement is not likely to occur in ways that achieve the highest benefit. In many cases, GSAs may have limited capacity, knowledge and financial resources for incorporating land retirement and restoration into their GSPs. In addition,
Conservation land use options that can be part of the solution for meeting groundwater sustainability include: top left, temporary flooding of farm fields at the right times of year to create "pop-up" wetlands for wildlife; top right, wetland and riparian habitat in dedicated recharge basins that can provide high-value habitat for migratory birds and the threatened giant garter snake; bottom left and bottom right, restored riparian corridors along rivers and restored upland grasslands and scrublands, which could reduce the demand for water and provide ecosystem service and human benefits.
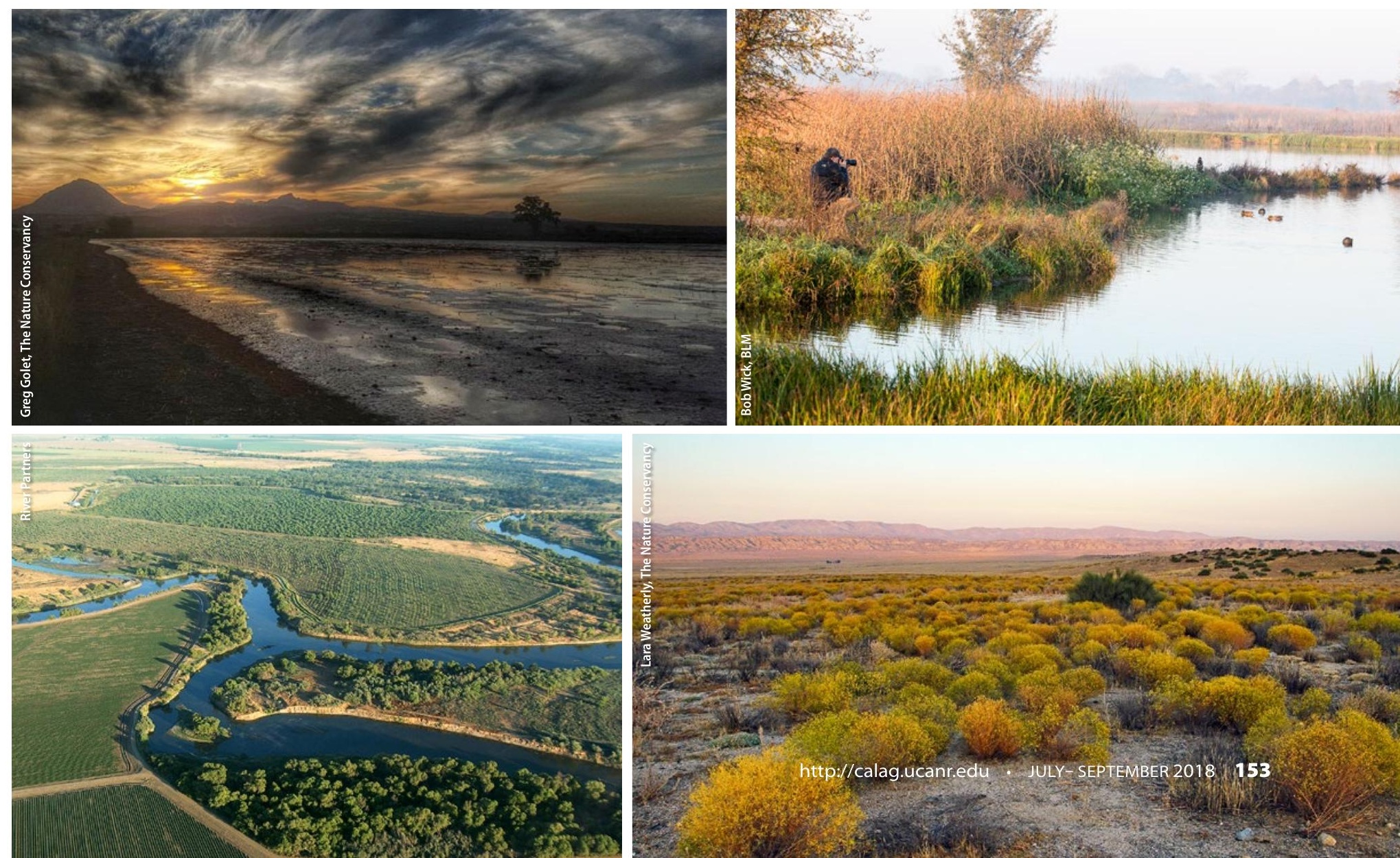
to demonstrate the potential of SLRR, further work is needed to develop and evaluate different scenarios of land use that include land retirement and restoration based on different options and values. We need direct, on-the-ground experiments of land restoration to measure the costs and benefits, refine methods for land restoration, and resolve questions about the exact types and amounts of benefits that can be derived. Another need is collaborative exploration of funding mechanisms to compensate farmers for lost production and to pay for land restoration. Therefore, new partnerships and broad collaboration are needed to shape San Joaquin Valley land retirement in a way that increases the long-term viability of agriculture while improving social and environmental outcomes.

An emerging partnership between Pixley and Lower Tule GSAs (Tulare County) and The Nature Conservancy to develop a pilot project is one example of such a collaboration. The Nature Conservancy is providing scientific capacity to inform where SLRR can best be positioned in the Tule subbasin, using analyses to evaluate optimal selection of lands for SLRR and to quantify potential water quality and greenhouse gas benefits. South Valley Water Association is working with the GSAs to identify landowners willing to implement on-the-ground restoration experiments that demonstrate how to design, fund and implement land restoration. Collaboratively, we are identifying and working to secure public and private funding that can support broad-scale implementation of SLRR as an important part of the solution to groundwater sustainability for GSAs.

Incorporating SLRR into GSPs will be most successful when GSP priorities are aligned with, or supported by, other planning tools. County general plans, regional conservation investment strategies, natural community conservation plans and habitat conservation plans will all play a role in ensuring land retirement unfolds in a way that maximizes benefits and minimizes economic impacts to San Joaquin Valley communities. Making sure these planning efforts include SLRR, and that they can be successful in achieving multiple benefits that serve many members of the community, will require partnerships and collaboration between counties, state and federal agencies, and the local GSAs.

Meeting the long-term sustainability goals of SGMA will require land use changes. Planning for that eventuality in a strategic way could transition the San Joaquin Valley landscape to one that is more agriculturally, socially, economically and ecologically resilient. CA

\section{References}

Almaraz M, Bai E, Wang C, et al. 2018. Agriculture Is a major source of NOx pollution in California. Sci Advances 4(1):eaao3477. https://doi. org/10.1126/sciadv.aao3477

Beyer HL, Dujardin Y, Watts ME, Possingham HP. 2016. Solving conservation planning problems with integer linear programming. Ecol Model 328(2016):14-22. https://doi.org/10.1016/j.ecolmodel.2016.02.005

Bianchi FJJA, Booij CJHJ, Tscharntke T. 2006. Sustainable pest regulation in agricultural landscapes: a review on landscape composition, biodiversity and natural pest control. Proc R Acad Soc B 273:1715-27. https://doi.org/10.1098/ rspb.2006.3530

Brender JD, Weyer PJ, Romitti PA, et al. 2013. Prenatal nitrate intake from drinking water and selected birth defects in offspring of participants in the national birth defects prevention study. Environ Health Persp 121(9):1083-9 https://doi. org/10.1289/ehp.1206249 Butterfield HS, Cameron D, Brand $E_{,}$et al. 2013. Western San Joaquin Valley least conflict solar assessment. Unpublished report. San Francisco, California: The Nature Conservancy. 27 p. www.scienceforconservation. org/assets/downloads/WSJV_ SolarAssessment_2013.pdf
Butterfield HS, Kelsey R, Hart A, et al. 2017. Identification of potentially suitable habitat for strategic land retirement in the San Joaquin Desert. Unpublished report. San Francisco, California: The Nature Conservancy. 25 p. www.scienceforconservation. org/products/strategic-landretirement

[CADWR] California Department of Water Resources. 2014. Summary of recent, historical, and estimated potential for future land subsidence in California.

Cameron DR, Marvin DC, Remucal JM, Passero MC. 2018. Ecosystem management and land conservation can substantially contribute to California's climate mitigation goals. Proc Natl Acad Sci 114(48):12833-8. https://doi. org/10.1073/pnas.1707811114

[CDFA] California Department of Food and Agriculture. 2017. California Agricultural Statistics Review 2016-2017. https:// www.cdfa.ca.gov/statistics/

Community Water Center. 2013. Water \& health in the Valley: Nitrate contamination of drinking water and the health of San Joaquin Valley residents. Health and Drinking Water Series. https://d3n8a8pro7vhmx. cloudfront.net/community watercenter/pages/58/attachments/original/1394396864/ CWC_Water-and-Health-in-theValley-Nitrate.pdf?1394396864
DeFries RS, Foley JA, Asner GP. 2004. Land-use choices: balancing human needs and ecosystem function. Front Ecol Evolution 2(5):249-57. https://doi.org/10.1890/1540 9295(2004)002[0249:LCBHNA] 2.0.CO;2

Farr T, Jones C, Liu Z. 2017. Progress Report: Subsidence in California, March 2015-September 2016. California Department of Water Resources. https://water. ca.gov/LegacyFiles/waterconditions/docs/2017/JPL\%20subsidence $\% 20$ report $\% 20$ final\%20 for $\% 20$ public\%20dec\%20 2016.pdf

Hanak E, Mount J, Chappelle C, et al. 2015. What if California's drought continues? Public Policy Institute of California. http:// ppic.org/publication/what-ifcalifornias-drought-continues/

Hanak E, Lund J, Arnold B, et al. 2017. Water stress and a changing San Joaquin Valley. San Francisco, California: Public Policy Institute of California. www.ppic.org/publication water-stress-and-a-changingsan-joaquin-valley/

Harter T, Lund J, Darby J, et al. 2012. Addressing nitrate in California's drinking water, with a focus on Tulare Lake Basin and Salinas Valley groundwater. Center for Watershed Sciences, University of California, Davis.
Keet CA, Keller JP, Peng RD. 2017. Long-term coarse particulate matter exposure is associated with asthma among children in medicaid. Am J Resp Crit Care Med 197(6):737-46. https://doi.org/10.1164/ rccm.201706-12670C

Kennedy CM, Hawthorne PL, Miteva DA, et al. 2016. Optimizing land use decisionmaking to sustain Brazilian agricultural profits, biodiversity and ecosystem services. Biol Conserv 204(Part B):221-30. https://doi.org/10.1016/j.biocon.2016.10.039

Klein AM, Brittain C, Hendrix SD, et al. 2012. Wild pollination services to California almond rely on semi-natural habitat. J Appl Ecol 49(3):723-32. https://doi.org/10.1111/j.13652664.2012.02144.x

Kremen C, Williams NM, Thorp RW. 2002. Crop pollination from native bees at risk from agricultural intensification. Proc Natl Acad Sci 99(26):16812-6. https://doi.org/10.1073/ pnas.262413599

Lortie CJ, Filazzola A, Kelsey R, et al. 2018. Better late than never: a synthesis of strategic land retirement and restoration in California. Ecosphere 9(8):e02367. https://doi.org/10.1002/ ecs2.2367
Melton F, Rosevelt C, Guzman $R$, et al. 2015. Fallowed Area Mapping for Drought Impact Reporting: 2015 As sessment of Conditions in the California Central Valley. NASA Ames Research Center Report. https://nex.nasa.gov/nex/resources/371/

Pearce D, Strittholt J, Watt T, Elkind E. 2016. A path forward: Identifying least-conflict solar PV development in California's San Joaquin Valley. Berkeley, CA: Center for Law, Energy \& the Environment. https://scholarship law.berkeley.edu/cleepubs/1

Stewart JA, Butterfield HS, Richmond JQ, et al. 2018. Climatic niche contraction, habitat restoration opportunities, and conservation biogeography in California's San Joaquin Desert. PeerJ Preprints 6:e26758v1. https://doi.org/10.7287/peerj. preprints.26758v1

The Nature Conservancy. 2014. Groundwater and stream interaction in California's Central Valley: Insights for sustainable groundwater management. www.scienceforconservation. org/assets/downloads/GroundwaterStreamlnteraction_2016. pdf

Williams DF, Cypher EA, Kelly PA, et al. 1998. Recovery plan for upland species of the San Joaquin Valley, California. Portland, OR: U.S. Fish and Wildlife Service. 


\title{
Possible impacts of rising $\mathrm{CO}_{2}$ on crop water use efficiency and food security
}

\author{
Understanding the mechanisms involved in plants' response to rising $\mathrm{CO}_{2}$ levels may lead to the \\ development of crop plant varieties better adapted to future drought conditions.
}

Alexander J.Scavo, Morgana Sidhom, Felipe J. Rangel, Alexandre Miaule, Christine Emuka, Nusra Poomchongko, Suwayda Ali, Wouter-Jan Rappel, Julian I. Schroeder Cell and Developmental Biology Section, Division of Biological Sciences, Center for Food \& Fuel for the 21st Century, University of California, San Diego

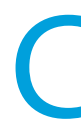
alifornia and the rest of the world are experiencing major changes in the availability of water and the concentration of atmospheric carbon dioxide $\left(\mathrm{CO}_{2}\right)$. Water and $\mathrm{CO}_{2}$ - along with energy from the sun - are the inputs to photosynthesis, the basis of plant growth and food production. Elevated $\mathrm{CO}_{2}$ can influence the water use efficiency and yield of crop plants. A clearer understanding of the mechanisms involved in those responses may lead to the development of crop plant varieties better adapted to expected future water and $\mathrm{CO}_{2}$ conditions.

In recent years, the United States has experienced an increased frequency of heat waves and drought and related loss of crops (Lesk et al. 2016). In 2014, drought cost California an estimated $\$ 2.2$ billion in lost agricultural production (Howitt et al. 2015). In California and elsewhere, the changing climate, population growth and mandates for sustainable management of surface water and groundwater are likely to make water for irrigation more scarce in the future.

From 1950 to 2000, global atmospheric $\mathrm{CO}_{2}$ concentration rose $33 \%$. It continues to climb (fig. 1) and is a major cause of the continuing rise in global

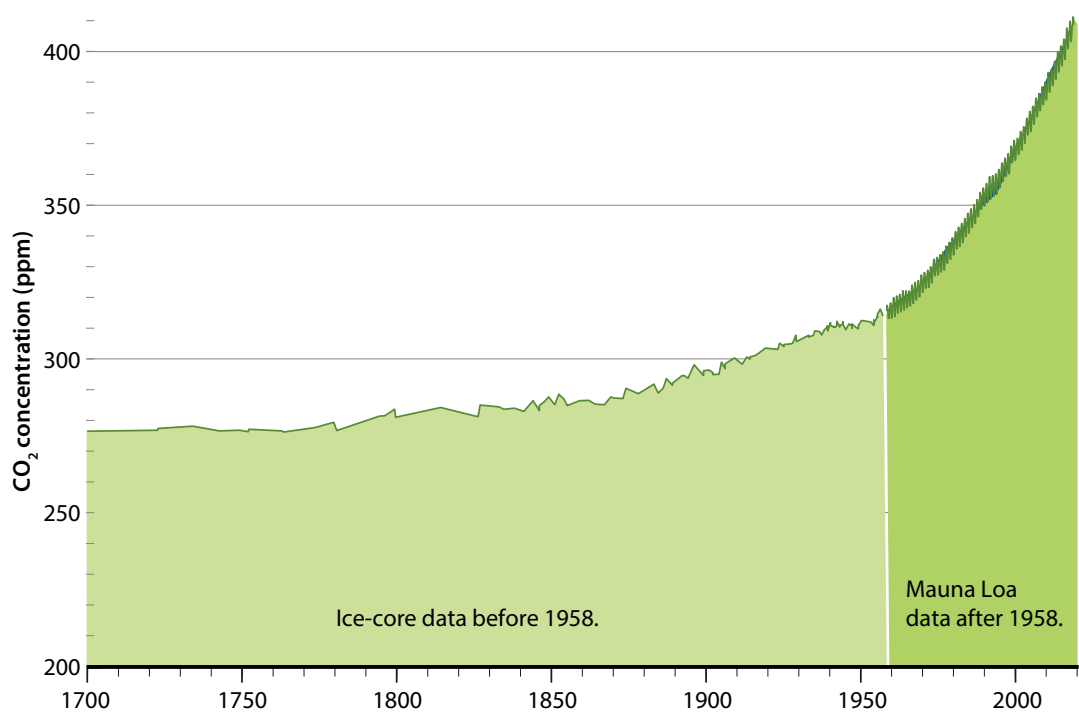

FIG. 1. The continuing steep increase in the atmospheric concentration of $\mathrm{CO}_{2}$. Used with permission from Dr. Ralph F. Keeling, UC San Diego's Scripps Institution of Oceanography $\mathrm{CO}_{2}$ program. temperature (Victor et al. 2014). Average temperatures in California have risen $2.5^{\circ} \mathrm{F}$ since 1880 , and this rate is expected to increase over the next century due to emissions of greenhouse gases (Pathak et al. 2018). Among other impacts, the rising temperature is expected to reduce the winter snowpack, effectively reducing California's water storage capacity and useful water supply (PPIC 2016).

\section{$\mathrm{CO}_{2}$ and stomatal pore apertures}

Research in our laboratory investigates the mechanisms by which $\mathrm{CO}_{2}$ elevation and drought cause closing of leaf stomata. Plant stomata are pores on leaf surfaces that enable the intake of $\mathrm{CO}_{2}$ and the release of water vapor. Over $90 \%$ of the water lost by plants through evapotranspiration is released via stomata (Hetherington and Woodward 2003).

Each stoma is surrounded by two specialized guard cells that open and close the central gas exchange pore (fig. 2). $\mathrm{CO}_{2}$ closes stomatal pores, by entering the guard cells, where it is converted to bicarbonate. The increased concentration of bicarbonate is thought
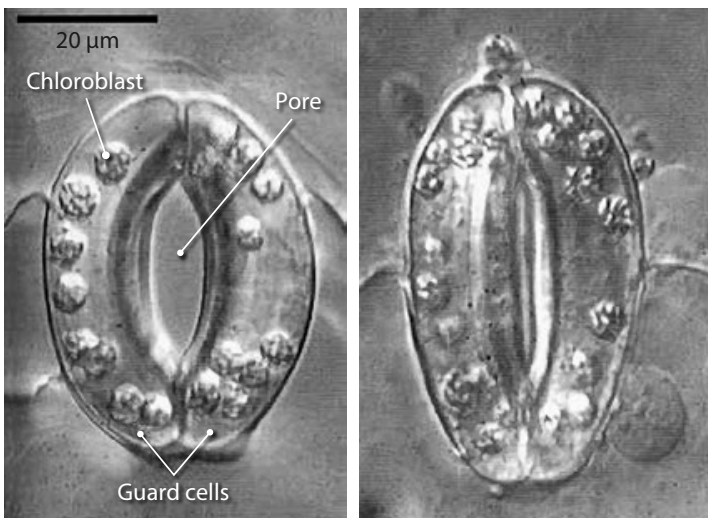

FIG. 2. Light microscopy of plant stomatal pores in the epidermis of leaves in open, left, and closed, right, conformations. Stomatal pores are embedded in the epidermis of the leaf, regulating water loss from the leaf and $\mathrm{CO}_{2}$ uptake from the atmosphere. The two guard cells surround the central pore through which water is lost by plants. Image reproduced from Plant Physiology, 2nd Edition, p. 523, edited by Taiz and Zeiger. By permission of Oxford University Press, USA. 


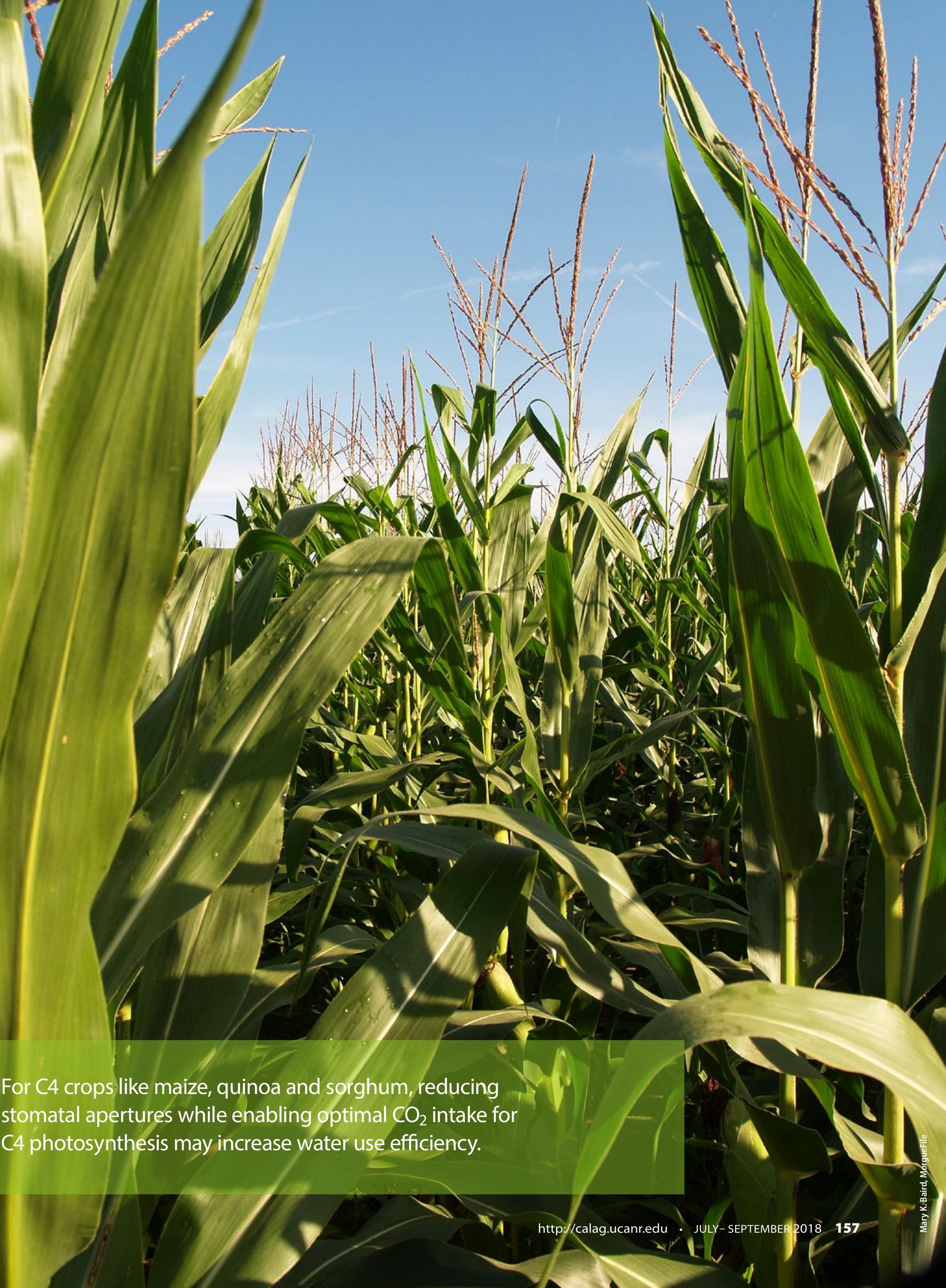


An advanced understanding of the mechanisms and genes that mediate $\mathrm{CO}_{2}$ regulation of stomata could become valuable for better adjusting $\mathrm{C} 3$ plants in light of the steeply increasing atmospheric $\mathrm{CO}_{2}$. For most $\mathrm{C} 4$ crops, photosynthesis is generally already working at maximum capacity, due to the increased atmospheric $\mathrm{CO}_{2}$ concentration; such crops would thus instead be candidates for the manipulations described above that aim to increase water use efficiency by reducing stomatal apertures while enabling optimal $\mathrm{CO}_{2}$ intake for $\mathrm{C} 4$ photosynthesis.

\section{Stomatal density, heat tolerance}

One important potential complication: elevated $\mathrm{CO}_{2}$ also tends to reduce the density of stomata on leaves of some plant species (Woodward 1987). This effect, together with $\mathrm{CO}_{2}$-induced reduction in stomatal apertures, can reduce a plant's capability to cool itself because of reduced evaporation of water from leaves. This may increase susceptibility to heat stress (Engineer et al. 2016), which in turn can affect water use and yield.

In a recent study of soybeans exposed to elevated $\mathrm{CO}_{2}$, the $\mathrm{CO}_{2}$-induced reduction in stomatal pore density and aperture resulted in increased leaf temperature and a net increase in water demand, compared to soybean plants grown in environments with lower $\mathrm{CO}_{2}$ concentrations (Gray et al. 2016).

Thus, the effects of stomatal manipulations will need to be tested in the field and their benefit may depend on the heat response of individual crops.

\section{Future outlook}

Present research advances have led to an initial understanding of mechanisms by which plants sense $\mathrm{CO}_{2}$ concentration and transduce the $\mathrm{CO}_{2}$ signal to regulate water loss. This research is enabling the development of plants with increased water use efficiency and potentially improved yields, depending on growing conditions. However, many of the proteins and genes that make up the $\mathrm{CO}_{2}$ signal transduction network still remain unknown, and how these network components interact within the network is largely not understood at present. Uncovering the missing links in $\mathrm{CO}_{2}$ signal transduction is the focus of work in our laboratory and in other laboratories. Future research will be required to fully uncover all genes and proteins that cause $\mathrm{CO}_{2}$ regulation of stomatal pores. This research promises to provide not only an in-depth understanding of how plants respond to $\mathrm{CO}_{2}$ concentration changes, but also will provide advanced tools for breeding aimed at optimizing those responses to water and $\mathrm{CO}_{2}$ and climate conditions. This research is needed to help safeguard the California and U.S. agricultural economy and the food, feed and fuel it provides. CA

We thank Dr. Peggy Lemeaux, UC Berkeley Department of Plant and Microbial Biology, for comments on the manuscript, and California Agriculture Executive Editor Jim Downing and Associate Editor Dr. Matthew Gilbert, UC Davis Department of Plant Sciences, for improvements. Research in the authors' laboratories was supported by a grant from the National Science Foundation (MCB-1616236) (to JIS and WJR).

\section{References}

Engineer CB, HashimotoSugimoto M, Negi J, IsraelssonNordstrom M, et al. 2016. CO2 sensing and $\mathrm{CO} 2$ regulation of stomatal conductance: advances and open questions. Trends Plant Sci 21(1):16-30. http://doi.org/10.1016/s. tplants.2015.08.014

Gray SB, Dermody O, Klein SP, et al. 2016. Intensifying drought eliminates the expected benefits of elevated carbon dioxide for soybean. Nat Plants 2(9):16132. https://doi. org/10.1038/nplants.2016.132 Hetherington AM, Woodward $\mathrm{Fl}$. 2003. The role of stomata in sensing and driving environmental change. Nature 424(6951):901-8. https://doi. org/10.1038/nature01843
Howitt RE, Medellin-Azuara

JacEwan D, et al. 2015.

Economic Analysis of the 2014 Drought for California Agriculture. Center for Watershed Sciences, University of California, Davis, California. 20 p. https:// watershed.ucdavis.edu/files/ content/news/Economic_Im pact_of_the_2014_Califor nia_Water_Drought.pdf

$\mathrm{Hu} \mathrm{H}$, Boisson-Dernier A, Israelsson-Nordström $M$, et al. 2010. Carbonic anhydrases are upstream regulators of CO2-controlled stomatal movements in guard cells. Nat Cell Biol 12:87-93. https://doi. org/10.1038/ncb2009

Hughes J, Hepworth C, Dutton C, et al. 2017. Reducing stomatal density in barley improves drought tolerance without impacting on yield. Plant Physiol 174(2):776-787. https://doi. org/10.1104/pp.16.01844
Lesk C, Rowhani P, Ramankutty N. 2016. Influence of extreme weather disasters on global crop production. Nature 529:84-87. https://doi. org/10.1038/nature16467

Mohammed KAS. 2013. Effect of nutrient limitation on physiological and morphological plant traits related to growth and quality of tomato. Doctoral dissertation. LandwirtschaftlichGärtnerische Fakultät,

Humboldt-Universität zu Berlin, Berlin, Germany.

Pathak TB, Maskey MA

Dahlberg JA, et al. 2018 Agronomy 8(3):25. https://doi. org/10.3390/agronomy8030025

[PPIC] Public Policy Institute of California. 2016. California's Water: Climate Change and Water. PPIC Water Policy Center report. www.ppic.org/publica tion/californias-water-climatechange-and-water/
Scripps Institution of Oceanography. 2018. The Keeling Curve, San Diego, California: Scripps Institution of Oceanography, CO2 Program. https://scripps.ucsd. edu/programs/keelingcurve/

Steward DR, Allen A. 2016. Peak groundwater depletion in the high plains aquifer, projections from 1930 to 2110. Agr Water Manage 170:36-48. https://doi.org/10.1016/j.ag wat.2015.10.003

Victor DG, Zhou D, Ahmed EHM, et al. 2014. Introductory chapter. In: Edenhofer O, Pichs-Madruga R, Sokona Y, et al. (eds.). Climate Change 2014: Mitigation of Climate Change. Contribution of Working Group III to the Fifth Assessment Report of the Intergovernmental Panel on Climate Change. Cambridge, United Kingdom and New York, NY: Cambridge University Press.
Woodward Fl. 1987. Stomatal numbers are sensitive to increases in $\mathrm{CO} 2$ from pre-industrial levels. $\mathrm{Na}$ ture 327(6123):617-8. https:// doi.org/10.1038/327617a0 


\title{
Research highlights
}

\author{
Recent articles from the Agricultural Experiment Station campuses and UC ANR's county offices, \\ institutes and research and extension centers.
}

\section{Grafting standard tomato varieties onto pathogen-resistant rootstocks may be as effective as soil fumigation}

In the small number of trials that directly compared grafted tomato plants to fumigation treatments in pathogeninfested fields, the grafted plants often gave higher yields. Other studies without fumigation treatments showed that pathogen resistance in some rootstocks was often strong enough to achieve high yields in pathogeninfested conditions.

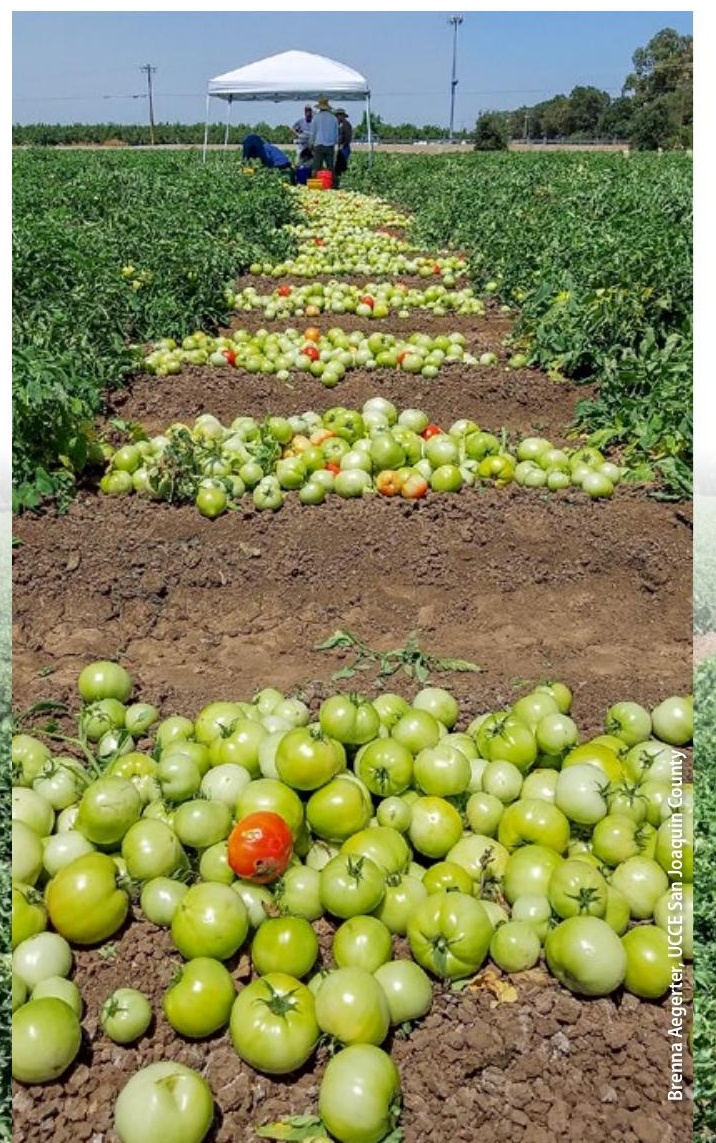

n Europe and Asia, producers of fresh market tomatoes often use grafted plants - scions of a popular market variety grafted on to rootstocks that are especially vigorous or resistant to soilborne diseases. California growers rarely use grafted plants now, but there's increasing interest in whether grafting could maintain high yields in pathogen-infested fields without soil fumigation.

A worldwide review of all available published trial

Maxifort was the most common rootstock used in the trials. It is resistant to seven pathogens: corky root rot, Fusarium wilt races 1 and 2 (but not 3), Fusarium crown and root rot, Verticillium wilt, nematodes and tomato mosaic virus. That makes it a good candidate for fields, or parts of fields, that cannot be fumigated because of regulatory restrictions. In late July 2018, the authors harvested their third year of California grafted tomato trials, and are preparing a more Californiafocused article on their results.

Grieneisen ML, Aegerter BJ, Stoddard CS, Zhang M. 2018. Yield and fruit quality of grafted tomatoes, and their potential for soil fumigant use reduction: A meta-analysis. Agron Sustain Dev 38:29. https://doi. org/10.1007/s13593-018-0507-5

\section{4 hours of high temperature affects avocado ripening, causes disorders}

Department of Land, Air and Water Resources at UC Davis, and UC Cooperative Extension farm advisors Brenna J. Aegerter (San Joaquin County) and C. Scott Stoddard (Merced County). The data came from 159 publications and 126 locations around the world, including a few in California.

The researchers warn that grafting is no magic bullet, but it may allow growers to reduce fumigant use. In the small number of trials that directly compared grafted plants to fumigation treatments in pathogen-infested fields, the grafted plants often gave higher yields. Other studies without fumigation treatments showed that pathogen resistance in some rootstocks was often strong enough to achieve high yields in pathogen-infested conditions. Fruit quality seldom varied significantly between grafted and nongrafted plants. alifornia avocados often are exposed to high temperatures after harvest, either in the field or during preconditioning (ethylene treatment), especially in summer. It's been known that long periods of high temperatures can delay ripening time and reduce fruit quality, but a new study indicates pronounced effects after only short periods of high temperature following harvest. Authors of the study concluded that it's important to maintain avocados at temperatures below $25^{\circ} \mathrm{C}$ following harvest and that the ideal temperature to ripen the fruit is $20^{\circ} \mathrm{C}$. The authors also found that ripening below $20^{\circ} \mathrm{C}$ resulted in significantly longer ripening times and resulted in poorer coloration of the ripened fruit.

Mary Lu Arpaia, UC Cooperative Extension specialist, Jim Sievert and Sue Collin, staff research associates (retired) in the Department of Botany and Plant Sciences at UC Riverside, working with David Obenland, research physiologist with the USDA Agricultural Research Service, Parlier, studied for two seasons holding avocados from multiple harvest times for the first 24 or 48 hours of the ripening period at 
high temperatures $\left(20^{\circ} \mathrm{C}\right.$ to $\left.35^{\circ} \mathrm{C}\right)$, with and without ethylene. In the third season, they made a detailed assessment of ripening temperatures $\left(15^{\circ} \mathrm{C}\right.$ to $\left.25^{\circ} \mathrm{C}\right)$ on ripening time and fruit quality.

Results from the first two seasons showed that even a 24-hour exposure to temperatures of $25^{\circ} \mathrm{C}$ and above inhibits ripening and increases postharvest disorders such as stem end rot and body rot. In season 1 , the incidence of stem end rot increased from $9.7 \%$ at $20^{\circ} \mathrm{C}$ to $32.3 \%$ at $35^{\circ} \mathrm{C}$, and body rot increased from $3.9 \%$ to $20.2 \%$ for the same treatment comparison. Ethylene applied during the exposure period was ineffective in preventing the disorders.

In the third-season trial, temperature was also shown to be critical. Fruit ripened below $20^{\circ} \mathrm{C}$ took slightly longer to ripen. Additionally, the authors found that the ripened fruit at either $15^{\circ} \mathrm{C}$ or $18^{\circ} \mathrm{C}$ remained more green then fruit ripened at the higher temperatures. Avocados ripened above $20^{\circ} \mathrm{C}$ were more likely to develop pink discoloration in the mesocarp. Ripening temperature had no effect on overall likeability, or ratings of grassy or rich flavor.

Arpaia ML, Collin S, Sievert J, Obenland D. 2018. 'Hass' avocado quality as influenced by temperature and ethylene prior to and during final ripening. Postharvest Biol Tec 140:76-84.

\section{Aiding climate-stressed species by protecting habitat across elevations}

$\mathrm{M}$

ountainous areas provide habitat for disproportionately high

numbers of plant and animal species. As the planet warms, species native to mountainous areas may adapt to altered climate conditions by extending their ranges to different altitudes. Protecting mountain habitat can meaningfully contribute to species survival and diversity - but if protected areas are established at only a portion of the elevations over

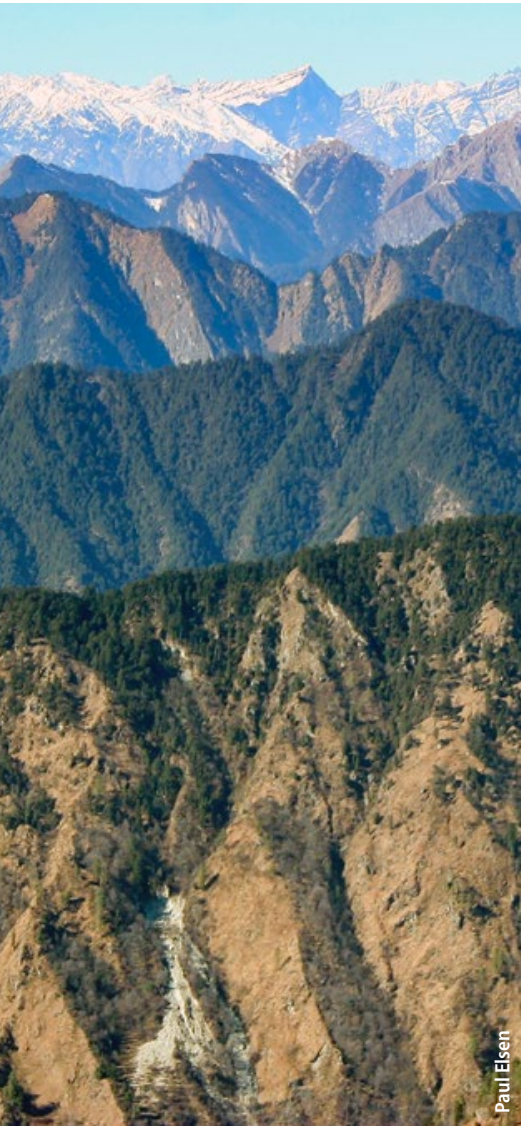
which species will be moving, they may ultimately fail to preserve species.

To understand elevation patterns in existing protected areas, and to gain insight into the elevations at which future protected areas might optimally be established, researchers led by Paul R. Elsen - a conservation research fellow in UC Berkeley's Department of Environmental Science, Policy, and Management - analyzed the elevational distributions of more than 44,000 protected areas situated across more than 1,000 mountain ranges. Within various geographical regions, the team calculated the proportion of elevational gradients that are protected across at least $17 \%$ of their extent (a minimum standard established by an international agreement known as the Convention on Biological Diversity).

Elsen and his colleagues found that, if a strict definition of "protected areas"

Fewer than $25 \%$ of elevations in the Himalayan Mountains - a global biodiversity hotspot - contain enough protected areas to safeguard species affected by climate change.

is employed, about three-quarters of the world's mountain ranges fail to meet the Convention's $17 \%$ protection target across at least one-half of their elevational gradients. The research team also determined that nearly $40 \%$ of the world's mountain ranges do not contain any protected areas at all. These deficiencies could, as climate change progresses, undermine protected areas' ability to protect biodiversity.

Elsen and his colleagues suggest that elevation zones that are currently underrepresented by protection be prioritized when future protected areas are established. Otherwise, they say, protecting $17 \%$ of the land distributed across mountain regions' elevational gradients will require that nearly half the world's total mountainous area be incorporated into protected areas.

Elsen PR, Monahan WB, Merelender AM. 2018. Global patterns of protection of elevational gradients in mountain ranges. P Natl Acad Sci USA 115(23):6004-9. https://doi. org/10.1073/pnas.1720141115

\section{Going deeper into social vulnerability: A study of a dystopic novel}

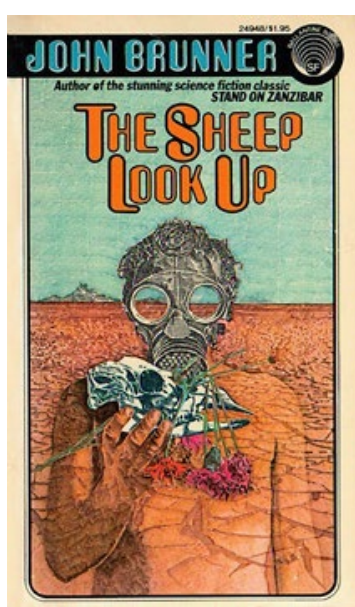

The Sheep Look Up by John Brunner

Berkeley, has analyzed the themes and topics of the novel that resonate for social science theorists and teachers in environmental social sciences. It provides a counterfactual analysis by opening "a window into how the world might have been without, for example, the U.S. Environmental Protection Agency (EPA) or the U.N. Environment Programme (UNEP)," she writes. It warns what will happen if we do not act, and it models the transition from a bad situation to an apocalyptic one.

Environmental changes are hard to see on the ground and therefore hard to grasp. "Storytelling and the building of characters, settings, and a novel's trajectory" help with that, writes O'Neill. She brings in examples from New York magazine, television and film. Any imaginative work that helps people draw connections "serves a positive function in academic disciplines that deal with complex problems and uncertain futures," O'Neill says. She especially recommends The Sheep Look Up as an unconventional type of "scenario analysis," to discuss the complex conditions under which communities become vulnerable to an unraveling of the social fabric and how things come back together again.

O'Neill K. 2018. The sheep look forward: Counterfactuals, dystopias, and ecological science fiction as a social science enterprise. Elem Sci Anth 6:44. https://doi.org/10.1525/ elementa.303 


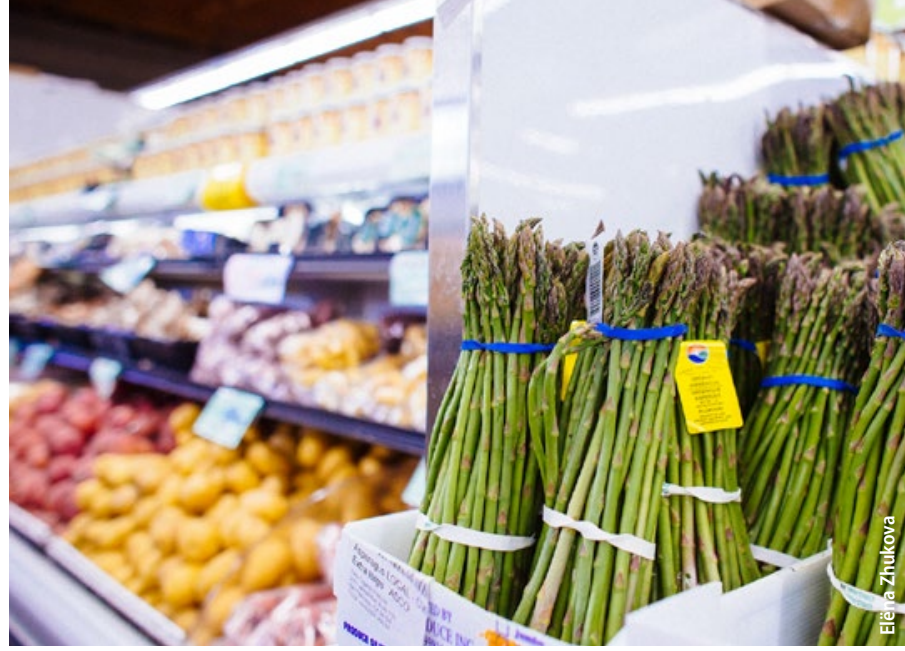

Researchers determined that while large grocery stores in low-income areas generally offered high-quality produce, they charged $27 \%$ more for produce, on average, than comparison supermarkets. Convenience stores, meanwhile, charged more than twice as much, on average, for lower-quality produce.

\section{Fresh produce in low-income areas: High cost and low quality}

- resh fruit and vegetable consumption lowers the risk of chronic

disease and delivers other important health benefits. While fewer than $10 \%$ of Americans meet dietary recommendations for fruits and vegetables, people of low socioeconomic status consume even fewer fruits and vegetables than their higher-income counterparts. A number of studies have examined whether healthy food is less available in low-income communities than in higher-income locations, but little research has focused on the quality and affordability of healthy food in low-income communities.

To redress this gap, a team of researchers led by Wendi Gosliner - a project scientist at the Nutrition Policy Institute of the UC Division of Agriculture and Natural Resources - analyzed data that the California Department of Public Health gathered between 2011 and 2015 from stores in 225 low-income neighborhoods in the state. Gosliner and her colleagues analyzed produce availability, quality and price in the nearly 1,500 retail stores in the database, which included large groceries, small markets and convenience stores. Gosliner's team sought to identify patterns involving store type and produce availability, quality and price. The team also examined stores' participation in the Supplemental Nutrition Assistance Program (SNAP) and the Supplemental Nutrition Program for Women, Infants, and Children (WIC).

The researchers determined that prices were higher in low-income neighborhoods than in a set of comparison stores, with prices in large grocery stores in these areas charging $27 \%$ more for produce, on average, than comparison supermarkets; convenience stores, meanwhile, charged more than twice as much, on average, as comparison supermarkets. While large grocery stores in low-income areas generally offered high-quality produce, few convenience stores sold high-quality fruit $(25 \%)$ or high-quality vegetables (14\%). Stores participating in nutrition assistance programs, however, featured more, more varied, and higher-quality produce than did nonparticipating stores. The researchers suggest that more work is needed to determine how to provide low-income communities with better access to high-quality, affordable produce. They also suggest that programs such as WIC and SNAP might represent part of the solution.

Gosliner W, Brown DM, Sun BC, et al. 2018. Availability, quality and price of produce in low income neighbourhood food stores in California raise equity issues. Public Health Nutr 21(9):1639-48. https://doi.org/10.1017/S1368980018000058

\section{A bird repellent stops voles from girdling citrus trees}

/oles girdle fruit trees and vines, causing extensive damage near

the base of the trunks. Tree guards and rodenticides may control them, but the guards are expensive and rodenticide use is very restricted in food crops. A bird repellent, anthraquinone, may be the answer growers have been seeking.

Two scientists in the Department of Wildlife, Fish, and Conservation Biology at UC Davis - UC Cooperative Extension specialist Roger Baldwin and staff research associate Ryan Meinerz - worked with Scott Werner and Gary Witmer from the USDA National Wildlife Research Center in Colorado to trial anthraquinone on 1-year-old citrus trees planted in 3.3 meter-by-2.1 meter fiberglass tubs recessed in the ground. Anthraquinone is a naturally occurring compound that works as a postingestive repellent - after ingesting it from treated material, birds and voles avoid it.

Anthraquinone was applied to the base of the tree trunks in 10 of the tubs. The control consisted of untreated trees in another 10 tubs. Half of each tub had been planted with cover crops known to be liked by voles, and the other half was kept vegetation free. Two voles were released in each tub and tree trunks were monitored for damage weekly for 5 weeks in summer and 6 weeks in spring.

The reduction in vole girdling to treated trees was $90 \%$ to $100 \%$ when compared with untreated trees across both seasons. No girdling damage was observed on treated trees in vegetation-free areas during summer, although vegetation removal did not seem to impact vole girdling damage during spring. Damage to trees in the first week of treatment, a necessary step for voles to learn to avoid the repellent, was minimal and unlikely to have a long-term impact on tree health. The repellent was effective through the length of the trial periods, with efficacy likely extending well beyond the observed time frame, but more research is needed on its longevity to assess its cost effectiveness in relation to tree guards.

Baldwin RA, Meinerz R, Witmer GW, Werner SJ. 2018. The elusive search for an effec tive repellent against voles: An assessment of anthraquinone for citrus crops. J Pest Sci 91:1107-13. https://doi.org/10.1007/s10340-018-0979-8
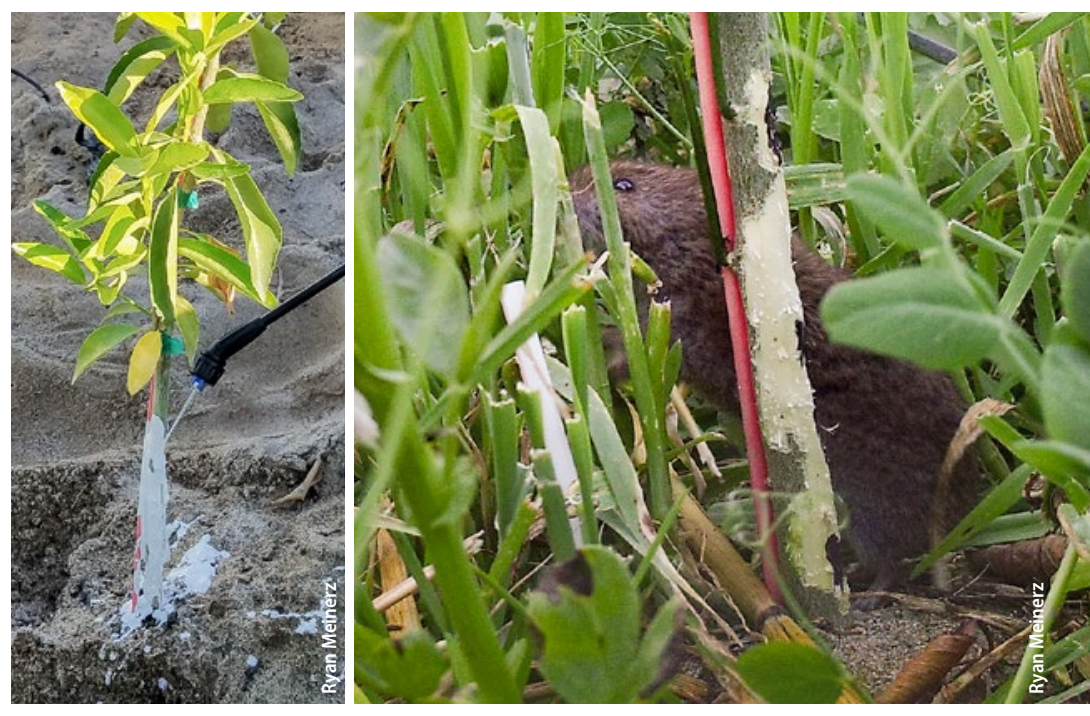

Anthraquinone application, left. Anthraquinone, a naturally occurring compound used as bird repellent, can reduce the girdling of fruit trees and vines by voles, right. In a trial using citrus trees, researchers found it reduced vole girdling by $90 \%$ to $100 \%$. 
sources (e.g., river water, treated wastewater, desalinated water) and recharge methods (e.g., infiltration basins, injection wells, farmland) to replenish underlying aquifers (Dahlke et al. 2018; Dillon 2005; Russo et al. 2015).

In recent years, there has been growing interest in flooding farmland with excess surface water in winter to recharge groundwater (Bachand et al. 2014; Dahlke et al. 2018; Kocis and Dahlke 2017). This approach, called on-farm recharge or agricultural groundwater banking, is capable of capturing large volumes of water, particularly from high-magnitude streamflows from storm events, which occur frequently during the rainy winter season. However, as groundwater sustainability plans are developed, tools are critically needed to understand the physical distribution and occurrence of such excess surface water flows.

Although aquifer recharge can be conducted with any available water (e.g., stormwater, recycled water, desalination, surface water), high-magnitude streamflows (i.e., flood flows) likely represent the most accessible and largest source of water available for future expansion of groundwater banking (Harter and Dahlke 2014; Kocis and Dahlke 2017; Scanlon et al 2016). Demand for this water during the winter from the agricultural sector is relatively low. Reservoirs often make flood control releases of stored water in anticipation of large storm events, and these underutilized releases are expected to increase in frequency and magnitude in the coming decades as a result of climate warming (Das et al. 2013; Dettinger 2011; Hanak and Lund 2012; Yu et al. 2015). Additionally, despite overallocation of surface water by the State Water Resources Control Board (SWRCB) (Grantham and Viers 2014; Scanlon et al. 2016), there seems to exist an abundance of surface water during the winter and wet years, resulting in flood risk for much of the Central Valley (DWR 2016), which could potentially be reduced by capturing high-magnitude flows.

\section{In recent years, there has been}

\section{growing interest in flooding} farmland with excess surface water in winter to recharge groundwater (Bachand et al. 2014; Dahlke et al. 2018; Kocis and Dahlke 2017).

To evaluate high-magnitude streamflow for groundwater recharge efforts, we conducted a statistical analysis of historical daily streamflow records to provide insights into its physical availability and spatial distribution (Kocis and Dahlke 2017). Our goal was to create an index and web application of high-magnitude streamflow availability for groundwater recharge across the Central Valley, including a relative comparison of watersheds for different time periods (e.g., November to April), using the statistical analyses presented in Kocis

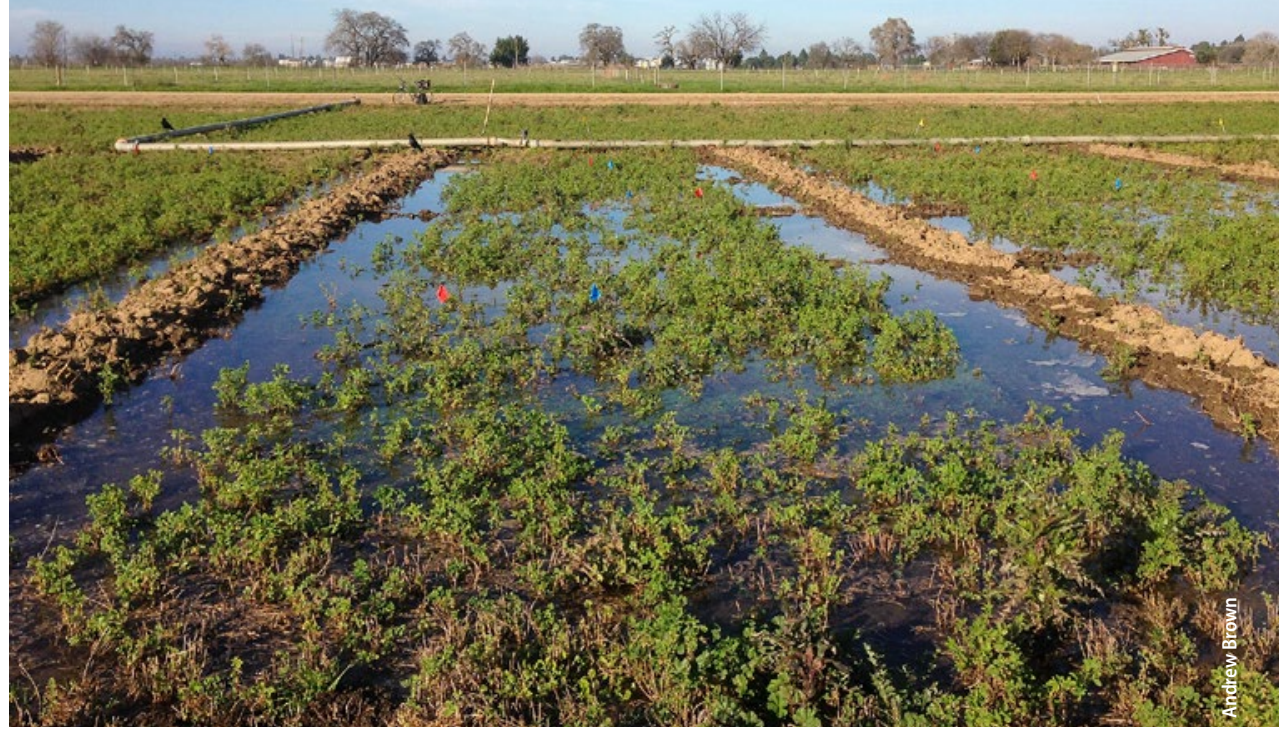

and Dahlke (2017), that could be used by stakeholders for improved water resources management.

\section{Historical data on high- magnitude flows}

We used historical daily streamflow data from United States Geological Survey (USGS) stream gauges in the Central Valley that had more than 50 years of data (93 sites total, visible in figure 1). Gauge sites were classified as impaired or unimpaired (i.e., unaffected by artificial diversions, surface water storage or other works of humans; Slack et al. 1994) by cross-referencing the sites with the Hydro-Climatic Data Network (HCDN). Thirteen of the 93 sites were unimpaired.

This study used the 90th percentile of streamflow, calculated from the full record of available streamflow data, to designate what constituted a physically available high-magnitude flow. Most of the stream gauges are located downstream of large surface water reservoirs, thus they are representative of high-magnitude flows not captured and stored by surface water reservoirs (e.g., flood releases from reservoirs). Using the 90th percentile was motivated by several factors. First, while most surface water in California is legally allocated by the SWRCB, high-magnitude streamflow (i.e., runoff from big storm events including flood flows and reservoir releases for flood control) during the winter is often not. The SWRCB does not currently consider high-magnitude flows for permanent water right/ permit applications or water planning in California, but estimates surface water availability purely on longterm average flow, which ignores a large fraction of the streamflow available during the winter rainy season. Second, the 90th percentile is often used by the USGS and the environmental flow community to designate flows as "much above normal," or as "high" (Henriksen et al. 2006; Olden and Poff 2003; Richards 1990; USGS 2016). Hence, we adopted this threshold for our designation of high-magnitude streamflow.
In 2014, California passed legislation mandating the sustainable management of groundwater basins. One approach for achieving sustainability, called on-farm recharge or agricultural groundwater banking, is capable of capturing large volumes of water, particularly from high-magnitude streamflows that occur during storm events. 


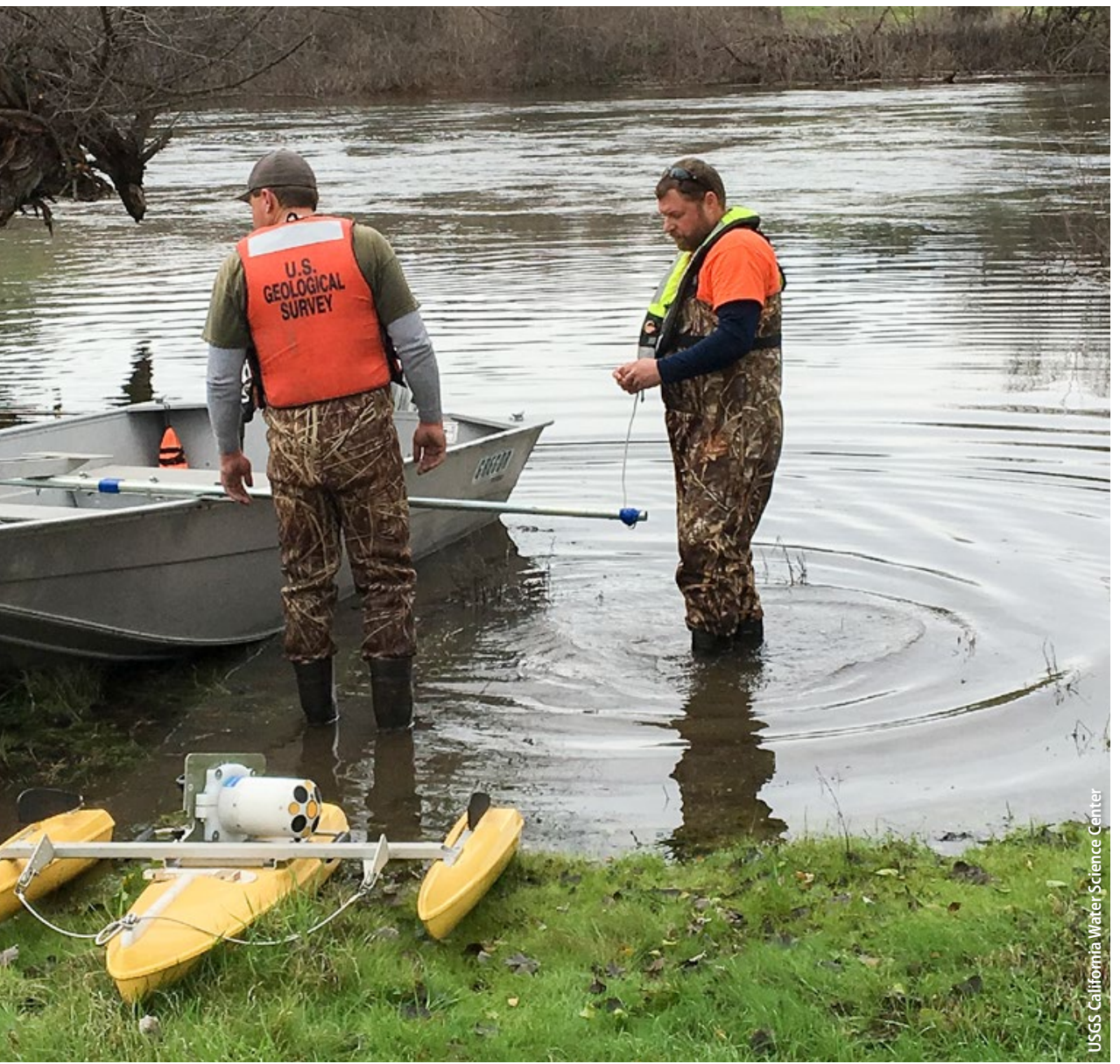

U.S. Geological Survey technicians prepare to go out to the center of the channel in the San Joaquin River below Friant Dam to get an accurate measurement of water flow during releases from the dam for flood control. Capturing such releases for aquifer recharge could potentially reduce winter flood risk in the Central Valley.

\section{Streamflow metrics}

For each stream gauge, five statistical metrics were calculated to inform on the availability of high-magnitude flows: magnitude, duration, timing, intra-annual frequency and interannual frequency (Kocis and Dahlke 2017). Magnitude is the total flow volume above the 90th percentile. Duration is the number of days above the 90th percentile. Timing is the day of the hydrologic year (DOHY) of the center of mass (COM) of flows above the 90 th percentile; COM is defined by the day when $50 \%$ of the total flow volume above the 90th percentile in a given time period (e.g., winter) has passed.

Intra-annual frequency is the count of 1-day peaks that occur over the 90th percentile; a 1-day peak occurs on a day when the flow is higher than both the previous day and the next day. Interannual frequency is the fraction of years with flow above the 90 th percentile. Not all years in the historical records have flow above the 90th percentile; therefore, these years were excluded from the calculation of the magnitude, timing, duration and intra-annual frequency metrics. This process is referred to as zero deflation.

\section{Calculation periods}

All metrics reflect the average value over specific calculation periods. Given potential changes in the flow regime due to the construction of dams or diversions within the watershed of each gauge, the metrics were calculated over two periods of record: (1) the full record of available data and (2) the record of data since the most recent impairment (i.e., post-impairment period). For the Sacramento River Basin and the San Joaquin Valley (comprised of the San Joaquin River Basin and the Tulare Lake Basin), the post-impairment periods of record are 1970 to 2014 and 1989 to 2014, respectively.

Flow metrics were also calculated for different time periods and the five water year types (critical, dry, below normal, above normal and wet) defined in the San Joaquin Valley Index and Sacramento Valley Index (SWRCB 1995, Null and Viers 2013). Time periods were the hydrologic year (Oct. 1 to Sept. 30), the winter rainy season (November to April), the winter season (December to February) and each month between November and April.

\section{Streamflow availability ratings}

We developed a streamflow availability rating for recharge (STARR) based on three of the five high-magnitude streamflow metrics that emerged to be the most indicative for the availability of excess surface water from high-magnitude flow: magnitude, duration and interannual frequency.

STARR was calculated using an empirical weighting method, the rank-ordered centroid weighting method (Barron and Barrett 1996), that combines the weighted, ranked equal-area ratings of the magnitude, duration and interannual frequency metrics for the contributing watershed of each stream gauge. For the watersheds of the 93 stream gauges analyzed by Kocis and Dahlke (2017), STARR was determined for three time periods: the hydrologic year, November to April, and December to February.

\section{Watershed scale}

The STARR index displays the high-magnitude flow availability (developed from point gauge locations) for groundwater recharge at the watershed scale. The upstream contributing watershed was derived for each of the 93 stream gauges using the 1-arc-second National Elevation Dataset (USGS 2009). Watersheds were delineated in ArcGIS with a drainage area threshold (flow accumulation threshold) equal to $1 \%$ of the maximum flow accumulation. If several stream gauges exist along the same river, the contributing areas were visually overlaid such that smaller upstream watersheds remain on top of larger downstream watersheds. For accuracy, the upstream drainage areas were compared to those provided by USGS.

\section{Four-step process}

The STARR calculation process included four steps:

First, three spatial flow metrics, $V / A, D / P$ and $Y W F$, were developed for the watershed of each of the 93 stream gauges. The magnitude, $V$ (in cubic kilometers), was standardized by the watershed area, $A$ (square kilometers). The duration, $D$, was standardized by the 
number of days in the calculation period, $P$ (e.g., 90 days from December to February), and the interannual frequency (fraction of years with high-magnitude flow) was left unchanged and notated as YWF.

Then, using an equal-area classification method, the spatial flow metrics were scored from 1 to 6 . First, values in each metric were sorted from smallest to largest. Next, the score was determined relative to other watersheds in the study region, the Central Valley, by breaking the metric values into six equal-area classes with the same number of watersheds in each class.

Next, the rank-ordered centroid method (Barron and Barrett 1996) was used to develop an additive multi-attribute model for the three spatial flow metrics to calculate the final numeric STARR value. The model allows developing an empirical formula to calculate the STARR and determining weighting coefficients for the three spatial flow metrics considered in the formula based on their relative importance as outlined in Barron and Barrett 1996. In this formula (see equation (1) below), the interannual frequency was given the highest weight (considered the most important factor), duration was given the lowest weight (considered the least important factor, of the three) and the weight on magnitude was chosen to fall in between. The resulting STARR formula was

$$
\begin{aligned}
& \text { STARR }=0.611 \times \operatorname{ranked}(Y W F)+0.277 \times \\
& \operatorname{ranked}(V / A)+0.111 \times \operatorname{ranked}(D / P)
\end{aligned}
$$

The final STARR ratings were calculated by entering the first round of values from step 2 into equation (1). Using an equal-interval ranking, the resulting numeric
STARR values (ranging from 1 to 6) were then split into six equal intervals corresponding to the STARR classes (e.g., $1<=$ numeric STARR $<1.83$ is very poor). The numerical STARR values were categorized as very poor, poor, moderately poor, moderately good, good and excellent.

Watersheds with a high STARR (i.e., excellent rating) are generally characterized by large high-magnitude flows that persist for a high number of days and recur, on an interannual basis, with high frequency. Conversely, watersheds with a low STARR (very poor rating) generally contribute less high-magnitude flow than other watersheds within the study area, and the flow occurs only for a very short period of time each year, and recurs, on an interannual basis, with low frequency. A high STARR value corresponds to watersheds that have excellent physical surface water availability relative to other watersheds in the Central Valley, while a low STARR value corresponds to watersheds that have very poor physical surface water availability.

\section{Optimal month rating}

We used the STARR index to also develop a decision support tool for the optimal time when high-magnitude streamflow is available for recharge across the Central Valley. We developed the optimal month rating (OMR) to answer the question: "For any watershed, what is the month in which most high-magnitude flow is physically available?" The OMR identifies the month within a time period of interest that provides the greatest water availability and highest flow reliability (longest duration,
FIG. 1. Streamflow availability rating for recharge (STARR) for the Sacramento River Basin, San Joaquin River Basin and Tulare Lake Basin during December to February (A), November to April (B) and the hydrologic year (C).
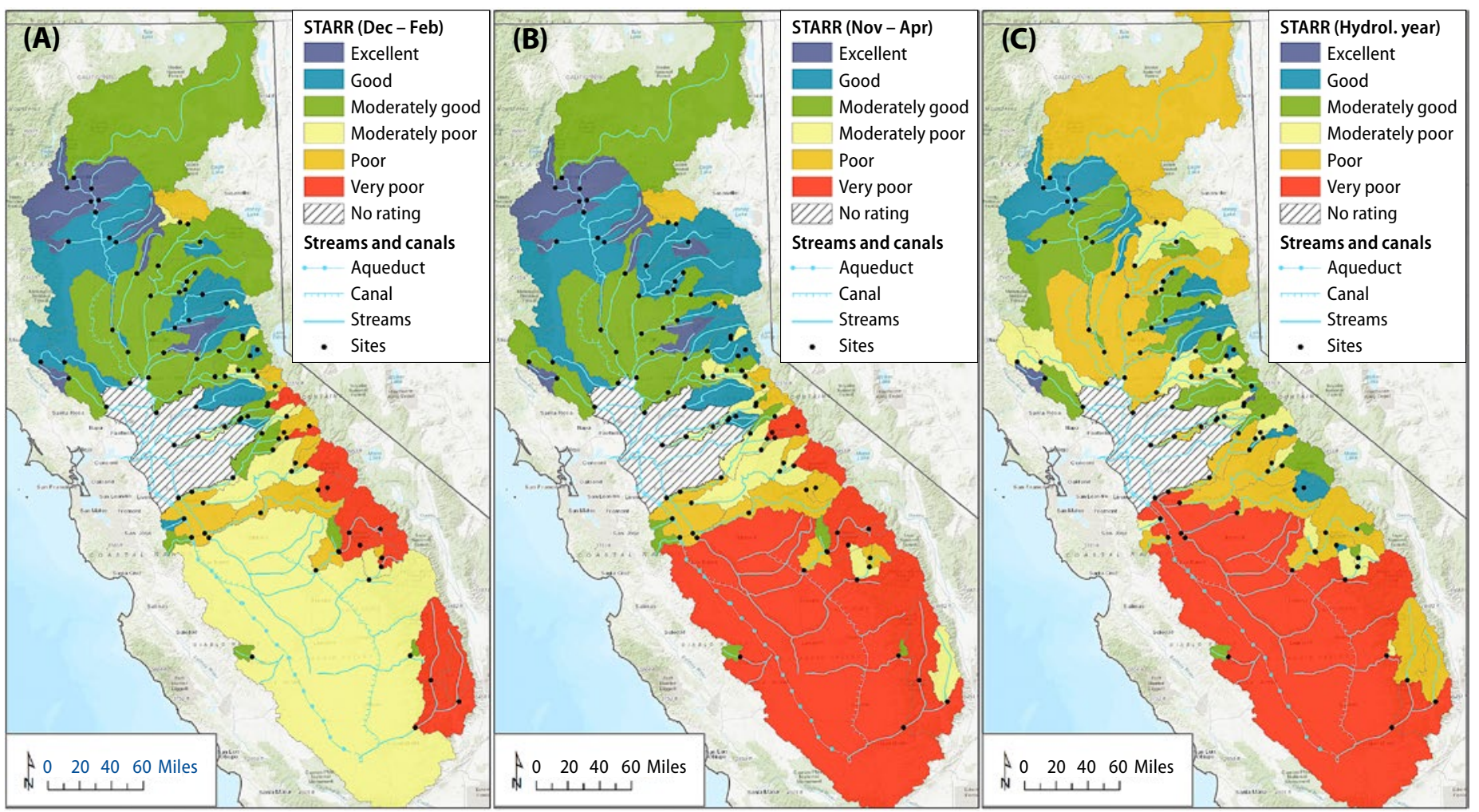
TABLE 1. Spatial distribution of streamflow availability ratings for recharge (STARR) for the contributing areas of 93 stream gauges within the Sacramento River Basin and San Joaquin Valley

\begin{tabular}{|c|c|c|c|c|c|c|}
\hline \multirow[t]{2}{*}{ STARR } & \multicolumn{2}{|c|}{$\begin{array}{c}\text { December to February } \\
\text { Contributing area }\end{array}$} & \multicolumn{2}{|c|}{$\begin{array}{l}\text { November to April } \\
\text { Contributing area }\end{array}$} & \multicolumn{2}{|c|}{$\begin{array}{l}\text { Hydrologic year } \\
\text { Contributing area }\end{array}$} \\
\hline & acres & \# sites & acres & \# sites & acres & \# sites \\
\hline Excellent & $2,022,829$ & 13 & $2,140,252$ & 13 & 109,142 & 3 \\
\hline Good & $4,295,153$ & 17 & $5,470,998$ & 18 & $2,664,422$ & 22 \\
\hline Moderately good & $11,042,192$ & 22 & $9,360,678$ & 16 & $4,401,728$ & 20 \\
\hline Moderately poor & $12,846,026$ & 12 & $2,039,866$ & 15 & $2,839,750$ & 21 \\
\hline Poor & $2,164,866$ & 15 & $2,435,685$ & 17 & $12,586,170$ & 19 \\
\hline Very poor & $3,032,128$ & 14 & $13,955,715$ & 14 & $12,801,980$ & 8 \\
\hline
\end{tabular}

greatest frequency and/or largest volume) and is determined by estimating the highest monthly STARR value for each watershed in a given time period (e.g., November to April).

OMR is determined in a similar fashion to STARR, but instead of comparing one watershed to another watershed, OMR compares the water availability in a single watershed from one month to another month within a given time period. OMR is determined for two time periods: December to February and November to April.

\section{Streamflow availability for recharge highest in Sacramento River Basin}

Between

December

and February,

30 of the 93

watersheds

have excellent

or good

streamflow

availability,

an area of

over 6.3

million acres.
STARR was calculated for the Sacramento River Basin, the San Joaquin River Basin and the Tulare Lake Basin - an area of over 35.4 million acres (about one-third of the land surface of California) (fig. 1). Kocis and Dahlke (2017) estimated that in an average year with highmagnitude flow (e.g., years when streamflow exceeds the 90th percentile flow), between November and April approximately 1.88 million acre-feet (2.31 cubic kilometers) and 0.97 million acre-feet (1.2 cubic kilometers) of high-magnitude flow are exported from the Sacramento River Basin (USGS site 11447650) and the San Joaquin River Basin (USGS site 11303500), respectively, to the Sacramento-San Joaquin Delta.

Most of the watersheds with the greatest highmagnitude flow availability are in the Sacramento River Basin, which generally receives more precipitation than the southern Central Valley. The interannual frequency indicated that those watersheds carry high-magnitude flows on average in 7 to 9 out of 10 years, while watersheds in the San Joaquin River Basin and Tulare Lake Basin carry high-magnitude flows on average in only 2 to 5 out of 10 years (Kocis and Dahlke 2017).

STARR shows distinct patterns for the highmagnitude flow availability in winter and during the hydrologic year (fig. 1; table 1). Between December and February, 30 of the 93 watersheds have excellent or good streamflow availability, an area of over 6.3 million acres, or $17.8 \%$ of the study area (table 1 ). These watersheds are primarily in the Sacramento River Valley and the northern San Joaquin Valley and include mainly unimpaired tributaries from the Coast Ranges and the Sierra Nevada (fig. 1A). Watersheds with poor or very poor December to February STARR are primarily High Sierra watersheds, where streamflow availability during winter is limited because most precipitation falls as snow and only becomes snowmelt runoff during the spring and early summer. In contrast, the Tulare Lake Basin is ranked moderately poor. Here, streamflow availability is limited, occurring only during winter (December to February) when rainfall produces runoff, or flooding during wet years.

For the November to April period, the distribution of watersheds with excellent and good streamflow availability for recharge (fig. 1B, table 1) is similar to that for the December to February period. Most of those watersheds are in the Sacramento River Basin, occupying about $42 \%$ of the basin. Streamflow availability for recharge in the San Joaquin River Basin and Tulare Lake Basin is predominately moderately poor to very poor, with a few moderately good ratings on the west side of the San Joaquin River. Most of the valley floor of the Tulare Lake Basin has very poor streamflow availability for groundwater recharge.

During the hydrologic year (Oct. 1 to Sept. 30), streamflow availability for groundwater recharge varies between good and very poor throughout the Central Valley (fig. 1C). The Tulare Lake Basin generally has very poor excess streamflow availability; high-magnitude streamflow availability in the largest tributaries to the San Joaquin River from the Sierra Nevada is either poor or moderately poor. The low ratings can be attributed to the low interannual frequency at which high-magnitude flows occur and the low overall magnitude of those flows compared to the size of the watersheds.

Within the Sacramento River Basin during the hydrologic year, most watersheds below major rim reservoirs, including the upper Sacramento and Feather rivers, are rated poor or moderately poor, while most unimpaired streams and headwater catchments are rated good or moderately good. Unimpaired watersheds in the Sacramento River Basin lack major control structures (e.g., surface reservoirs, major diversions) and therefore carry high-magnitude flow for longer periods throughout the winter and, in some cases, the shoulder 
months (September to November, March to July), which results in good and moderately good STARR for the hydrologic year. For most of the impaired streams in the Sacramento River Basin, the high-magnitude flow availability in spring, summer and fall is regulated or prevented by major reservoirs.

\section{Optimal months for recharge identified}

In the Sacramento River Basin, the OMR indicates that for the December to February period, February is the ideal month for groundwater recharge in terms of streamflow availability for recharge (fig. 2). In the San Joaquin River Basin and Tulare Lake Basin, the ideal month for groundwater recharge is January for the December to February period, and December for some of the Sierra Nevada watersheds. During December to February, water availability stems primarily from rainfall, not snowmelt.

Excess surface water availability that includes snowmelt is reflected in the November to April OMR (fig. 2B), which identifies March as the ideal month for the San Joaquin River Basin and Tulare Lake Basin, and February, again, as the ideal month for the Sacramento River Basin. In the Sierra Nevada tributaries, April is the ideal month for streamflow availability, clearly indicating snowmelt as the main source.

\section{Web tool for decision-making}

The streamflow availability metrics (magnitude, timing, duration, interannual and intra-annual frequency of flow above the 90th percentile) and STARR and OMR maps are available as an interactive web tool (fig. 3) at http://recharge.ucdavis.edu/STARR. More information on it is provided in the technical appendix.

Web-based decision support tools have proven useful in supporting farmers and landowners in decisionmaking processes. For agricultural groundwater banking, several such tools help identify suitable on-farm recharge locations. For example, the Soil Agricultural Groundwater Banking Index (SAGBI) (casoilresource. lawr.ucdavis.edu/sagbi/) developed by O'Geen et al. (2015) recommends recharge locations based on soil suitability by considering five factors: soil profile percolation rate, root zone residence time, chemical limitations, topography and soil surface conditions. Crop suitability research for groundwater recharge is available for alfalfa (Dahlke et al. 2018) and almonds (Volder et al. 2016). The California Department of Water Resources recently published a detailed land use survey of cropland parcels within California, distinguishing 12 different land use classes (gis.water.ca.gov/ app/CADWRLandUseViewer/). This land use survey represents the most accurate (i.e., in terms of cropping system and spatial accuracy) land use and land cover dataset available to date for water resources planners for water budget calculations.
Our STARR web tool provides another layer of information that growers, landowners and water district managers can use to plan agricultural groundwater banking programs as part of their operations or to develop groundwater sustainability plans. We envision the STARR web tool being used at a local scale with other tools. For example, to identify suitable recharge areas within groundwater management areas, SAGBI could be used to identify areas with suitable soils, land use surveys could be used to identify areas with suitable crops, the eWRIMS (Electronic Water Rights Information Management System) database could be used to identify current surface water right holders, and infrastructure maps could be used to identify areas with the necessary conveyance infrastructure. The intersection of soil suitability, crop suitability, land use, conveyance infrastructure, legal water availability, and physical water availability (STARR) is the ideal location to conduct an agricultural groundwater banking project.

A recent survey conducted by the Public Policy Institute of California indicates that many water district managers cite infrastructure capacity constraints as a major barrier to the expansion of existing recharge programs (Hanak et al. 2018); many water districts and counties currently lack the infrastructure to divert high-magnitude flows (DWR 2017; O'Geen et al. 2015). The STARR web tool can be used to advise the planning and expansion of water conveyance systems at district and watershed scales to deliver water to suitable recharge lands, since it provides detailed information on the volumes and timing of when high flows are available. Comparing peak flow volumes to the capacity of existing conveyance systems allows water managers
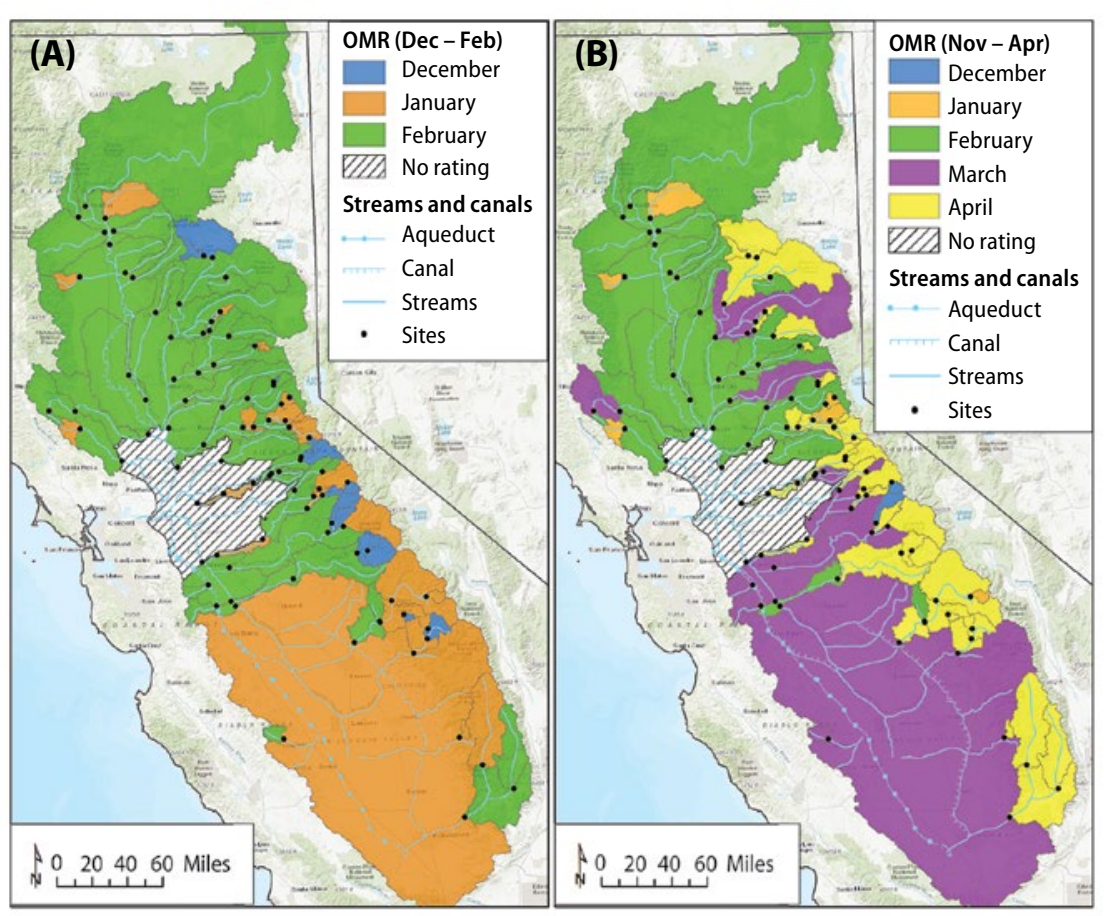

FIG. 2. Optimal month rating (OMR) for groundwater recharge based on high-magnitude streamflow availability in December to February (A) and November to April (B). 
FIG. 3. Interactive, webbased map displaying the magnitude, timing, duration, interannual and intra-annual frequency of high-magnitude flows for the 93 sites analyzed within the Central Valley. Users can click on a site of interest on the map, which loads a bar graph for the selected highmagnitude streamflow metric, record length and time period. In the example shown above, users can see the average high-magnitude flow volume for the stream gauge at the Mokelumne River below Camanche Dam for each month between November and April and each water year type. The displayed flow volumes are based on estimates considering the full record of streamflow data available for that site.

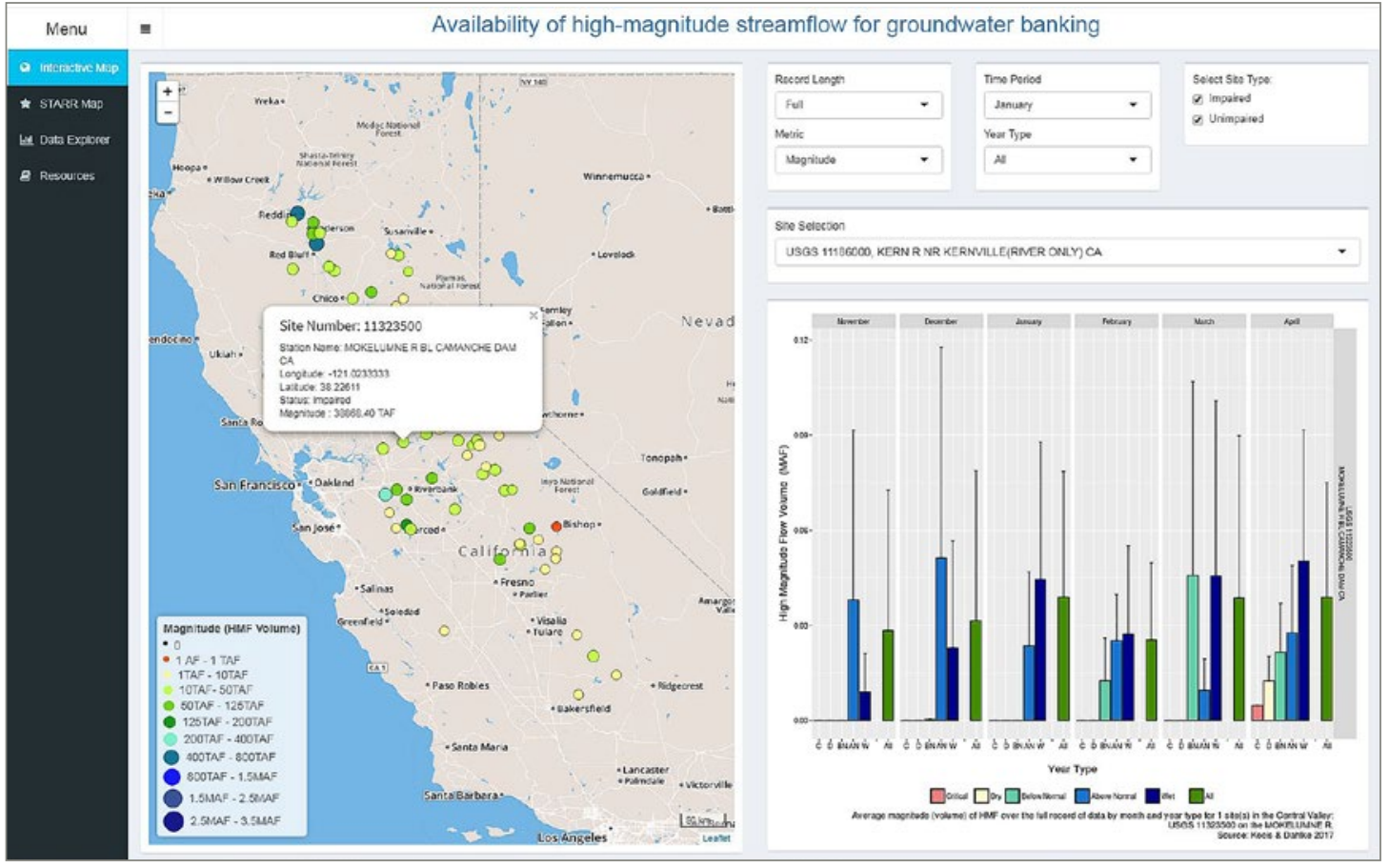

to determine the need for expansion or new construction of conveyance infrastructure.

\section{Transfers from north to south}

As indicated in figure 1, streamflow availability for groundwater recharge in the Central Valley displays a clear north-south gradient, with highest availability in the Sacramento River Basin. The availability of excess surface water is spatially disparate to agricultural land suitable for groundwater recharge. The most highly rated soils (with a SAGBI rating of excellent, good or moderately good) are located on the broad alluvial fans on the east side of the Central Valley (near the Mokelumne, Stanislaus, Merced, Kern and Kings rivers); in the Sacramento Valley, suitable land is limited to narrow alluvial bands along the Sacramento River and its major tributaries.

This spatial disparity in water availability and suitable recharge locations seen in nearly every visualization of STARR suggests long-term investment is needed in statewide water projects that could convey excess surface water from the Sacramento River Basin to suitable land in the southern Central Valley. Water transfers would allow balancing the critically overdrafted Kern, Kings, Tule, Kaweah, and Tulare Lake groundwater basins, where there is a generally high water demand (DWR 2016).

OMR indicates that water transfers from the Sacramento River Basin, where high-magnitude flow is available as early as November, to the San Joaquin and Tulare Lake Basins could be made early in the winter, when crops such as alfalfa and almonds are still dormant and before local flood flows from the High Sierra become available in March or April. Such water agencies to address many of the undesirable results listed in SGMA, including land subsidence, lowering of the water table and groundwater storage depletion.

Additionally, knowledge that in the San Joaquin River Basin and Tulare Lake Basin most high-magnitude flow originates from spring snowmelt could motivate changes in reservoir operation policies; more water from reservoirs could be released during late fall or early winter for groundwater recharge to create increased flexibility for flood management of more intense precipitation events (Hanak and Lund 2012; Maurer and Duffy 2005).

\section{Water rights, legal use of flows}

Given that groundwater recharge is not considered a "beneficial use" in the California Water Code (California Water Code 2017), the legal use of the highmagnitude flows calculated in this study remains questionable for the near future. Landowners and water districts planning new groundwater recharge programs will likely have to obtain a new surface water right or change an existing water right.

The SWRCB currently estimates the water availability for a new appropriative surface water right using a method similar to the rational runoff method (Kuichling 1889; SWRCB 2001), which estimates the average annual unimpaired runoff at a diversion point of interest considering only the contributing area, average annual precipitation and the land use within the watershed (SWRCB 2001). This conservative method is used to ensure that there is "unappropriated water available to supply the applicant" (Water Code section 1375(d)), while accounting for "the amounts of water transfers would allow local groundwater sustainability 
needed to remain in the source for protection of beneficial uses" (Water Code section 1243), such as recreation and the preservation of fish and wildlife habitat.

However, as indicated by Grantham and Viers (2014), in many areas of California, mainly the Central Valley, surface water has been overallocated to the extent that surface water rights account for nearly 10 times the natural surface water supplies. This, theoretically, precludes any additional appropriation of surface water. Yet, over-appropriation is, to a large extent, an artifact of the water availability analysis conducted by the SWRCB, which is based on average annual flows and does not take into account the large variability in streamflow. Hence, new permitting approaches that would legally permit the use of high-magnitude flow for groundwater recharge are needed.

Allowing a water right permit for the diversion of "high flow" could bridge the gap between policy requirements (such as the need for a temporary or permanent water right for surface water diversions), legal requirements (for stream reaches that are already legally over-appropriated) and physical surface water availability for groundwater recharge (in the form of flood flows during above normal or wet years). Such permits would have to agree on legally acceptable high flow thresholds at the point of diversion to ensure that high flow diversions for groundwater recharge do not cause injury to existing water rights holders or environmental flow considerations.

Permits could be restricted to the winter period, from November to March, and define strict in-stream flow requirements (e.g., the passage of channel-forming flows or fall flushing flows for sediment and nutrient transport) (see Kocis and Dahlke 2017 for a more detailed discussion of these considerations). Solving these regulatory challenges to groundwater recharge, along with a potential expansion of infrastructure capacity, will open new avenues to greater water security in California. CA

H.E. Dahlke is Associate Professor in Integrated Hydrologic Sciences and T.N. Kocis is Ph.D. Student in the Hydrologic Sciences Graduate Group, Department of Land, Air and Water Resources, UC Davis.

\section{References}

Bachand PAM, Roy SB, Choperena J, et al. 2014. Implications of using on-farm flood flow capture to recharge groundwater and mitigate flood risks along the Kings River, CA. Environ Sci Technol 48(23):13601-9.

Barron FH, Barrett BE. 1996.

Decision quality using ranked attribute weights. Manage Sci 42(11):1515-23.

Bouwer H. 2002. Artificial recharge of groundwater: Hydrogeology and engineering Hydrogeol J 10(1):121-42.

Brown RF, Signor DC. 1974. Artificial recharge - state of the art. Groundwater 12(3):152-60. California Water Code. 2017. http://leginfo.legislature.ca.gov/ faces/codesTOCSelected.xhtml? toc Code $=$ WAT\&tocTitle $=+$ Water +Code+-+WAT

[CDFA ] California Department of Food and Agriculture. 2015. California Agricultural Statistics Review, 2015-2016. www.cdfa.ca.gov/statistics/ PDFs/2016Report.pdf

Dahlke HE, Brown A, Orloff S, et al. 2018. Managed winter flooding of alfalfa recharges groundwater with minimal crop damage. Calif Agr 72(1):65 75. https://doi.org/10.3733/ ca.2018a0001

Das T, Maurer EP, Pierce DW, et al. 2013. Increases in flood magnitudes in California under warming climates. J Hydrol 501:101-10.

Dettinger M. 2011. Climate change, atmospheric rivers, and floods in California - a multimodel analysis of storm frequency and magnitude changes. J Am Water Resour As 47:514-23.

Dillon P. 2005. Future management of aquifer recharge. Hydrogeol J 13(1):313-6.

[DWR] California Department of Water Resources. 2015. California's Most Significant Droughts: Comparing Historical and Recent Conditions. Sacramento: DWR. www. water.ca.gov/waterconditions/ docs/California_Signficant Droughts_2015_small.pdf

DWR. 2016. Groundwater Basins Subject to Critical Conditions of Overdraft. www.water.ca.gov/ groundwater/sgm/pdfs/CODbasins_2016_Dec19.pdf

DWR. 2017. Water Available for Replenishment. http://wdl.water.ca.gov/groundwater/sgm/ wafr.cfm

Faunt CC. 2009. Groundwater Availability of the Central Valley Aquifer, California. USGS professional paper No. 1766. Sacramento: US Department of the Interior, US Geological Survey.
Grantham TE, Viers JH. 2014. 100 years of California's water rights system: Patterns, trends and uncertainty. Environ Res Lett 9(8):084012.

Hanak E, Lund JR. 2012. Adapting California's water management to climate change. Clim Change 111:17-44.

Hanak E, Lund J, Dinar A, et al. 2011. Managing California's Water: From Conflict to Reconciliation. San Francisco: Public Policy Institute of California. 482 p.

Hanak E. 2018. The State of Groundwater Recharge in the San Joaquin Valley. www.ppic org/blog/state-groundwaterrecharge-san-joaquin-valley/

Harter T, Dahlke HE. 2014. Out of sight but not out of mind:

California refocuses on groundwater. Calif Agr 68:54-5.

Henriksen JA, Heasley J, Kennen

JG, Nieswand S. 2006. Users' Manual for the Hydroecological Integrity Assessment Process Software (Including the New Jersey Assessment Tools). Reston, VA: US Geological Survey.

Kocis TN, Dahlke HE. 2017 Availability of high-magnitude streamflow for groundwater banking in the Central Valley, California. Environ Res Lett 12(8):084009.

Kuichling E. 1889. The relation between the rainfall and the discharge of sewers in populous districts. Trans Am Soc Civil Eng 20:1-56.

Maurer EP, Duffy PB. 2005. Uncertainty in projections of streamflow changes due to climate change in California. Geophys Res Lett 32:1-5.

Null SE, Viers JH. 2013 In bad waters: water year classification in nonstationary climates. Water Resour Res 49:1137-48.

O'Geen AT, Saal MBB, Dahlke HE, et al. 2015. Soil suitability index identifies potential areas for groundwater banking on agricultural lands. Calif Agr 69(2):75-84.

Olden JD, Poff NL. 2003. Redundancy and the choice of hydro logic indices for characterizing streamflow regimes. River Res Appl 19:101-21.

Richards RP. 1990. Measures of flow variability and a new flow based classification of Great Lakes tributaries. J Great Lakes Res 16:53-70.

Russo TA, Fisher AT, Lockwood BS. 2015. Assessment of managed aquifer recharge site suitability using a GIS and modeling. Groundwater 53(3):389-400.
Scanlon BR, Reedy RC, Faunt CC, et al. 2016. Enhancing drought resilience with conjunctive use and managed aquifer recharge in California and Arizona. Environ Res Lett 11(3):035013.

Slack JR, Lumb AM, Landwehr JM, US Geological Survey. 1994. Hydro-Climatic Data Network (HCDN)_A USGS Streamflow Data Set for the US for the Study of Climate Fluctuations. US Department of the Interior, US Geological Survey.

[SWRCB] State Water Resources Control Board. 1995. Water Quality Control Plan for the San Francisco Bay/SacramentoSan Joaquin Delta Estuary. 95-1WR. www.waterboards. ca.gov/waterrights/water issues/programs/bay delta/ wq_control_plans/1995wqcp/ docs/1995wqcpb.pdf (accessed Aug. 3, 2018)

SWRCB. 2001. Evaluation of State Water Resources Control Board Water Availability Analysis. MBK Engineers report. 8 p. www.cwemf.org/workshops/ mbkreport.pdf

SWRCB. 2014. Sustainable Groundwater Management Act $\S \S 346-1-10$, $\S 3347$ $1-23$, §§ 348-1-3. State of California. www.water.ca.gov/ cagroundwater/docs/2014\%20 Sustainable\%20Groundwater\%20Management\%20Legislation\%20with\%202015\%20 amends\%201-15-2016.pdf [USGS] United States Geological Survey. 2009. National Elevation Dataset (NED). US Department of the Interior, US Geological Survey. http://nationalmap.gov/ elevation.html

USGS. 2016. Daily Streamflow Conditions, USGS Current Water Data for the Nation. US Department of the Interior, US Geological Survey. http://waterdatausgs.gov/nwis/rt

Volder A, Shackel K, Lamp inen B, et al. 2016. Winter Recharge and Irrigation. UC Davis Dept of Plant Sciences. https://ffalmonds. com/WebLink/ElectronicFile. aspx? docid $=2333 \& d$ bid $=0$

Xiao M, Koppa A, Mekonnen Z, et al. 2017. How much groundwater did California's Central Valley lose during the 2012-2016 drought? Geophys Res Lett 44(10):1-8.

Yu Z, Jiang P, Gautam MR, et al. 2015. Changes of seasonal storm properties in California and Nevada from an ensemble of climate projections. J Geophys Res-Atmos 120:2676-88. 


\section{Survey of the pathogen of Alternaria late blight reveals different levels of carboxamide fungicide resistance in the main pistachio producing regions of California}

Resistance was greatest in counties at the northern and southern ends of the Central Valley, where weather conditions are conducive to pathogen infection.

by Paulo Lichtemberg, Ryan Puckett, Daniel Felts, Yong Luo, Lorene Doster, David Rodriguez and Themis Michailides

\section{Abstract}

Alternaria late blight (ALB), caused mainly by the fungal pathogen Alternaria alternata, is an important pistachio disease that causes severe tree defoliation and fruit shell staining. Its control relies on multiple fungicide sprays, including carboxamide fungicides. In 2015, we surveyed 35 orchards representing nine pistachio producing counties of California to determine the current situation of Alternaria resistance to four widely used carboxamide fungicide active ingredients. This survey showed that isolates collected in the northern (Tehama, Glenn and Colusa counties) and southern (Tulare, Kings and Kern counties) Central Valley presented higher frequencies of carboxamide resistance than isolates collected from orchards in the central region (Fresno, Madera and Merced counties). The number of carboxamide usages in a year is the main factor determining elevated resistance. By extracting the $A$. alternata DNA and sequencing the carboxamide target genes, we evaluated the prevalence of specific molecular alterations (mutations) associated with carboxamide fungicide resistance. Finally, we identified cross-resistance patterns among different carboxamide fungicides, leading to recommendations about combinations to avoid.

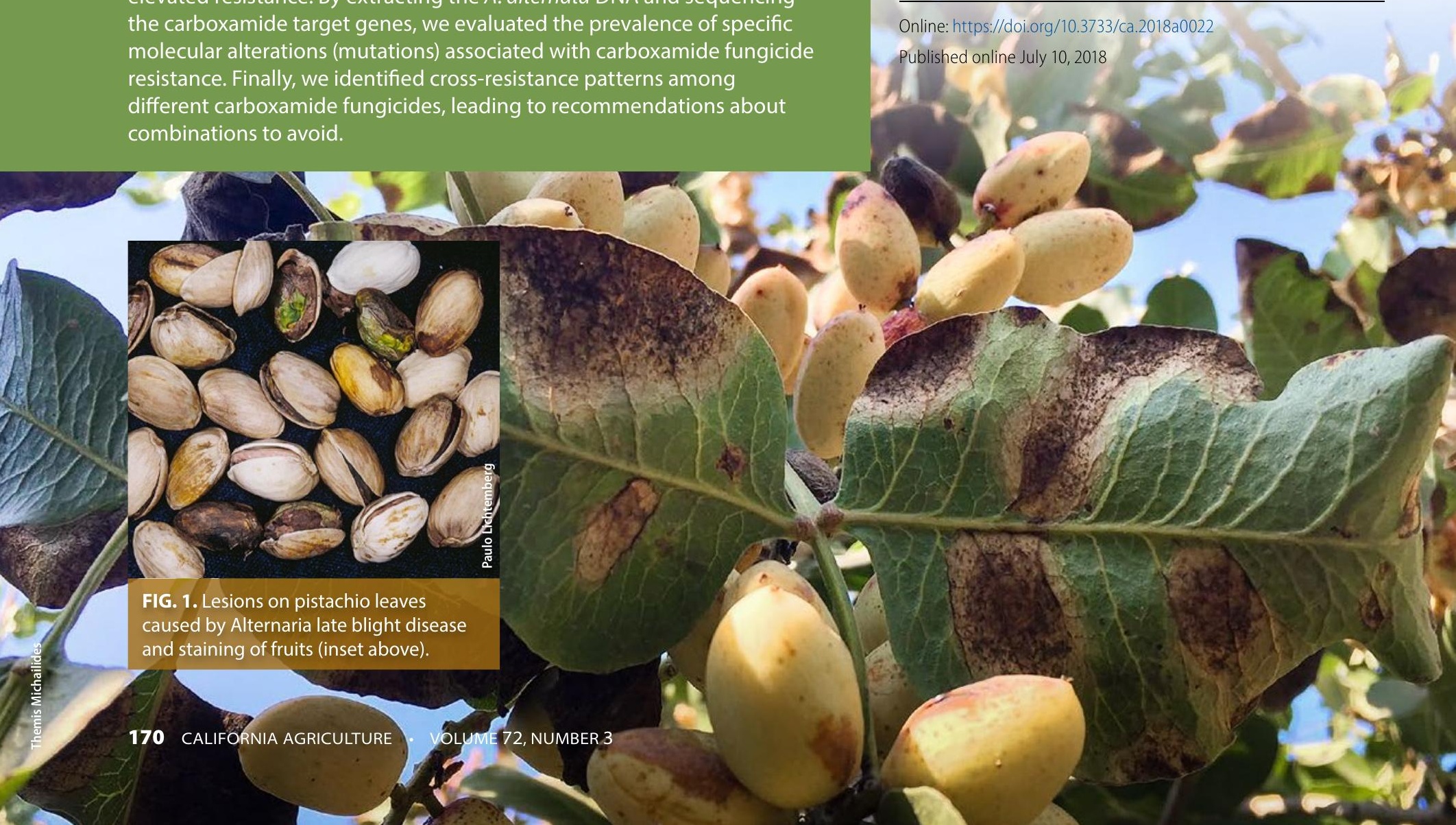

lternaria late blight (ALB) is among the most
important and destructive diseases in pistachio,
representing a major annual concern for commercial growers in California (Avenot and Michailides 2015). ALB is caused by three related species of Alternaria (A. alternata, A. arborenses and A. tenuissima); the most common is $A$. alternata. Damages from the disease are observed in the foliage (fig. 1) and fruits (fig. 1 , inset), resulting in premature defoliation of fruitbearing and non-bearing shoots, brown or black shell staining, and mold of the kernels, which reduce fruit quality (Michailides et al. 2016). A severe infection can cause losses exceeding $\$ 1,000$ per acre (T. Michailides, Kearney Agricultural Research and Extension Center, personal communication). 
ALB control relies on up to three fungicide applications, which must be applied between June and the first week of August (before the appearance of disease leaf lesions) to be effective (Adaskaveg et al. 2017; Michailides et al. 2016). Carboxamides, also known as succinate dehydrogenase inhibitors, or SDHIs, are the primary tool for ALB control in pistachios. Formulations of four carboxamide active ingredients (a.i.) - boscalid, fluxapyroxad, fluopyram and penthiopyrad - are registered in California. Commercially available products include solo formulations as well as mixtures with quinone outside inhibitors and demethylation inhibitors (table 1). All these carboxamide fungicides target a single pathogen site blocking the fungal respiration process, and thus are prone to resistance selection (Oliver and Hewitt 2014; Stammler et al. 2015).

In California, Pristine (a.i. boscalid) was the first modern carboxamide registered to control ALB in pistachio, and resistance of $A$. alternata was observed just two seasons after its registration in 2003. Since then, resistance has become widespread. In 2005, 12\% of $A$. alternata isolates collected from a commercial orchard in Kern County, where boscalid had been used for two successive years, with two or three sprays per season - showed high levels of resistance (Avenot and Michailides 2007). Five years later, isolates highly resistant to boscalid accounted for 59\% of the sampled population in California (Avenot et al. 2014).

The increased number of isolates with high levels of carboxamide resistance may ultimately lead to practical resistance that affects the efficacy of these fungicides. Although Avenot et al. (2012) reported a lack of disease control due to boscalid resistance in several California pistachio orchards, trials at the UC Kearney Agricultural Research and Extension Center in Parlier and at commercial pistachio orchards in California show that carboxamide fungicides, including boscalid, continue to provide consistent disease control (Adaskaveg et al. 2017).

It is difficult to predict when carboxamide field failure may occur. Carboxamide resistance surveys and the regular molecular characterization of the pathogen population can help to provide growers and pest control advisers updated information that may influence fungicide recommendations.

While previous reports have included valuable information concerning the carboxamide resistance of the ALB pathogen in California pistachio (Avenot et al. 2014), information on regional variations in resistance has not been published. Regional-level information on resistance can help to guide growers' carboxamide application decisions.

Our study evaluated A. alternata resistance by region to the four carboxamide fungicides registered for pistachio and investigated the molecular basis of resistance. We focused on isolates from the three regions that account for $99.3 \%$ of California pistachio production (ACP 2017). We defined the northern region as
TABLE 1. Carboxamide formulations registered for pistachio in California

\begin{tabular}{|c|c|c|}
\hline & Manufacturer & $\begin{array}{l}\text { Carboxamide active } \\
\text { ingredient }\end{array}$ \\
\hline \multicolumn{3}{|l|}{ Solo formulations } \\
\hline Luna Privilege & Bayer Crop Science & Fluopyram \\
\hline Fontelis & DuPont & Penthiopyrad \\
\hline \multicolumn{3}{|c|}{ Mixtures with quinone outside inhibitors } \\
\hline Luna Sensation & Bayer Crop Science & Fluopyram \\
\hline Merivon & BASF & Fluxapyroxad \\
\hline Pristine & BASF & Boscalid \\
\hline \multicolumn{3}{|c|}{ Mixtures with demethylation inhibitors } \\
\hline Luna Experience & Bayer Crop Science & Fluopyram \\
\hline
\end{tabular}

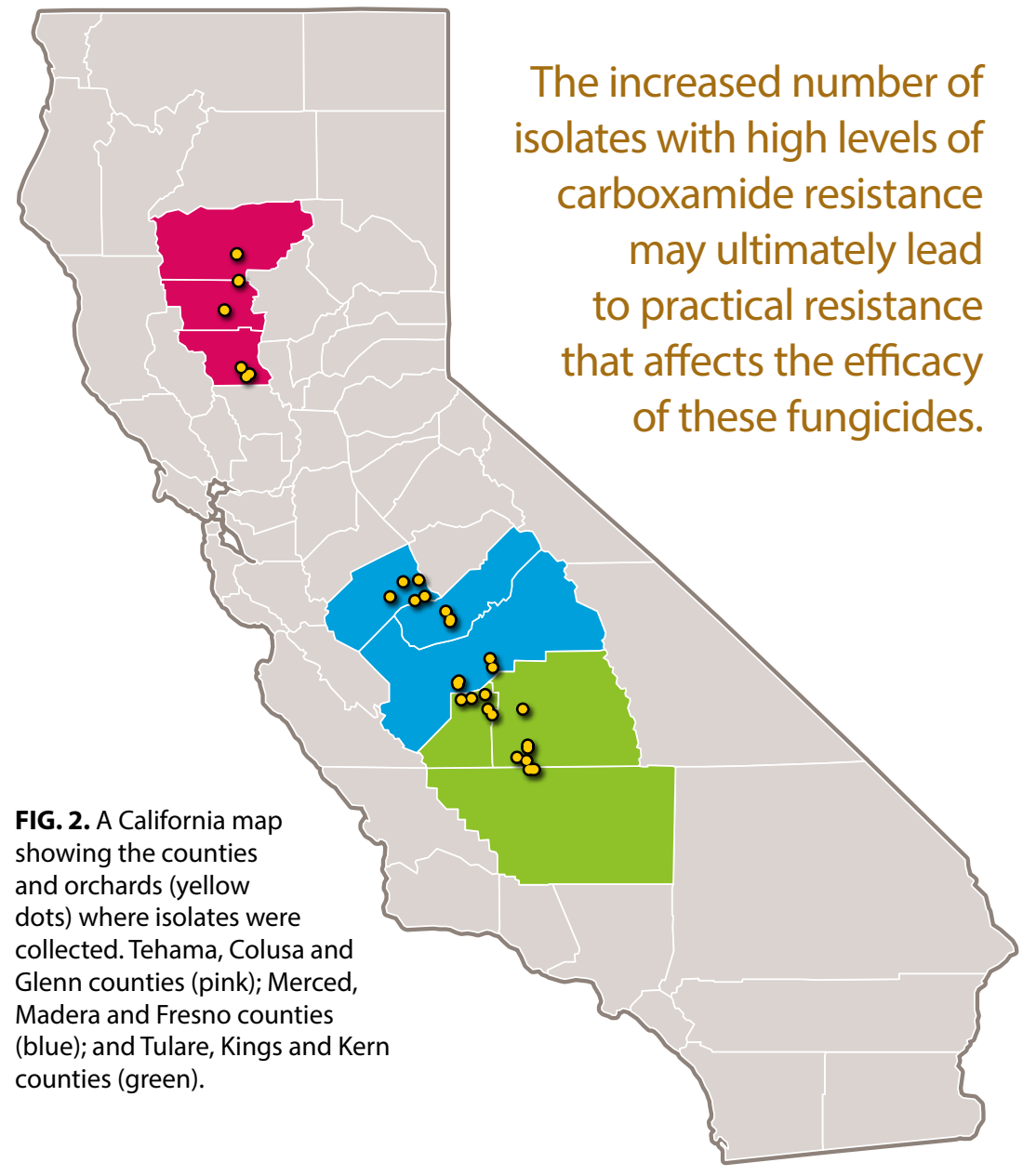

Colusa, Glenn and Tehama counties, the central region as Fresno, Madera and Merced counties, and the southern region as Kern, Kings and Tulare counties (fig. 2).

\section{Fungal isolates used in this study}

From May through July 2015, we collected a total of 167 A. alternata isolates from 35 commercial pistachio orchards in the three regions (fig. 2). Carboxamides have been used for many years in all orchards sampled. The mean number of carboxamide applications per year 


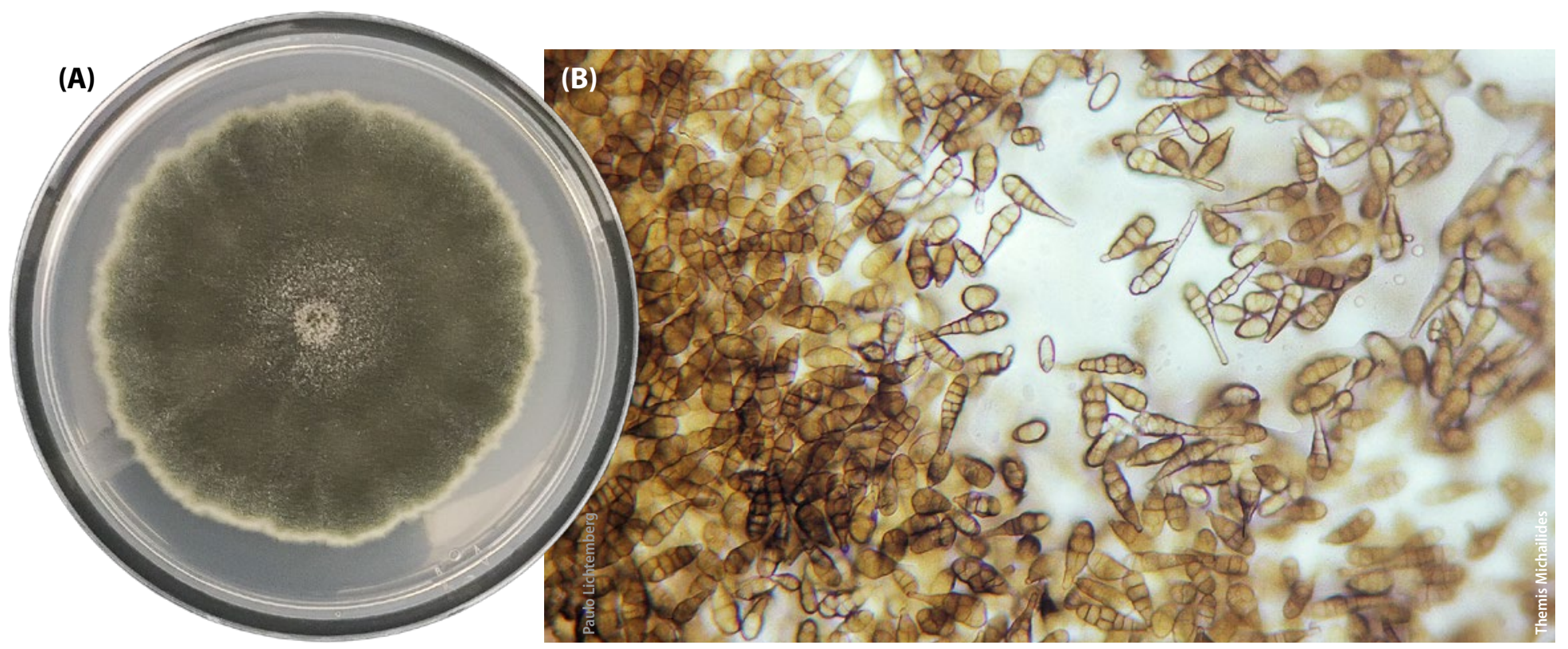

FIG. 3. Alternaria alternata colony (A) and dark, multi-celled conidia (B).
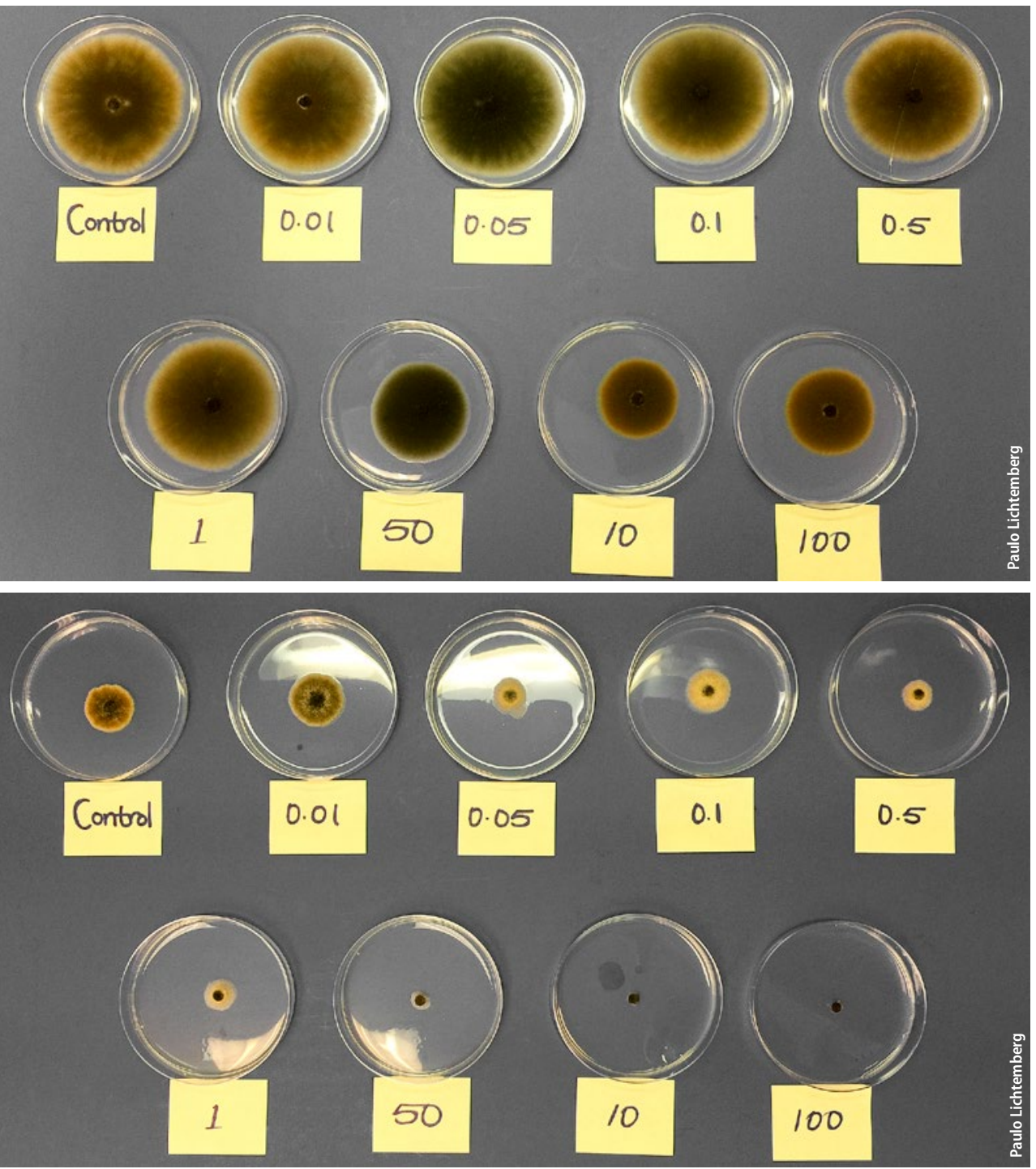

FIG. 4. Alternaria alternata fungicide sensitivity assay showing the mycelial inhibition of a resistant $(A)$ and sensitive $(B)$ isolate.

for each region is summarized in table 3 . We tested 48 isolates from the northern region, 59 from the central region and 60 from the southern region. Isolates were recovered from asymptomatic leaves using the overnight freezing incubation technique (ONFIT), followed by a purification to select a colony single conidia (fig. 3).

\section{Testing pathogen sensitivity to carboxamide fungicides}

The sensitivity of A. alternata to each carboxamide a.i. was determined as the concentration of the fungicide that inhibits fungal growth by $50 \%$, known as the $\mathrm{EC}_{50}$ value (fig. 4). The $\mathrm{EC}_{50}$ value is the standard measure of fungal sensitivity to fungicides. To obtain the sensitivity values, fungicide stock solutions were prepared at a concentration of 10 grams a.i. per liter. The fungicides used were as follows: technical grade boscalid (a.i. 99\%, BASF, The Chemical Company), fluopyram (a.i. 99.13\%, Bayer CropScience) and penthiopyrad (a.i. 99.5\%, DuPont Company), each diluted in acetone; and the commercial product of fluxapyroxad (Sercadis 300 SC, BASF, The Chemical Company) diluted in sterile deionized water. Each stock solution was diluted in autoclaved yeast-bacto-agar media at final concentrations of 0 (control), $0.01,0.03,0.12,0.48,1.92,7.68,30.72$ and $122.88 \mu \mathrm{g} / \mathrm{ml}$. For each tested isolate, a $5-\mathrm{mm}$ mycelial plug was transferred to a fresh plate containing yeastbacto-agar medium, amended with one of the above fungicide concentrations. Plates were incubated for a week before measuring colony diameter. Each isolate $\mathrm{EC}_{50}$ value corresponds to the dosage that inhibits the colony by $50 \%$ relative to the growth at the 0 dose (without fungicide). Linear regression functions were used to determine these values.

For the purposes of analysis, we assigned six sensitivity categories, or phenotypes — from highly resistant 
to highly sensitive - to ranges of $\mathrm{EC}_{50}$ values (table 2) (Avenot et al. 2014).

\section{Genetic mutations associated with carboxamide resistance}

DNA mutations in fungal pathogens are one source of resistance to fungicides (Oliver and Hewitt 2014). To identify genetic mutations associated with carboxamide resistance, we used a molecular approach, gene sequencing, to test the presence of different point mutations at the $A a S d h B, C$ and $D$ genes. In total, six different mutations were studied, the $\mathrm{H} 277 \mathrm{Y} / \mathrm{L} / \mathrm{R}$ at the AaSdhB gene, the H134R and S135R at the AaSdhC gene, and the $\mathrm{D} 123 \mathrm{E}$ at the $A a S d h D$ gene. The absence or presence of different mutations determines which genotype the A. alternata isolate belongs to.

\section{Statistical analysis}

The $\mathrm{EC}_{50}$ values were obtained by first making the logarithm $\left(\log _{10}\right)$ transformation of the fungicide concentrations and then performing linear regressions of the colony inhibition values by the $\log _{10}$ concentrations of fungicides. The $\mathrm{EC}_{50}$ values were calculated from the significant $(P<0.05)$ linear regression equations obtained for each isolate. Changes in sensitivity density curves were analyzed with the two-sample Kolmogorov-Smirnov test by comparing the cumulative frequency distribution of two datasets at a time. The arithmetic means of $\mathrm{EC}_{50}$ values for the regions were calculated separately. Significant differences were verified with the Welch two-sample $t$-test, considered significant at $P<0.05$. Pearson correlation analysis was used to determine cross-resistance among the four tested carboxamides. The statistical software $\mathrm{R}$ (version 3.4.0) was used for data analysis and graphical representation.

\section{A. alternata resistance to carboxamide in California}

The A. alternata resistance survey to carboxamides fungicides showed different levels of sensitivity among and within the California regions where the isolates were collected. Our data on sensitivity density distribution, mean sensitivity value ( $\mathrm{EC}_{50}$ value), and the frequency of isolate phenotypes demonstrate that the northern and southern pistachio producing regions possess a greater number of isolates with higher resistance to carboxamides than the central region. The results for A. alternata sensitivity density distribution show similar curves for isolates collected from the northern and southern regions when testing boscalid (fig. 5A; $P=0.258$ ), fluopyram (fig. 5B; $P=0.55$ ), fluxapyroxad (fig. 5C; $P=0.73$ ) and penthiopyrad (fig. 5D; $P=0.28$ ). Clearly, the sensitivity density distribution curves for the northern and southern regions were shifted toward resistance in comparison with the
TABLE 2. Level of resistance (phenotype*) according to the $\mathrm{EC}_{50}$ value

\begin{tabular}{|l|l|}
\hline Range of $\mathrm{EC}_{50}$ value & Level of sensitivity (phenotype) \\
\hline$<0.01 \mu \mathrm{g} / \mathrm{ml}$ & Highly sensitive (HS) \\
\hline $0.01-1 \mu \mathrm{g} / \mathrm{ml}$ & Sensitive (S) \\
\hline $1-5 \mu \mathrm{g} / \mathrm{ml}$ & Reduced sensitivity (RS) \\
\hline $5-10 \mu \mathrm{g} / \mathrm{ml}$ & Low resistant (LR) \\
\hline $10-100 \mu \mathrm{g} / \mathrm{ml}$ & Moderately resistant (MR) \\
\hline $100 \mu \mathrm{g} / \mathrm{ml}<$ & Highly resistant (HR) \\
\hline${ }^{*}$ Fungicide sensitivity phenotypes according to Avenot et al. (2014). \\
\hline
\end{tabular}

* Fungicide sensitivity phenotypes according to Avenot et al. (2014).

central region. Significant differences between central and northern regions were observed for boscalid (fig. 5A; $P=3.0 \times 10^{-5}$ ), fluopyram (fig. 5B; $P=7.6 \times 10^{-7}$ ), fluxapyroxad (fig. 5C; $P=2.3 \times 10^{-8}$ ) and penthiopyrad (fig. 5D; $P=3.3 \times 10^{-10}$ ). Similarly, the central region differed from the southern region for boscalid (fig. 5A; $P=0.0014$ ), fluopyram (fig. 5B; $P=3.4 \times 10^{-5}$ ), fluxapyroxad (fig. $5 \mathrm{C} ; P=2.5 \times 10^{-7}$ ) and penthiopyrad (fig. 5D; $\left.P=4.0 \times 10^{-8}\right)$.

The mean $\mathrm{EC}_{50}$ values obtained for different carboxamides corroborate the information above, where the sensitivity values obtained for the central region (14.62, $5.3,5.14$ and $3.89 \mu \mathrm{g} / \mathrm{ml})$ were statistically $(P<0.05)$ lower than the values encountered from the northern $(48.76,18.68,46.02$ and $26.73 \mu \mathrm{g} / \mathrm{ml})$ and southern $(41.16,27.7,42.92$ and $16.46 \mu \mathrm{g} / \mathrm{ml})$ regions for boscalid, fluopyram, fluxapyroxad and penthiopyrad, respectively (table 3 ).

The frequency of sensitivity phenotypes within regions for the tested fungicides showed two major trends. First, isolates exhibiting moderately resistant (MR) and highly resistant (HR) phenotypes tend to be more prevalent in the northern and southern regions (fig. 6). Second, highly sensitive (HS) and sensitive (S) phenotypes together were dominant within the central population. Furthermore, a detailed phenotype frequency analysis revealed that the two most resistant phenotypes (MR and HR) from the north accounted for higher frequencies of isolates tested with boscalid (fig. 6A; 62.4\%), fluxapyroxad (fig. 6B; $64.6 \%$ ) and penthiopyrad (fig. 6D; 47.9\%), but not for fluopyram (fig. 6C; 31.2\%), where the two intermediate sensitivity phenotypes, reduced sensitivity (RS) and low resistant (LR), were present in $41.7 \%$ of isolates (fig. 6C). In the south, the same analysis showed that MR and HR phenotypes accounted for higher frequencies when tested for boscalid (fig. 6A; $51.7 \%$ ) and fluxapyroxad (fig. 6B; 64.6\%); but for penthiopyrad, higher frequencies were observed for the RS and LR phenotypes together (fig. 6D; 48.2\%). The phenotype frequency for fluopyram in the southern region showed a balanced distribution among the two most sensitive (HS and S; fig. 6C; 38.3\%), the two 
(A)

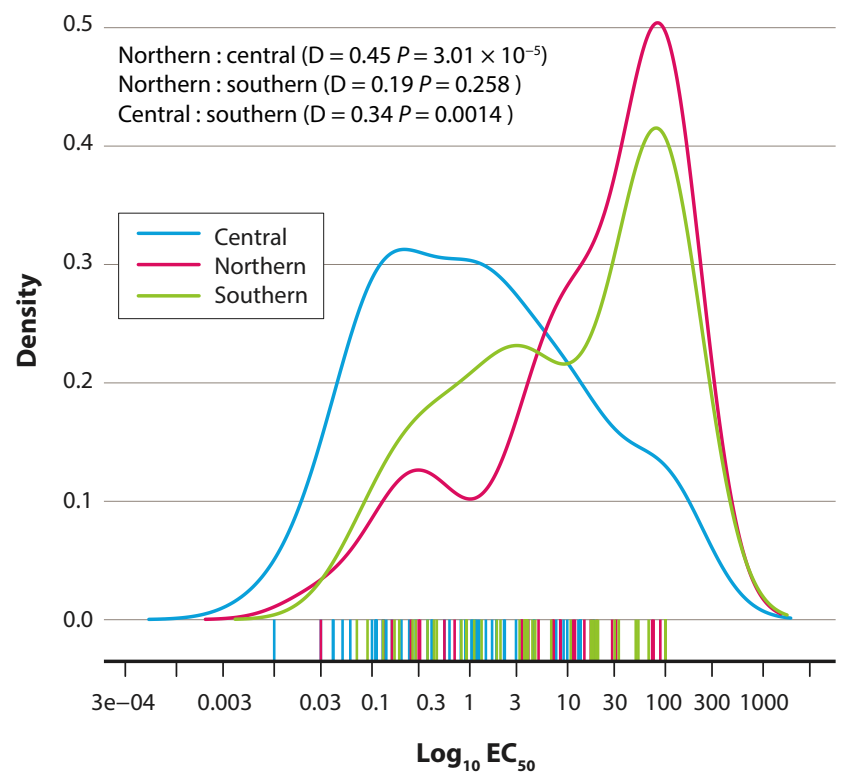

(C)

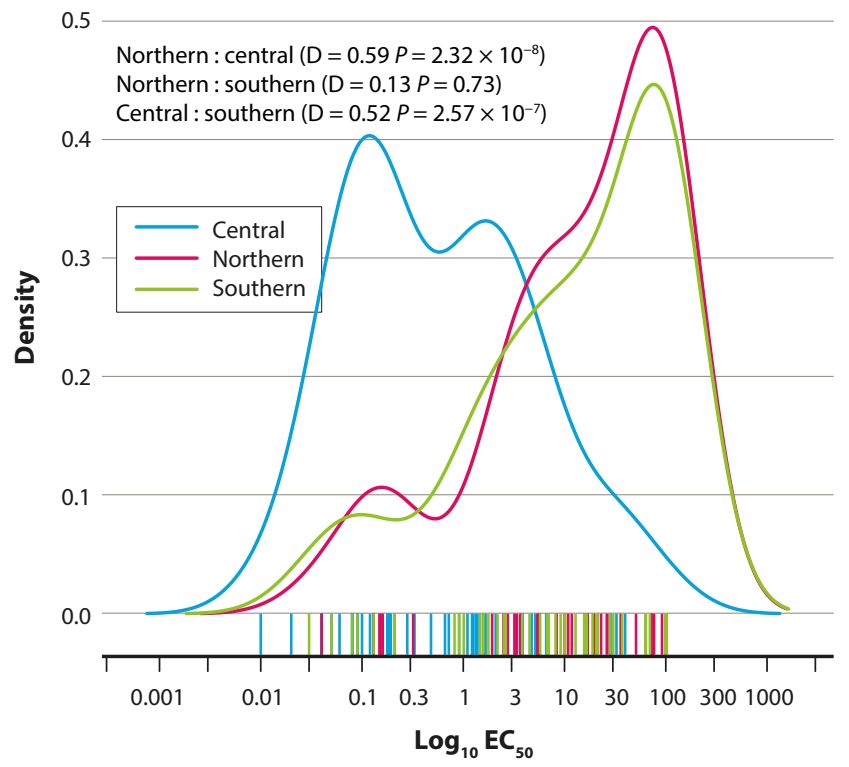

(B)

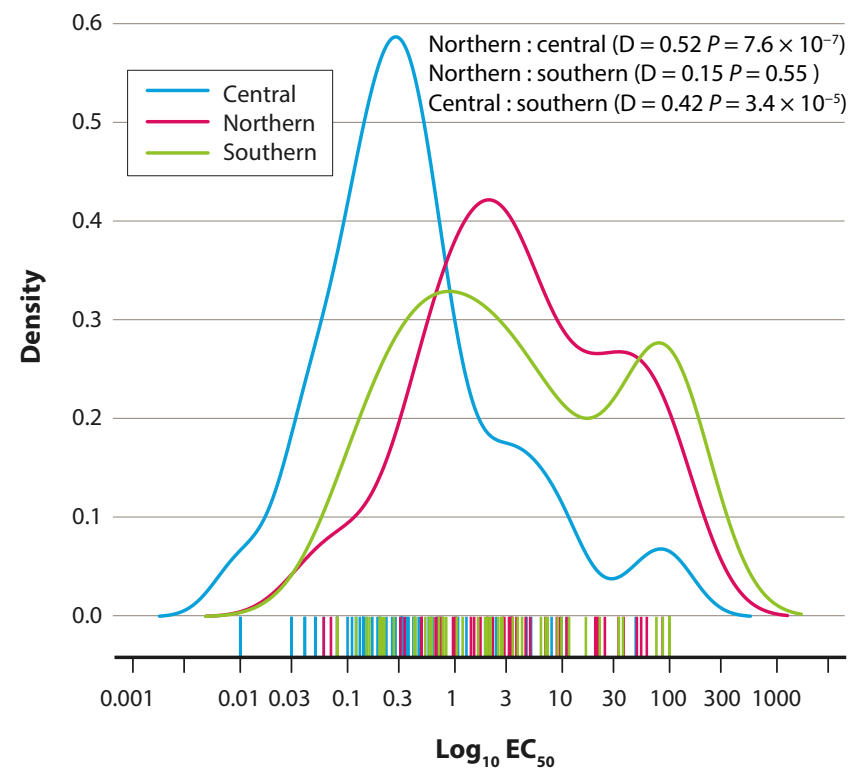

(D)

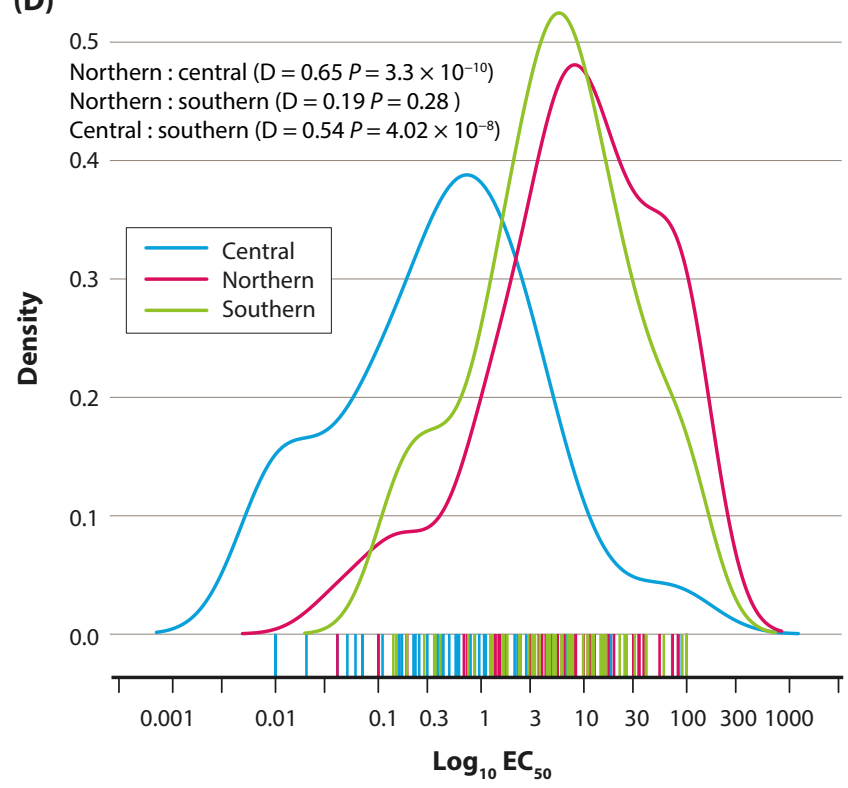

FIG. 5. Alternaria alternata sensitivity density distribution for carboxamides fungicides (A) boscalid, (B) fluopyram, (C) fluxapyroxad and (D) penthiopyrad on the three major pistachio producing areas of California. $\mathrm{EC}_{50}$ values were log transformed prior to plotting. The figure shows that for all carboxamide fungicide used in this study, A. alternata isolates from the northern (Tehama, Glenn and Colusa counties) and southern (Kern, Kings and Tulare counties) Central Valley counties are shifted significantly toward resistance in comparison to the central counties (Fresno, Madera and Merced).

TABLE 3. Comparison of the pistachio producing regions of California regarding the mean $\mathrm{EC}_{50}$ value and number of carboxamide (SDHI) spray application per season

\begin{tabular}{|c|c|c|c|c|c|c|c|c|c|c|c|}
\hline \multirow{3}{*}{$\begin{array}{l}\text { Region } \\
\text { Northern }\end{array}$} & \multicolumn{2}{|c|}{ Boscalid } & \multicolumn{2}{|c|}{ Fluopyram } & \multicolumn{2}{|c|}{ Fluxapyroxad } & \multicolumn{2}{|c|}{ Penthiopyrad } & \multicolumn{3}{|c|}{ Mean SDHI application (range) } \\
\hline & \multicolumn{8}{|c|}{$E C_{50}(\mu \mathrm{g} / \mathrm{ml})^{*}$} & 2013 & 2014 & 2015 \\
\hline & 48.76 & $a$ & 18.68 & $a$ & 46.02 & $\mathrm{a}$ & 26.73 & a & $0.5(0-1)$ & $1.5(1-2)$ & $1.5(1-2)$ \\
\hline Central & 14.62 & $\mathrm{~b}$ & 5.3 & $b$ & 5.14 & $\mathrm{~b}$ & 3.89 & $\mathrm{~b}$ & $0.6(0-2)$ & $1(0-1)$ & $1(0-2)$ \\
\hline Southern & 41.16 & $\mathrm{a}$ & 27.7 & a & 42.92 & a & 16.46 & $\mathrm{a}$ & $0.8(0-1)$ & $1.4(0-3)$ & $2(1-3)$ \\
\hline
\end{tabular}

* Sensitivity value was compared using the Welch $t$-test (significance at $P<0.05$ ). 

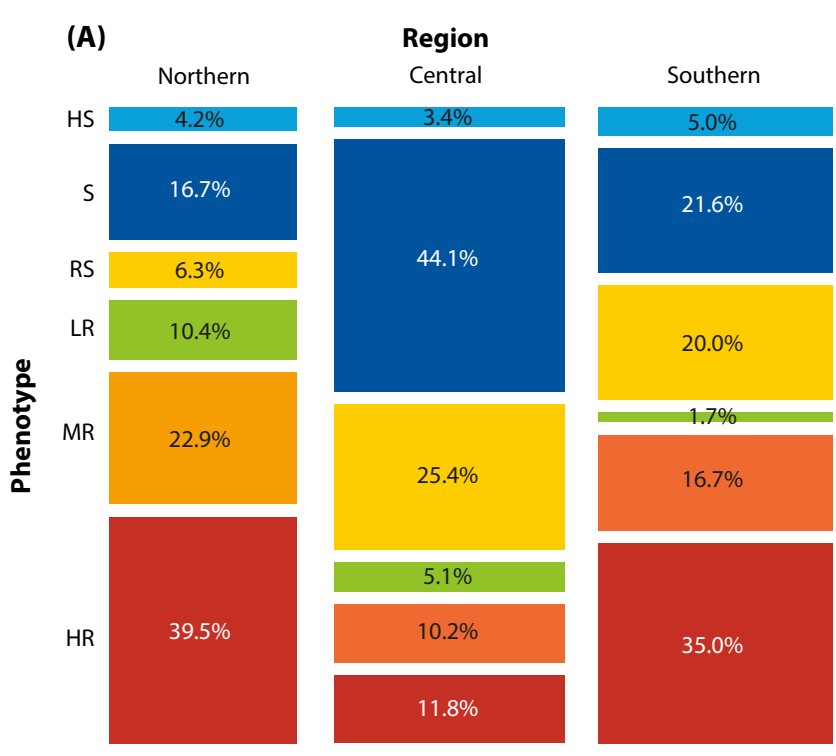

(C)
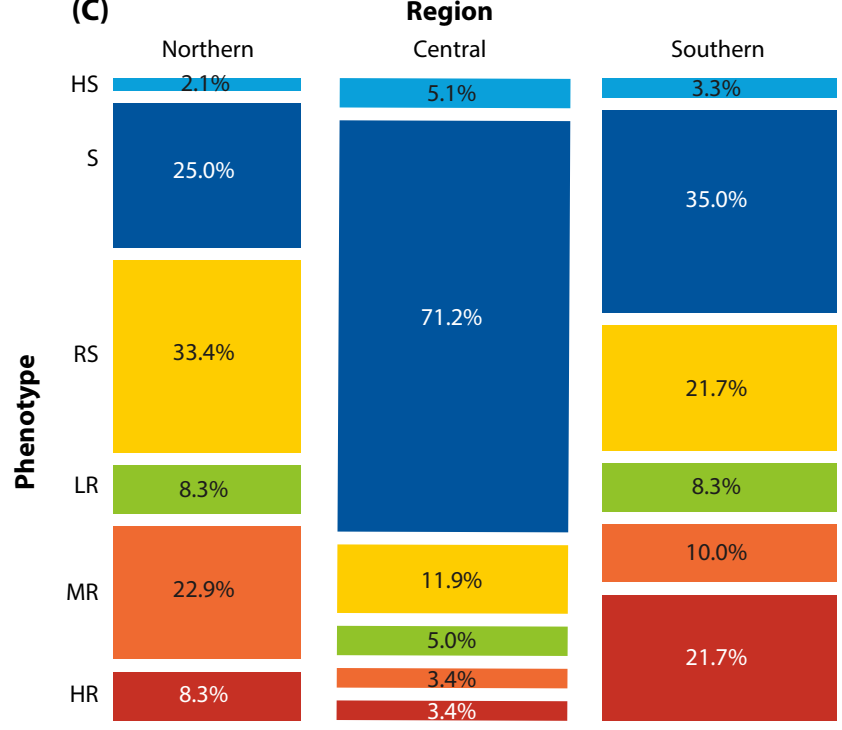

(B)

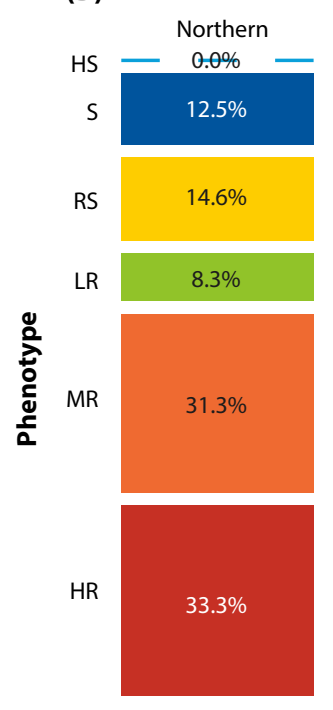

(D)

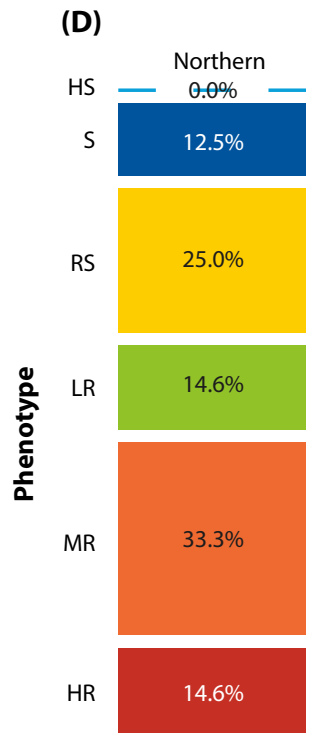

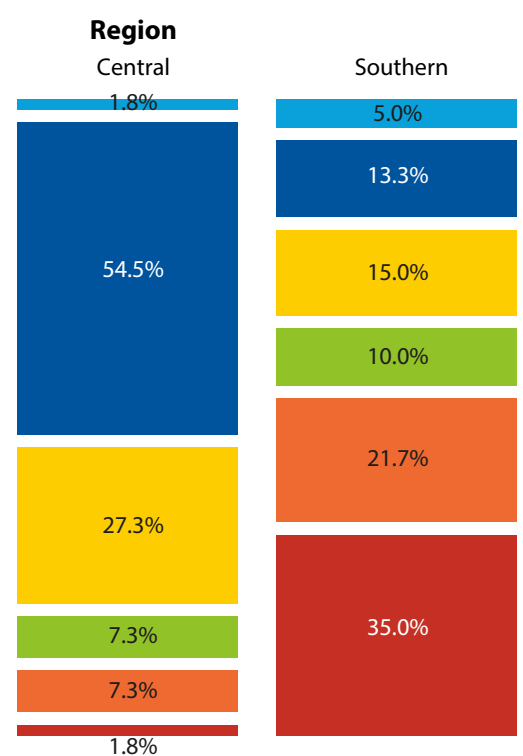
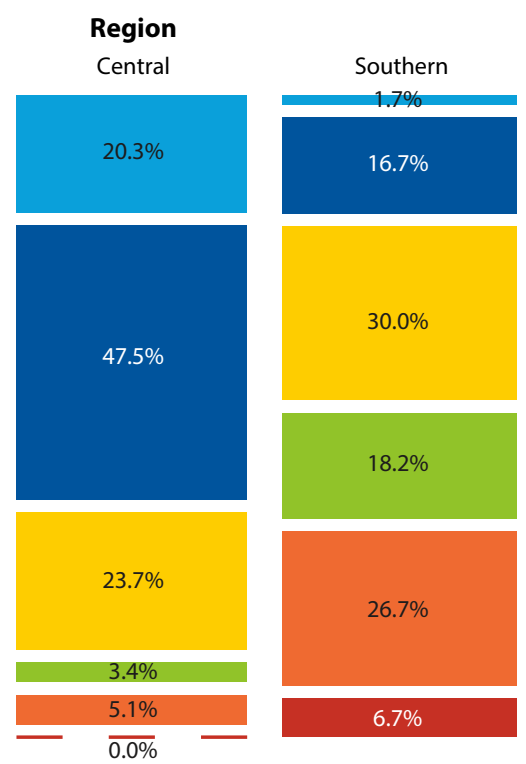

FIG. 6. Frequency of Alternaria alternata sensitivity phenotypes for carboxamide fungicides (A) boscalid, (B) fluxapyroxad, (C) fluopyram and (D) penthiopyrad on the three major pistachio producing areas of California. $\mathrm{HR}=$ highly resistant, $M R=$ moderately resistant, $\mathrm{LR}=$ low resistant, $\mathrm{RS}=$ reduced sensitivity, $\mathrm{S}=$ sensitive and $\mathrm{HS}=$ high sensitivity.

TABLE 4. The frequency of Alternaria alternata genotypes associated with carboxamide fungicide resistance in California pistachio

\begin{tabular}{|c|c|c|c|c|c|c|c|c|c|}
\hline \multirow[b]{2}{*}{ Genotype } & \multirow[b]{2}{*}{ Alternation } & \multicolumn{6}{|c|}{ Sensitivity phenotype } & \multirow[b]{2}{*}{ Total } & \multirow[b]{2}{*}{ Frequency $(\%$} \\
\hline & & HS & S & RS & LR & MR & HR & & \\
\hline 1 & No mutation & 2 & 31 & 15 & 4 & 10 & 13 & 75 & 46.3 \\
\hline ॥ & $\mathrm{SdhB} \mathrm{H} 277 \mathrm{Y}$ & 0 & 5 & 3 & 0 & 3 & 6 & 17 & 10.5 \\
\hline III & SdhB H277R & 0 & 0 & 0 & 0 & 0 & 0 & 0 & 0.0 \\
\hline IV & $\mathrm{SdhCH} 134 \mathrm{R}$ & 5 & 9 & 10 & 5 & 13 & 24 & 66 & 40.7 \\
\hline VII & SdhD D123E & 0 & 0 & 0 & 0 & 0 & 2 & 2 & 1.3 \\
\hline VIII & SdhC S135R & 0 & 0 & 0 & 0 & 0 & 1 & 1 & 0.6 \\
\hline IX & $S d h B H 277 \mathrm{~L}$ & 0 & 0 & 1 & 0 & 0 & 0 & 1 & 0.6 \\
\hline
\end{tabular}


intermediate phenotypes (RS and LR; fig. 6C; 30\%), and the two most resistant phenotypes (MR and HR; fig. 6C; 31.7\%).

\section{Links between carboxamide treatment and resistance}

In the recent past, A. alternata resistance build-up to carboxamide fungicides was observed in a short period in pistachio and peach orchards where boscalid had been sprayed twice or three times per year (Avenot and Michailides 2007; Yang et al. 2015). These two examples demonstrated that recurrent use of carboxamides is the most important factor causing the ALB resistance build-up within a population. In pistachio orchards surveyed for this study, in 2015, carboxamide fungicides were sprayed once or twice in the northern orchards, and from zero to three times in the southern orchards - in both cases, more than in the central region (table 3).

Previous research has established the importance of weather conditions in the spread of Alternaria species. Most severe epidemics are associated with maximum daily temperatures of $28^{\circ} \mathrm{C}$ to $32^{\circ} \mathrm{C}$, combined with wet conditions provided by rain, irrigation or dew (Rotem 1994). In California, these favorable conditions occur from late summer through early fall because of relatively long periods of dew and high relative humidity in August and September compared with spring and summer (Michailides et al. 2016). Weather conditions more favorable to ALB disease contribute to growers applying fungicides more times each summer in the northern and southern counties than in the central counties (CIMIS 2017). In turn, more fungicide sprays result in more pressure under the target fungi population, increasing the selection for resistant isolates.

Weather data for the studied locations in 2013 to 2015 showed that climate conditions in the northern and southern counties were more conducive to ALB disease (fostering more severe cases of the disease and more disease cycles per season) than were conditions in the central counties.

Another factor: In the northern counties, weather conditions are conducive to another important fungal disease of pistachios, Botryosphaeria panicle and shoot blight (caused by Botryosphaeria dothidea, commonly known as BOT, and treated with the same fungicides registered for ALB). Morgan et al. (2009) reports that some growers in this region have used as many as seven fungicide applications annually. The increased number of fungicide sprays needed in the northern counties to control BOT increases the exposure of Alternaria species to carboxamides, even when the pathogens are latent - that is, not actively growing and causing damage to the pistachio tissue.

\section{Genetic mutations of surveyed ALB isolates}

In California, $46.3 \%$ of the A. alternata population belongs to the genotype I, composed of isolates without any described mutation associated with carboxamide resistance, meaning that they are sensitive to carboxamide fungicides (table 4). Of the isolates carrying mutations associated with carboxamide resistance, the genotype IV (H134R) was most often observed, with $40.7 \%$ of the total surveyed population, followed by genotype II (H277Y), accounting for 10.5\% (table 4) of the total population. With very low frequencies, the isolate mutants D123E (genotype VII), S135R (genotype VIII) and H277L (genotype IX) accounted for 1.3, 0.6 and $0.6 \%$ of the population, respectively (table 4 ). The genotype III (H277R), reported in past surveys, was not found in our study.

The two most observed mutations conferring carboxamide resistance in our study - H134R and H277Y - were also those found most frequently within the A. alternata populations of peach in South Carolina, where H134R and H277Y genotypes accounted for, respectively, $49.2 \%$ and $19 \%$ of the total studied isolates (Yang et al. 2015). However, the frequencies of the H134R and H277Y mutations we observed in $A$. alternata differed from those reported from a survey in California pistachio orchards performed by Avenot et al. (2014), which found higher frequencies of H277Y than H134R on isolates collected in 2010.

We believe these differences can be explained by two factors: (a) the use of different carboxamide a.i. selecting for different mutations and (b) the higher fitness or adaptability of H134R in comparison with H277Y when competing against isolates without any mutations, the sensitive isolates.

The evidence for the first hypothesis comes from the early 2000s. At that time, the fungicide Pristine (premixture of a.i. boscalid plus pyraclostrobin) was the most commonly used carboxamide to control ALB disease, and selected mostly for the H277Y genotype followed by the H134R (Avenot et al. 2014). Years later, with the registration for pistachio of Fontelis (a.i. penthiopyrad), Merivon (containing the a.i. fluxapyroxad) and Luna package (containing the a.i. fluopyram), the use of Pristine decreased, changing the mutation frequencies of $A$. alternata isolates within the California population to H134R (40.7\%) and H277Y (10.5\%) (table 4).

Stammler et al. (2015) have described how mutation type is related to the use of specific carboxamides. To corroborate this information, Sierotzki et al. (2010) described the major selection of H277Y mutation on A. alternata, by the solo use of boscalid, and the selection for H134R when using the a.i. isopyrazam and the boscalid/pyraclostrobin mixture. In California, the use of Fontelis, Merivon and Luna products (a.i. penthiopyrad, fluxapyroxad and fluopyram, respectively), may also have contributed to modify the genotype 
composition of the A. alternata population, but the extent to which genotype modifications occur in response to the use of the a.i. products has yet to be studied. Recent, preliminary studies in two commercial orchards in Tulare County, where fluopyram (a.i. of Luna products) was sprayed twice each season for the last 2 years, showed the persistence of ALB pathogens carrying the H134R mutation (P. Lichtemberg, unpublished data).

Our second hypothesis, regarding the relative fitness of the H134R genotype over H277Y when mixed with sensitive genotypes, is supported by Fan et al. (2015). Their study of peach isolates of A. alternata carrying the $\mathrm{H} 277 \mathrm{Y}$ and $\mathrm{H} 134 \mathrm{R}$ mutations found that the mutant genotypes were not out-competed by sensitive isolates over the course of five successive transfers in the absence of carboxamide, and their frequencies stabilized at about 60\% (H134R) and 30\% (H277Y) from an initial 50\%-50\% mixture. In pistachio populations of A. alternata, studies of competition between resistant mutants and sensitive isolates have not been performed, but observations on spore production and mycelial growth suggest advantages of H134R over H277Y (P. Lichtemberg, personal observation).

\section{Carboxamide cross-resistance}

Carboxamide cross-resistance - when an isolate resistant to one fungicide is found to also be resistant to another fungicide belonging to the same chemical group - was tested for the whole study population $(n=167)$ and revealed weak to moderate resistance relationships among the four carboxamides (fig. 7). Resistance to boscalid showed a moderate relationship to resistance to fluxapyroxad $(r=0.40)$ and penthiopyrad $(r=0.46)$, and a weak relationship to resistance to fluopyram ( $\mathrm{r}$ $=0.26$ ). Among the studied interactions, resistance to both fluxapyroxad and penthiopyrad revealed the highest positive correlation coefficient and intensity $(r$ $=0.65$; see ellipse shape, fig. 7 ). Additionally, resistance to fluopyram was moderately correlated to resistance to penthiopyrad $(r=0.56)$ and fluxapyroxad $(r=0.49$; fig.7).

These results suggest that isolates resistant to boscalid have a higher risk of resistance selection from treatment with fungicides containing penthiopyrad and fluxapyroxad, than from treatment with fluopyram. This observation strengthens the recommendation made by Avenot et al. (2014) that Fontelis (a.i. penthiopyrad) and Merivon (a.i. fluxapyroxad) should be avoided or carefully used in areas with a history of Pristine usage (containing the a.i. boscalid). The relatively high correlation of fluopyram with penthiopyrad and fluxapyroxad may be associated with the high frequency of isolates carrying the H134R mutation in the California population

The cross-resistance patterns for carboxamides are complex and are related to different levels of resistance conferred by different mutations, and the role of each mutant genotype within the population (Olaya et al. 2016; Sierotzki et al. 2010; Stammler et al. 2015). Regardless of the role of any particular genotype in the development of cross-resistance, it is reasonable to conclude that resistance to different carboxamides may be always associated with the application of carboxamides, and that overuse of these products should be avoided.

\section{Final remarks and recommendations}

In this study, we reported that A. alternata sensitivity to carboxamide fungicides in the northern and southern pistachio producing regions of California was shifted toward resistance in comparison to the central region. We also observed that fluopyram (one a.i. component of Luna fungicides) is the carboxamide a.i. causing the least selection of isolates with altered sensitivity, meaning that fluopyram presents the highest levels of activity against ALB in pistachio. The sensitivity results obtained with fluopyram in our studies in vitro reflect the results obtained in recent field trials performed at Kearney Agricultural Research and

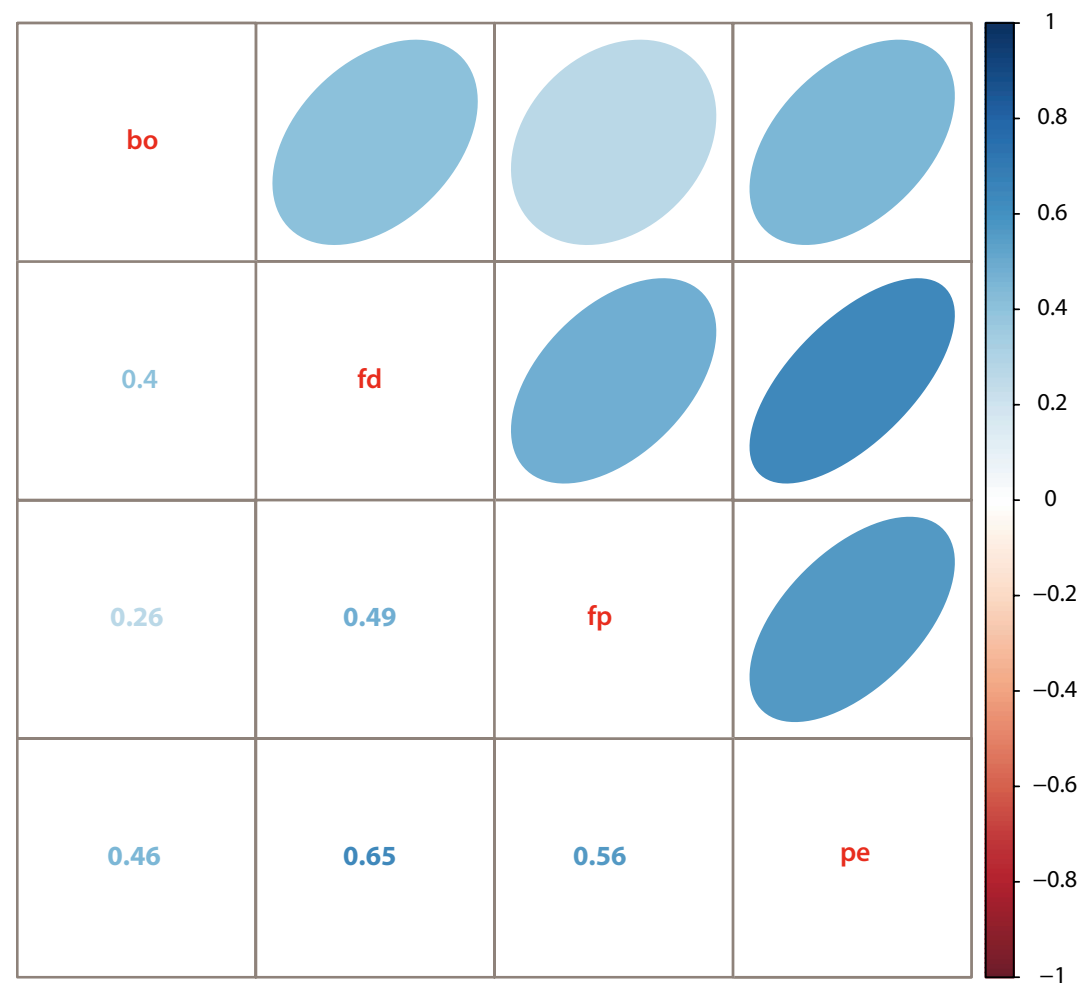

FIG. 7. Cross-resistance levels among carboxamide fungicides tested on Alternaria alternata isolates collected in pistachio producing regions of California. Ellipses show correlation intensity (more elliptical indicates a stronger relationship between two fungicides) and the colors represent the coefficient of correlation, $r$ (see scale at right of chart: 0 indicates no relationship, 0.30 a weak positive correlation, 0.5 a moderate correlation, and 0.70 a strong correlation). Abbreviations: bo = boscalid, the active ingredient of Pristine; $\mathrm{fd}=$ fluxapyroxad, the active ingredient of Merivon; $\mathrm{fp}=$ fluopyram, the active ingredient of Luna products; and pe = penthiopyrad, the active ingredient of Fontelis. 
Extension Center (Michailides et al. 2017). The other registered carboxamides such as Merivon (fluoxapyroxad), Pristine (boscalid) and Fontelis (penthiopyrad) still provide excellent and consistent control — despite the elevated pathogen resistance we observed - and are important components of ALB management in California pistachio.

To preserve the efficacy of these fungicides as long as possible, growers should consider the usage of multisite activity inorganics and chloronitrile fungicides (belonging to Fungicide Resistance Action Committee - FRAC - codes M1, M2 and M5) as part of a seasonal ALB control program. Multi-site activity inorganics and chloronitriles are less prone to develop resistance because they act on multiple pathogen cell functions. As a result, a combination of molecular alterations (difficult to find in the nature) in the pathogen would be necessary for the development of resistance. A drawback of chloronitrile fungicides in pistachio is the potential for phytotoxicity problems (which may damage fruit and leaves) when sprayed early in the season. For this reason, chloronitrile fungicides should be applied as the second or third spray for ALB control. Multi-site activity inorganics are not known to have this problem in pistachio.

Additionally, we recommend cultural practices that increase air movement and reduce humidity inside the orchards such as tree hedging and drip-irrigation (Michailides et al. 1995 and 2016).

Currently, at the Kearney Agricultural Research and Extension Center, we are performing several studies designed to inform anti-resistance strategies for use by growers. This work includes (a) testing the persistence of various genotypes (resistant-mutants and sensitives) within the A. alternata population, under laboratory and field conditions, to understand their fitness (adaptability) on environment without carboxamide pressure, (b) evaluating multiple spray programs and cultural practices to slow the resistance build-up to carboxamides and affecting fruit quality (c) in vitro testing of carboxamides not yet registered for pistachio that may become treatment options for growers in the future and (d) developing molecular methods to identify carboxamide-resistant-mutant isolates while still latent, in order to inform pest control advisers and growers about the risks associated with carboxamide usage for each season.

By continuing to study the components of fungicide resistance in A. alternata, we can assist in the delay of the fungicide resistance and increase the usefulness of the chemical arsenal available to the pistachio growers of California. CA

\footnotetext{
P.S.F. Lichtemberg is Postdoctoral Researcher, R.D. Puckett is Research Associate, D.G. Felts is Research Associate, Y. Luo is Project Scientist, L. Doster is Laboratory Assistant, D. Rodriguez is Laboratory Assistant, and T.J. Michailides is Principal Investigator, Department of Plant Pathology, UC Davis, and Kearney Agricultural Research and Extension Center, Parlier, CA.

We thank the California Pistachio Research Board for the financial support of this study, and farm and pest advisors Todd Fukuda, Craig Kallsen, Carla Baker and David Doll for helping us to identify pistachio growers willing to participate in this survey. We also thank all the pistachio growers who kindly allowed us to survey their orchards and provided information on spray programs to support our conclusions.
}

\section{References}

[ACP] Administrative Committee for Pistachios. 2017. 2016

Pistachio bearing acreage, production and yield per acre by district and county. Administrative Committee for Pistachios. p 4. www.acpistachios.org/ pdf/2016-Statistics-Updated.pdf Adaskaveg J, Gubler W, Michailides T. 2017. Fungicides, bactericides, and biologicals for deciduous tree fruit, nut, strawberry, and vine crops. In: UC Pest Management Guidelines. University of California Davis. www.ipm.ucdavis.edu/ PDF/PMG/fungicideefficacytiming.pdf

Avenot $\mathrm{H}$, Biggelaar $\mathrm{H}$, Morgan DP, et al. 2012. Fungicidal activity of fluopyram for suppression of Alternaria species pathogenic on California pistachio. Resistant Pest Management Newsletter 22:10-4. Center for Integrated Plant Systems, Michigan State University.
Avenot HF, Michailides TJ. 2007. Resistance to boscalid fungicide in Alternaria alternata isolates from pistachio in California. Plant Dis 91:1345-50.

Avenot $\mathrm{H}$, Michailides T. 2015. Detection of isolates of Alternaria alternata with multiple-resistance to fludioxonil cyprodinil, boscalid and pyraclostrobin in California pistachio orchards. Crop Prot 78:214-21. Avenot $\mathrm{H}$, Van den Biggelaar H, Morgan D, et al. 2014. Sensitivities of baseline isolates and boscalid-resistant mutants of Alternaria alternata from pistachio to fluopyram, penthiopyrad, and fluxapyroxad. Plant Dis 98:197-205.

CIMIS. 2017. CIMIS Station Reports. California Irrigation Management Information System. www.cimis.water.ca.gov
Fan Z, Yang J-H, Fan F, et al. 2015. Fitness and competitive ability of Alternaria alternata field isolates with resistance to $\mathrm{SDH}, \mathrm{Qol}$, and MBC fungicides. Plant Dis 99:1744-50.

Michailides T, Morgan D, Doster M. 1995. Diseases of pistachio in California and their significance. Acta Hortic 419:337-43.

Michailides T, Morgan D, Doster M. 2016. Foliar, fruit, and branch diseases. In: L Ferguson, D Haviland, eds. Pistachio production manual. Oakland, CA: University of California Agriculture and Natural Resources. p 265-92.

Michailides T, Felts D, Puckett R, et al. 2017. Management of Alternaria late blight of pistachio. In: Research 2017 Executive Summaries. California Pistachio Research Board. p 67-8.
Morgan D, Driever G, Felts D, et al. 2009. Evaluation of two disease warning systems for Botryosphaeria panicle and shoot blight of California pistachio and efficient control based on early-season sprays. Plant Dis 93:1175-81.

Olaya G, Linley R, Edlebeck K, et al. 2016. Adepidyn fungicide: cross resistance patterns in Alternaria solani. In: 2016 APS Meeting American Phytopathological Society, Tampa, Florida. p S4.12.

Oliver RP, Hewitt HG. 2014 Fungicides in crop protection Second ed. CAB International, Oxfordshire, UK.

Rotem J. 1994. The genus Alternaria: biology, epidemiology, and pathogenicity. St Paul: APS Press.
Sierotzki H, Frey R, Morchoisne $M$, et al. 2010. Sensitivity of fungal pathogens to SDHI fungicides. In: H Dehne, H Deis ing, U Gisi, et al., eds. Modern Fungicides and Antifungal Compounds VI. Braunschweig, Germany DPG. Verlag. p 179-86. Stammler G, Wolf A, Glaettli A, et al. 2015. Respiration INHIBITORS: Complex II. In: H Ishii, Hollomon $D$, eds. Fungicide Resistance in Plant Pathology. Tokyo: Springer. p 105-18.

Yang J, Brannen P, Schnabel G. 2015. Resistance in Alternaria alternata to SDHI fungicides causes rare disease outbreak in peach orchards. Plant Dis 99:65-70. 


\title{
Modeled soil erosion potential is low across California's annual rangelands
}

\author{
The authors used the Revised Universal Soil Loss Equation computer model to evaluate \\ how high, medium and low levels of residual forage dry matter affect soil erosion potential across \\ California rangelands.
}

by Wilson B. Salls, Royce E. Larsen, David J. Lewis, Leslie M. Roche, Danny J. Eastburn, Allan D. Hollander, Mike Walkinshaw,

Stephen R. Kaffka, Kenneth W. Tate and Anthony T. O'Geen

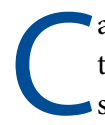
alifornia's annual rangelands occupy more than 16 million acres (6.5 million hectares), $\$ 3$ billion beef cattle industry. They also provide a variety of other societal services, including wildlife habitat, carbon sequestration, biodiversity and aesthetic value. Additionally, they lie within watersheds that regulate the quantity and quality of California's water supply. Limiting erosion is critical to the sustainability of rangeland ecosystems, and is directly linked to healthy soils.

Erosion is the leading cause of forage productivity degradation in the United States (OTA 1982; Pimentel et al. 1995); it threatens the vitality of rangelands in a variety of ways. Loss of topsoil and associated organic matter decreases available nutrients and the remaining soil's nutrient retention capacity. Eroded soils typically have diminished rooting depth, water infiltration rate and water-holding capacity. Soil loss decreases vegetative production, rooting, and thus vegetative cover - potentially accelerating additional erosion in a feedback loop of diminishing soil health, forage productivity and carbon sequestration (OTA 1982; Schuman et al. 2002; Thurow and Taylor 1999). Erosion from rangelands has also been associated with degraded water quality in adjacent streams and rivers (US EPA 2012) and can compromise an ecosystem's biotic integrity and hydrologic function (Pellant et al. 2005).

Excessive cattle grazing from high stocking rates, because it can increase erosion, is a primary issue

\section{Abstract}

We used the Revised Universal Soil Loss Equation (RUSLE) to evaluate how different residual forage dry matter (RDM) levels affect erosion potential in rangelands across California. The model was adapted to operate in a geographic information system (GIS) to model 14.8 million acres (6.0 million hectares) of land. Average erosion potential was low among all RDM scenarios and increased from an estimated 0.05 ton per acre per year (0.11 megagram per hectare per year) with the high RDM scenario to 0.12 ton per acre per year ( 0.27 megagram per hectare per year) with the low RDM scenario. Considering all RDM scenarios, fewer than 174,733 acres $(70,710$ hectares, or $1.2 \%$ of land) had erosion potential that exceeded soil loss tolerance values. Although achieving a uniform RDM target across a landscape may be an oversimplification of reality, simulations suggest that erosion potential on average is low in California's annual rangelands across high, moderate and low RDM recommendations. Moreover, our findings indicate that grazing management (maintaining moderate or high RDM) to mitigate erosion can be effective when targeted at areas of high vulnerability. facing rangeland sustainability worldwide (Briske et al. 2011; Menke and Bradford 1992). Stocking rate - a measure of annual grazing intensity defined as number of animal units ( $1,000 \mathrm{lb}$ beef cow) per acre - is the predominant grazing decision determining ecological, edaphic and production outcomes (Briske et al. 2011). On California's annual rangelands, residual dry forage matter (RDM) at the end of the summer dormant
Online: https://doi.org/10.3733/ ca.2018a0021 
TABLE 1. RUSLE model variables, with three cover ( $C$ factor) scenarios

\begin{tabular}{|c|c|c|c|c|c|c|}
\hline Variable & \multicolumn{2}{|c|}{ Name } & $\begin{array}{l}\text { Raster } \\
\text { resolution }\end{array}$ & Data source & Explanation & $\begin{array}{c}\text { Minimum-maximum, } \\
\text { mean, (SD) }\end{array}$ \\
\hline & & & $m$ & & & \\
\hline$A$ & \multicolumn{2}{|c|}{ Modeled annual soil loss } & 30 & $R, K, L S$ and $C$ variables & See article text & See article text \\
\hline$R$ & \multicolumn{2}{|l|}{$\begin{array}{l}\text { Rainfall runoff } \\
\text { erosivity factor }\end{array}$} & 250 & $\begin{array}{l}\text { Renard et al. 1997; SWRCB } \\
2015\end{array}$ & $\begin{array}{l}\text { Interpolation of rainfall } \\
\text { erosivity isolines }\end{array}$ & $\begin{array}{c}10-220 \\
36.0 \\
(27.6)\end{array}$ \\
\hline$K$ & \multicolumn{2}{|c|}{ Soil erodibility factor } & 30 & gSSURGO (USDA NRCS 2015b) & $\begin{array}{l}\text { Area-weighted average of } \\
\text { major components }\end{array}$ & $\begin{array}{c}0.003-0.640 \\
0.23 \\
(0.09)\end{array}$ \\
\hline$L$ & \multirow{2}{*}{\multicolumn{2}{|c|}{$\begin{array}{l}\text { Slope length factor } \\
\text { Slope steepness factor }\end{array}$}} & 30 & $\begin{array}{l}\text { Digital elevation model } \\
\text { (USGS 2015) }\end{array}$ & $\begin{array}{l}\text { L and S using r.watershed } \\
\text { (Ehlschlaeger 2015) }\end{array}$ & $\begin{array}{c}0.0-68.0 \\
1.2\end{array}$ \\
\hline$S$ & & & & & & $(2.5)$ \\
\hline \multirow[t]{3}{*}{$C$} & \multirow[t]{3}{*}{$\begin{array}{l}\text { Cover } \\
\text { management } \\
\text { factor }\end{array}$} & $\begin{array}{l}\text { Low } \\
\text { RDM }\end{array}$ & \multirow[t]{3}{*}{30} & \multirow[t]{3}{*}{ Cal Fire 2015} & \multirow[t]{3}{*}{$\begin{array}{l}\text { Subfactor approach (Renard et } \\
\text { al. 1997) based on vegetation } \\
\text { type and RDM }\end{array}$} & $\begin{array}{c}0.006-0.230 \\
0.014 \\
(0.007)\end{array}$ \\
\hline & & $\begin{array}{l}\text { Medium } \\
\text { RDM }\end{array}$ & & & & $\begin{array}{c}0.006-0.013 \\
0.009 \\
(0.003)\end{array}$ \\
\hline & & $\begin{array}{l}\text { High } \\
\text { RDM }\end{array}$ & & & & $\begin{array}{c}0.005-0.008 \\
0.006 \\
(0.001)\end{array}$ \\
\hline
\end{tabular}

season (just prior to the onset of fall rainfall-runoffevents) is the standard indicator of annual grazing intensity at a site (Bartolome et al. 2006; Bartolome et al. 2007; Tate et al. 2004). UC Agriculture and Natural Resources (UC ANR) grazing recommendations for California provide RDM guidelines for discrete classes of slope, tree cover and rainfall (Bartolome et al. 2006); the guidelines help ranchers achieve sustainable forage production by limiting soil degradation caused by erosion and also provide benefits to species composition (Bartolome et al. 1980; Bartolome et al. 2014).

To varying degrees, excessive grazing removes substantial vegetation and can compact soil and weaken or destroy aggregates - particularly when soils are wet - all of which can increase surface runoff, erosion and pollutant transport (Beckmann and Smith 1974; Hodgkinson 1993; Knoll and Hopkins 1959; Warren et al. 1986). Adequate vegetative cover reduces soil erosion by (1) protecting soil from raindrop impact, (2) attenuating runoff velocity (Wischmeier 1975), (3) increasing infiltration and (4) stabilizing soil (De Ploey 1982; Dunne et al. 1991; OTA 1982). Several studies indicate that proper grazing management of a site results in soil loss values similar to those for ungrazed land (Weltz et al. 1998).

Recently, the White House Office of Science and Technology Policy issued a national call to action to protect America's soil (OSTP 2016). The purpose was to inform decision-making and engage the public about soil degradation, with erosion as a primary focus. In response to this call to action, we - a group of UC soil and range scientists - evaluated erosion potential across 14.8 million acres (6.0 million hectares) of California's annual rangelands - including annual grasslands, oak savannas and oak woodlands (Cal Fire 2015) - and the impact of changes in vegetative cover on the sustainability of this resource, using the Revised Universal Soil Loss equation (RUSLE) model. Our objective was to identify regional patterns in erosion potential across high, medium and low RDM scenarios and demonstrate where grazing management works best to protect against soil erosion. Recognizing that California annual rangelands have relatively high vegetative cover, we sought to demonstrate the inherent resilience of this system to erosion under careful management.

\section{RUSLE model, GIS database}

RUSLE is an empirical model that predicts sheet and rill erosion. Other types of erosion such as gully, stream bank and stream bed erosion are not evaluated by RUSLE (Renard et al. 1997; Wischmeier and Smith 1978). Sheet erosion is caused by the movement of water over the land surface. Rill erosion is caused by surface runoff becoming concentrated in small channels that generally do not exceed 4 inches in depth (USDA NRCS 2015a). Gullies are larger channels, too large to be removed by normal tillage operations.

\section{Model inputs}

RUSLE predicts erosion based on six factors: rainfall, soil erodibility, slope length and steepness, cover management, and conservation practices (Renard et al. 1997). We developed a geographic information system (GIS) database to reflect the RUSLE equation:

$$
A=R \times K \times L \times S \times C \times P
$$


where $A$ is average annual soil loss due to rain-induced erosion, which we termed erosion potential, $R$ is the rainfall runoff erosivity factor, $K$ is the soil erodibility factor, $L$ is the slope length factor, $S$ is the slope steepness factor and $C$ is the vegetation cover management factor (table 1). $P$ is conservation practices. We assumed no conservation practices, and thus $P$ was left out of the model.

The GIS database contained a raster layer for each input factor. Spatial resolution was 30 meters, except for the $R$ factor, which was 250 meters. Three separate RDM scenarios were modeled as explained below. Details about how the $R, K, C, L$ and $S$ factors were digitized into a statewide GIS are described in Salls (2016).

$\boldsymbol{R}$ factor. A raster layer for average annual rainfall erosivity was derived from a map of $R$ factor isolines (Renard et al. 1997) and georeferenced by the California State Water Resource Control Board (SWRCB 2012). $R$ factor pixel values were derived by linear interpolation of georeferenced isolines at a resolution of 250 meters. To complete interpolation, isolines terminating outside of California were closed manually by georeferencing maps of neighboring regions and tracing the isolines. Closure of isolines terminating in Mexico or off the coast was approximated.

$\boldsymbol{K}$ factor. The soil erodibility layer was developed from the gridded soil survey geographic (gSSURGO) database (USDA NRCS 2015b). Surface horizon $K$ factor (including rock fragments) was used for each component, and major components were aggregated across SSURGO map units based on their percentages using an area-weighted average.

The $K$ factor was adjusted in the northern Sierra Foothills to account for the binding effect of iron oxides present in the metavolcanic parent materials. Singer et al. (1980) recorded the $K$ factor of one such soil, the Auburn Series, as 0.03 - far below the values in gSSURGO estimated using the system in Wischmeier and Smith (1978), which range from 0.22 to 0.30 . To correct for artificially high soil erodibility in areas with metavolcanic terrain, $K$ factors were multiplied by 0.14 .

$\boldsymbol{L}$ and $\boldsymbol{S}$ factors. The raster layer for the slope length and steepness factors was calculated from the national elevation dataset (NED) digital elevation model (USGS 2015). The product of $L$ and $S$ was calculated using the r.watershed module in GRASS GIS version 7.0

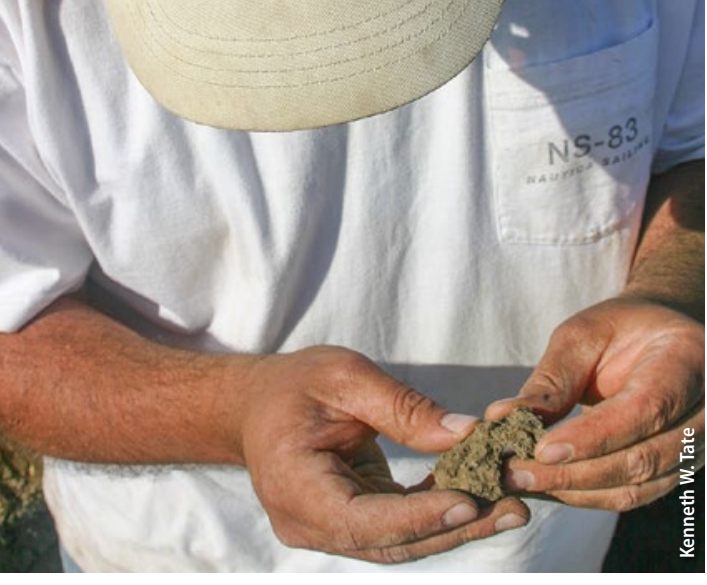

Co-author Toby O'Geen investigates evidence of soil compaction, which can occur on trails and loafing areas where livestock congregate. Soils are especially prone to compaction by excess traffic when wet, and compacted soils are prone to erosion.
(Ehlschlaeger 2015), which uses equations for calculating the LS factor (Weltz et al. 1998). NED 1-arc-second grid cells were reprojected into 30-meter pixels using bilinear interpolation.

C factor. Three RDM scenarios (low, moderate and high) were examined to approximate the UC Cooperative Extension (UCCE) grazing management RDM recommendations (table 2). The $C$ factor raster layer for each RDM scenario was calculated using the subfactor approach presented in Renard et al. (1997):

$$
C=P L U \times C C \times S C \times S R
$$

where $C$ is the vegetation cover management factor, $P L U$ is the prior land use, $C C$ is the canopy cover, $S C$ is the surface cover, and $S R$ is the surface roughness. Salls (2016) explains each sub-factor calculation.

To populate surface cover (SC) for the three modeled RDM scenarios, relationships between RDM and surface cover were established. These data do not exist for the range of conditions throughout California's annual rangelands. We used existing data collected from two different locations: 614 field plots in the northern Sierra Foothills region in Yuba County sampled during fall of 2013, 2014 and 2015, and 168 field plots in the Central Coast Range in eastern San Luis Obispo County collected during fall 2015 to establish a relationship between SC and RDM within each RDM scenario, which generally reflect UCCE grazing guidelines.

In each field plot, the area of bare ground was visually estimated, and vegetation was cut at the base, dried and weighed to determine RDM. Vegetative cover was calculated as the mean cover percentage of samples falling within high ( $>980$ pounds per acre, 1,100

TABLE 2. Mean measured cover percentages for annual grasses in the Sierra Foothills and Central Coast regions for three RDM scenarios used to calculate the surface-cover subfactor (SC)

\begin{tabular}{|c|c|c|c|c|c|c|}
\hline \multirow{3}{*}{ RDM scenario } & & & \multicolumn{2}{|c|}{ Mean cover } & \multicolumn{2}{|c|}{ Standard deviation cover } \\
\hline & \multicolumn{2}{|c|}{ RDM } & Sierra Foothills & Central Coast & Sierra Foothills & Central Coast \\
\hline & lb/acre & $\mathrm{kg} /$ hectare & \multicolumn{2}{|c|}{$\%$} & \multicolumn{2}{|c|}{$\%$} \\
\hline Low RDM & $<534$ & $<600$ & $90^{a *}$ & $63^{x}$ & 19 & 20 \\
\hline Medium RDM & $534-980$ & $600-1,100$ & $92^{b}$ & $77^{y}$ & 16 & 15 \\
\hline High RDM & $>980$ & $>1,100$ & $98^{c}$ & $93^{z}$ & 10 & 11 \\
\hline
\end{tabular}

* Superscript letters denote statistical differences among means of RDM classes $(p<0.04)$ using Kruskal-Wallis test. 


\section{Examples of sheet, rill and gully erosion in rangeland settings}

Sheet and rill erosion

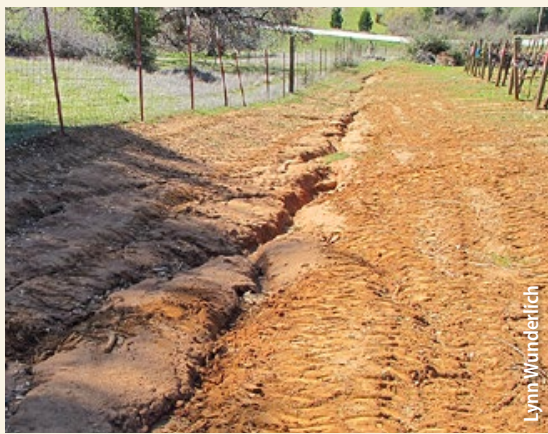

Sheet and rill erosion on an unimproved dirt road. Rills are the channel networks. Areas of sheet erosion are the smooth textured surface soil surrounding the rills.

\section{Sheet erosion is caused} by the movement of a thin film of water over the land surface. Rill erosion is caused by surface runoff becoming concentrated in small channels. Gullies are larger channels, too large to be removed by normal tillage operations.

\section{Stream bed erosion}

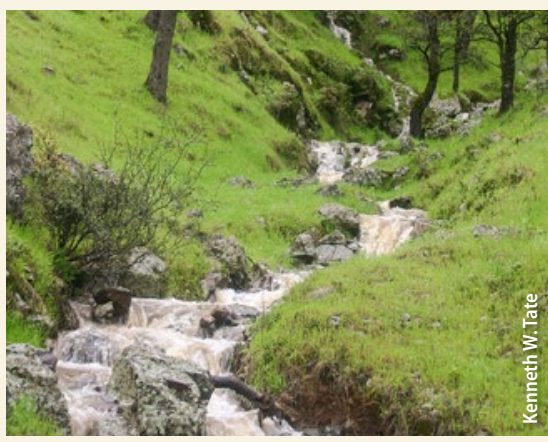

Turbid streamflow below a road crossing.

\section{Gully, sheet and rill erosion}
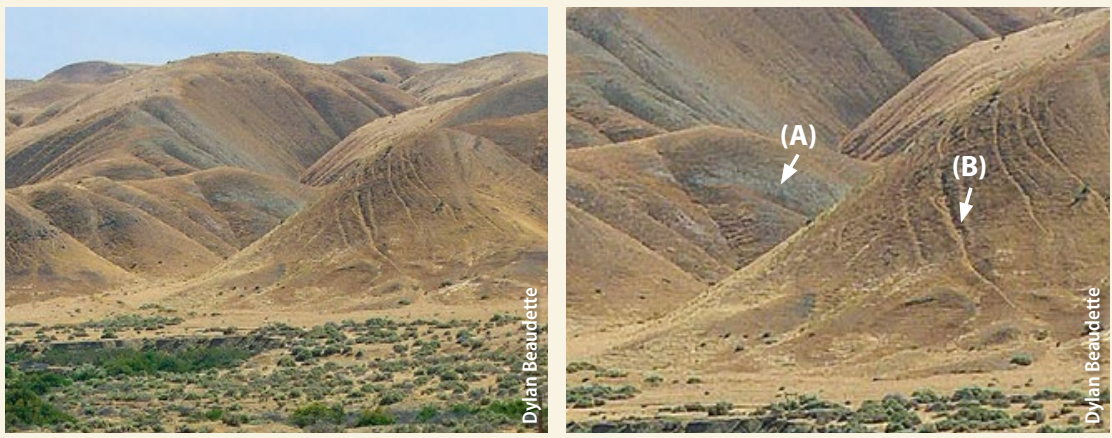

Evidence of sheet, rill and gully erosion on steep rangelands. (A) Sheet and rill erosion can strip topsoil, exposing underlying subsurface soil layers. Gullys form where water concentrates, resulting in deep channels (B) that are difficult to restore.

\section{Gully erosion}
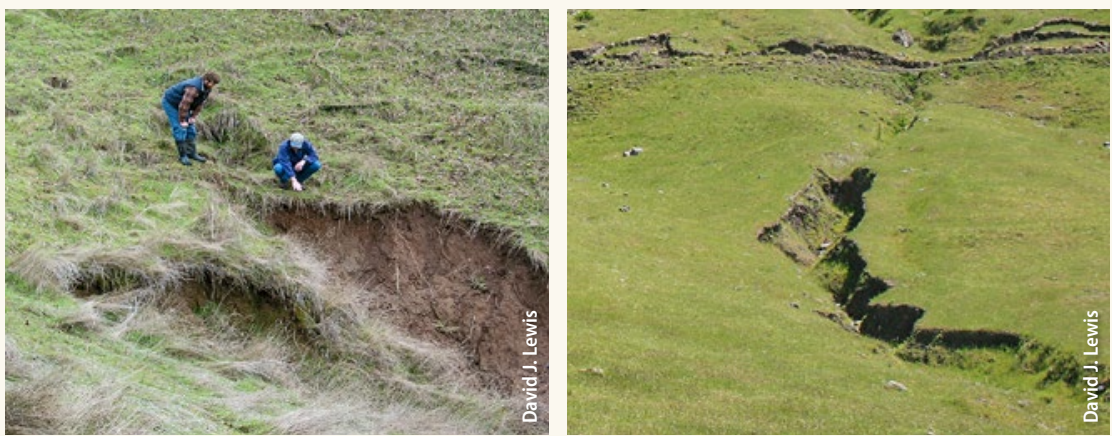

Left, gully erosion in upland headwaters of an intermittent stream. Right, an example of how poorly designed roads can focus runoff and cause gully erosion.

Stream bank erosion
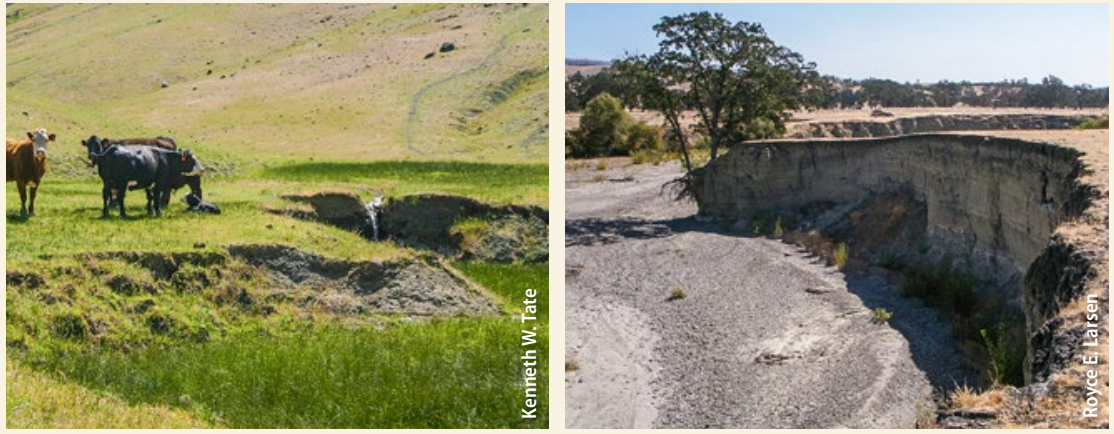

Left, cattle near a degraded stream bank. Right, incised stream channel, which leads to bank failure. 
kilograms per hectare), medium (534 to 980 pounds per acre, 600 to 1,100 kilograms per hectare) and low ( $<534$ pounds per acre, 800 kilograms per hectare) RDM classes (table 2).

\section{Relationship between cover and RDM}

Field plot cover assessments revealed high surface cover (SC in equation above) across all RDM classes, especially in the Sierra Foothills region (table 2). Percent cover remained high even in the low RDM scenario because of the high density of annual grasses that maintain surface cover. Each RDM scenario (low, medium and high) had significantly different mean vegetative cover percentages $(p<0.04)$. Mean SC was over $90 \%$ in the Sierra Foothills region across all RDM scenarios and increased slightly as RDM increased, ranging from $90 \%$ for low RDM to $98 \%$ for high RDM (table 2). Mean SC was lower in the Central Coast, ranging from 63\% for low RDM to 93\% for high RDM (table 2).

Mean SC values derived from measured relationships between SC and RDM in the Central Coast and Sierra Foothills (table 2) were assigned to rangeland productivity zones (RPZs) in a GIS (fig. 1 and see below). The Central Coast Range RDM SC relationship (table 2) was assigned to RPZs 4, 5 and 6, which are dry and warm areas (table 3). The Sierra Foothills RDM SC relationship (table 2) was assigned to RPZs 1,2 and 3, corresponding to cooler and wetter areas (table 3).

RPZs were developed using a cluster analysis of the following environmental variables: plant-available water at 30 and 150 centimeters, soil organic carbon at 30 and 150 centimeters, root zone depth, solar radiation, landscape position (Jasiewicz and Stepinski 2013), slope, flow accumulation, precipitation, and mean annual minimum and maximum temperatures. Random forest regression was used to compute importance values for all environmental variables in explaining an estimate of peak standing biomass determined

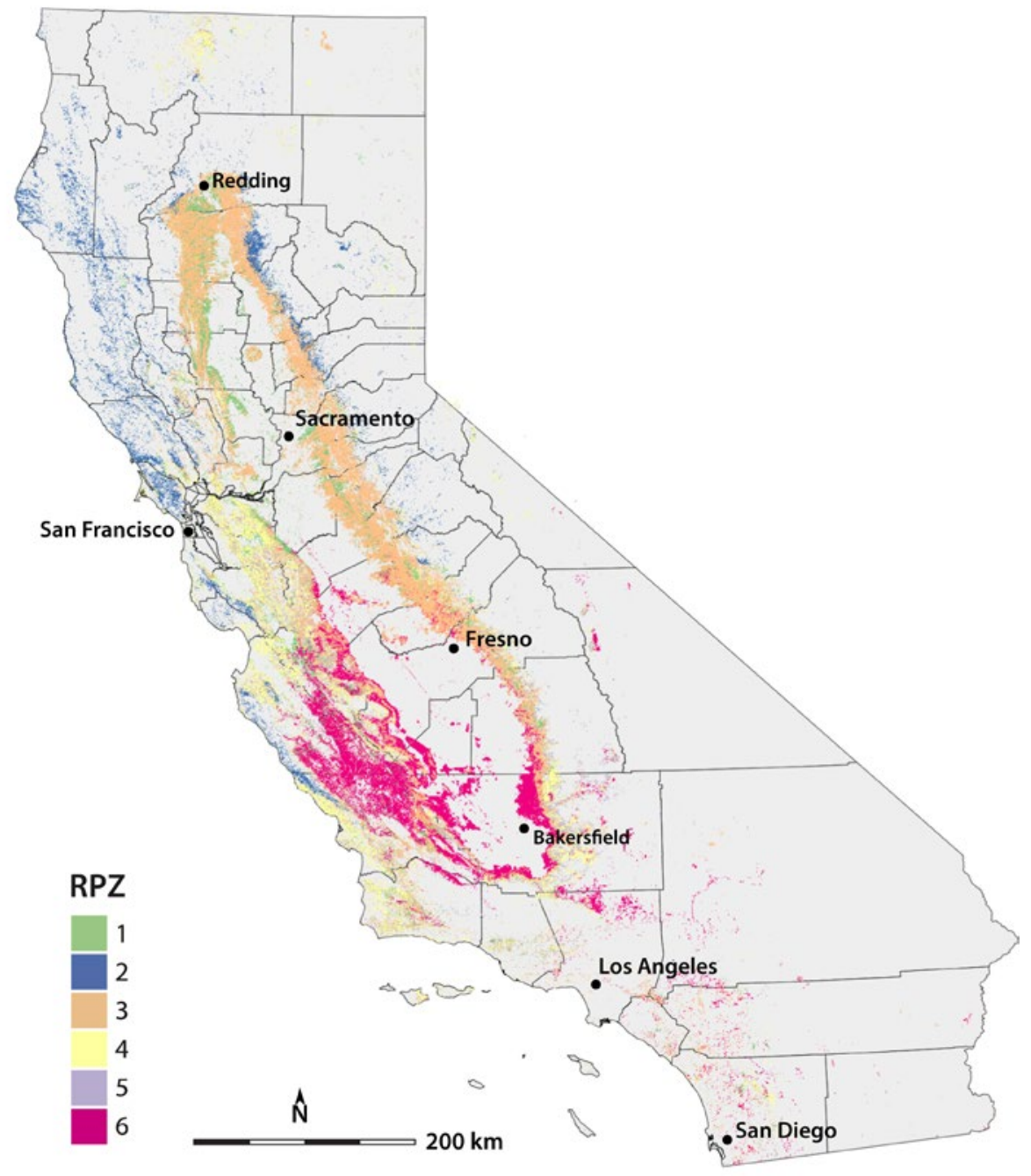

FIG. 1. Distribution of rangeland productivity zones (RPZs). These regions reflect differences in climate, soils and topography, which are factors directly related to soil erosion. RPZs 1, 2 and 3 were assigned the Sierra Foothills RDM cover relationship, and RMZs 4, 5 and 6 were assigned the Central Coast RDM cover relationship.

TABLE 3. Physiographic attributes of rangeland productivity zones (RPZs)

\begin{tabular}{|c|c|c|c|c|c|c|c|c|c|c|c|}
\hline \multirow[t]{3}{*}{ RPZ } & \multicolumn{10}{|c|}{ Mean values } & \multirow[t]{3}{*}{ General region (fig. 2) } \\
\hline & \multirow{2}{*}{$\begin{array}{l}\text { Area } \\
\text { acres }\end{array}$} & \multirow{2}{*}{$\begin{array}{c}\text { MAP* } \\
\text { in }\end{array}$} & \multirow{2}{*}{$\begin{array}{c}\text { Slope } \\
\%\end{array}$} & \multirow{2}{*}{$\begin{array}{c}\text { Elevation } \\
\qquad \mathrm{ft}\end{array}$} & \multirow[t]{2}{*}{ Aspect $†$} & \multicolumn{2}{|c|}{ Available water $\neq$} & \multirow{2}{*}{$\begin{array}{c}\text { Soil } \\
\text { depth } \\
\text { in }\end{array}$} & \multicolumn{2}{|c|}{$\begin{array}{l}\text { Mean annual } \\
\text { temperture }\end{array}$} & \\
\hline & & & & & & in & in & & $F^{\circ} \min$ & $F^{\circ} \max$ & \\
\hline 1 & $1,288,490$ & 22.0 & 7 & 889 & 177 & 1.5 & 7.0 & 56 & 47 & 74 & Scattered; mostly Northern Coast Ranges \\
\hline 2 & $1,438,382$ & 51.0 & 27 & 1,971 & 205 & 1.2 & 3.7 & 34 & 45 & 68 & Northern Coast Ranges \\
\hline 3 & $5,219,347$ & 22.0 & 15 & 1,056 & 177 & 1.1 & 2.6 & 22 & 48 & 75 & Sacramento Valley foothills \\
\hline 4 & $2,624,049$ & 21.0 & 27 & 1,932 & 166 & 1.3 & 4.1 & 35 & 46 & 70 & Inner Central Coast Ranges \\
\hline 5 & $1,226,207$ & 20.0 & 40 & 2,270 & 251 & 1.1 & 2.2 & 23 & 47 & 71 & Scattered; Central and Southern California \\
\hline 6 & $2,942,323$ & 12.3 & 13 & 1,328 & 182 & 1.3 & 48 & 44 & 47 & 77 & Southern Coast Ranges \\
\hline
\end{tabular}


FIG. 2. Average erosion potential differs statewide and for each RPZ due to differences in climate, surface cover, soils and topography. The effect of RDM scenarios (low, medium and high) on erosion potential is not constant among regions (RPZs).

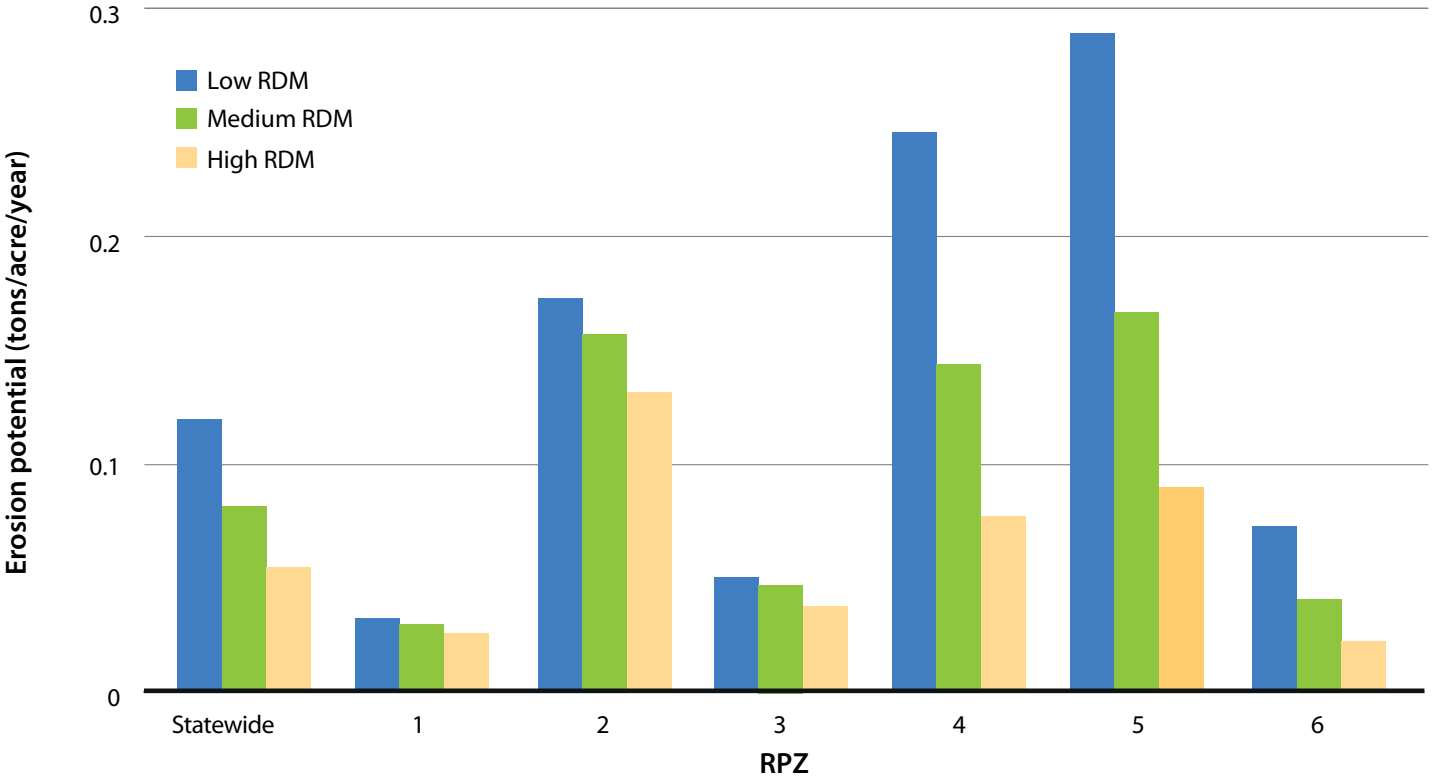

by Thematic Mapper (TM) scene (April 26, 2010) using MODIS Enhanced Vegetation Index (EVI). A partitioning around medoids approach was used to create the set of clusters. These clusters were mapped across the landscape using a random forest model to predict RPZs based on the geospatial input variables.

\section{Differences in erosion potential}

At the statewide scale, differences in erosion potential among RDM scenarios were relatively small. Of the three scenarios modeled, average erosion potential was highest for low RDM, at 0.12 ton per acre per year $(0.27$ megagram per hectare per year) (table 4$)$. For medium $\mathrm{RDM}$, it was 0.09 ton per acre per year (0.20 megagram per hectare per year), and it was lowest, at 0.05 ton per acre per year (0.11 megagram per hectare per year), for high RDM. Median erosion potential values showed the same trend among RDM scenarios, but they were lower than the average values, indicating that most values in each modeling grid were relatively small values (table 4).

A small portion of land was highly erodible under all scenarios because it received intense rainfall, contained erodible soils and/or had long, steep slopes. Maximum erosion potential was 33 tons per acre per year (74.0 megagrams per hectare per year) for low RDM, 19 tons per acre per year (42.6 megagrams per hectare per year) for medium RDM and 10 tons per acre per year (22.4 megagrams per hectare per year) for high RDM (table 4).

\section{RPZs with high erosion potential}

Erosion potential was not uniform across the state. RPZs 2, 4 and 5 had the highest erosion potential for all RDM cover scenarios (fig. 2). Among these three RPZs, zone 5 was most prone to erosion under low RDM (average $=0.29$ tons per acre per year, 0.65 megagram per hectare per year), while by a small margin zone 4 showed the highest resistance to erosion under high RDM (0.08 tons per acre per year, 0.17 megagram per hectare per year) (fig. 2). RPZs 4 and 5 had the greatest difference in erosion potential among cover scenarios. Despite having relatively high erosion potential, the difference among RDM cover scenarios was minimal in RPZ 2 (fig. 2); erosion potential in RPZ 2 differed by only 0.02 ton per acre per year (0.04 megagram per hectare per year) across RDM scenarios.

RPZs 4 and 5 were assigned the Central Coast Range SC-RDM relationship, which had low SC factor associated with low and moderate RDM compared to RPZs assigned with the Sierra Foothills SC data set. As a result, RPZs 4 and 5 were more sensitive to RDM reductions. These RPZs both had steep slopes (particularly RPZ 5) and thus high LS factors, leading to generally high erosion potential.

Erosion potential was relatively high in zone 2 for all scenarios. This was the case even though RPZ 2 was

TABLE 4. Statewide summary statistics of rangeland erosion potential for low, medium and high RDM scenarios

\begin{tabular}{|c|c|c|c|c|c|}
\hline RDM scenario & Mean & Median & Minimum & Maximum & $\begin{array}{l}\text { Standard } \\
\text { deviation }\end{array}$ \\
\hline & \multicolumn{5}{|c|}{ Tons/acre/year } \\
\hline Low RDM & 0.12 & 0.005 & $<0.005$ & 33 & 0.37 \\
\hline Medium RDM & 0.09 & 0.004 & $<0.005$ & 19 & 0.24 \\
\hline
\end{tabular}


TABLE 5. Area and percentage of area in which erosion potential exceeds $T$ factor, statewide and by rangeland productivity zone (RPZ), for the low, medium and high RDM scenarios

\begin{tabular}{|c|c|c|c|c|c|c|}
\hline & \multicolumn{3}{|c|}{ Area } & \multicolumn{3}{|c|}{ Proportion of land area } \\
\hline State & 174,735 & 79,506 & 28,990 & 1.2 & 0.5 & 0.2 \\
\hline $\mathrm{RPZ} 1$ & 70 & 50 & 24 & 0.0 & 0.0 & 0.0 \\
\hline RPZ 3 & 8,979 & 7,583 & 4,412 & 0.2 & 0.1 & 0.1 \\
\hline RPZ 4 & 81,363 & 31,970 & 7,844 & 3.1 & 1.2 & 0.3 \\
\hline RPZ 5 & 56,768 & 20,582 & 4,802 & 4.6 & 1.7 & 0.4 \\
\hline
\end{tabular}

assigned the high RDM SC relationship established from the Sierra Foothills data set, which resulted in high SC across all scenarios (table 2). With most of its area occurring in the North Coast and higher elevations of the Sierra Foothills, RPZ 2 had steep slopes and high rainfall intensity, and thus, generally high $R$ and $L S$ factor values, which explains the high erosion potential.

\section{RPZs with low erosion potential}

RPZs 1, 3 and 6 had low erosion potential for all RDM cover scenarios (fig. 2). RPZs 1 and 3 had extremely low mean erosion potential for all scenarios, with little difference between scenarios (fig. 2). RPZs 1 and 3 were assigned high RDM SC relationships established from the Sierra Foothills data, thus SC was high across all scenarios (table 2). Slope angles were also low, especially in RPZ 1, generally minimizing erosion potential.

RPZ 6 showed more substantial differences in erosion potential among scenarios. These differences were much smaller than in RPZs 4 and 5, though were similar proportionally. RPZ 6 was assigned the Central Coast Range SC data, which had lower mean SC subfactor values for RDM scenarios (table 2). Although RPZ 6 had the highest average $K$ factor, its conditions of gently sloping terrain, low precipitation and low rain intensity translated to low erosion potential.

\section{Relationship with soil loss tolerance}

Modeled erosion potential was compared against soil loss tolerance values ( $T$ values) across the study area. $T$ values identify the maximum level of acceptable erosion and are assigned based on estimates of the rate of soil formation and properties of the subsoil (Li et al. 2009). U.S. Department of Agriculture Natural Resources Conservation Service (USDA NRCS) defines $T$ as "the maximum rate of annual soil loss that will permit crop productivity to be sustained economically and indefinitely on a given soil" (USDA 2015b).

NRCS established $T$ values as integers from 1 through 5 tons per acre per year assigned to soil types, indicating the maximum allowable soil loss (Soil Survey Division Staff 1993). T values vary greatly across landscapes; those provided by soil survey may not always be accurate in rangelands, nor mapped at a scale fine enough to capture soil variability. We chose to compare modeled erosion potential with $T$ values because $T$ values are an established threshold condition used by the NRCS in conservation planning. While $T$ values are published for rangelands in soil survey reports, they were originally designed for cropland evaluation.

In this model, only small percentages of the state's rangelands exceeded $T$ values (table 5). A little over $1 \%$ (174,704 acres, 70,710 hectares) of rangeland had erosion potentials exceeding $T$ values for the low RDM scenario. It decreased to $0.5 \%$ for medium RDM (79,568 acres, 32,174 hectares) and 0.2\% (28,911 acres, 11,732 hectares) for high RDM. Even if all rangelands in the state had the most conservative $T$ value of 1 ton per acre per year (2.2 megagrams per hectare per year), more than $75 \%$ of rangelands would have erosion
Erosion potential was not uniform across the state. RPZs 2, 4 and 5 had the highest erosion potential for all RDM cover scenarios.

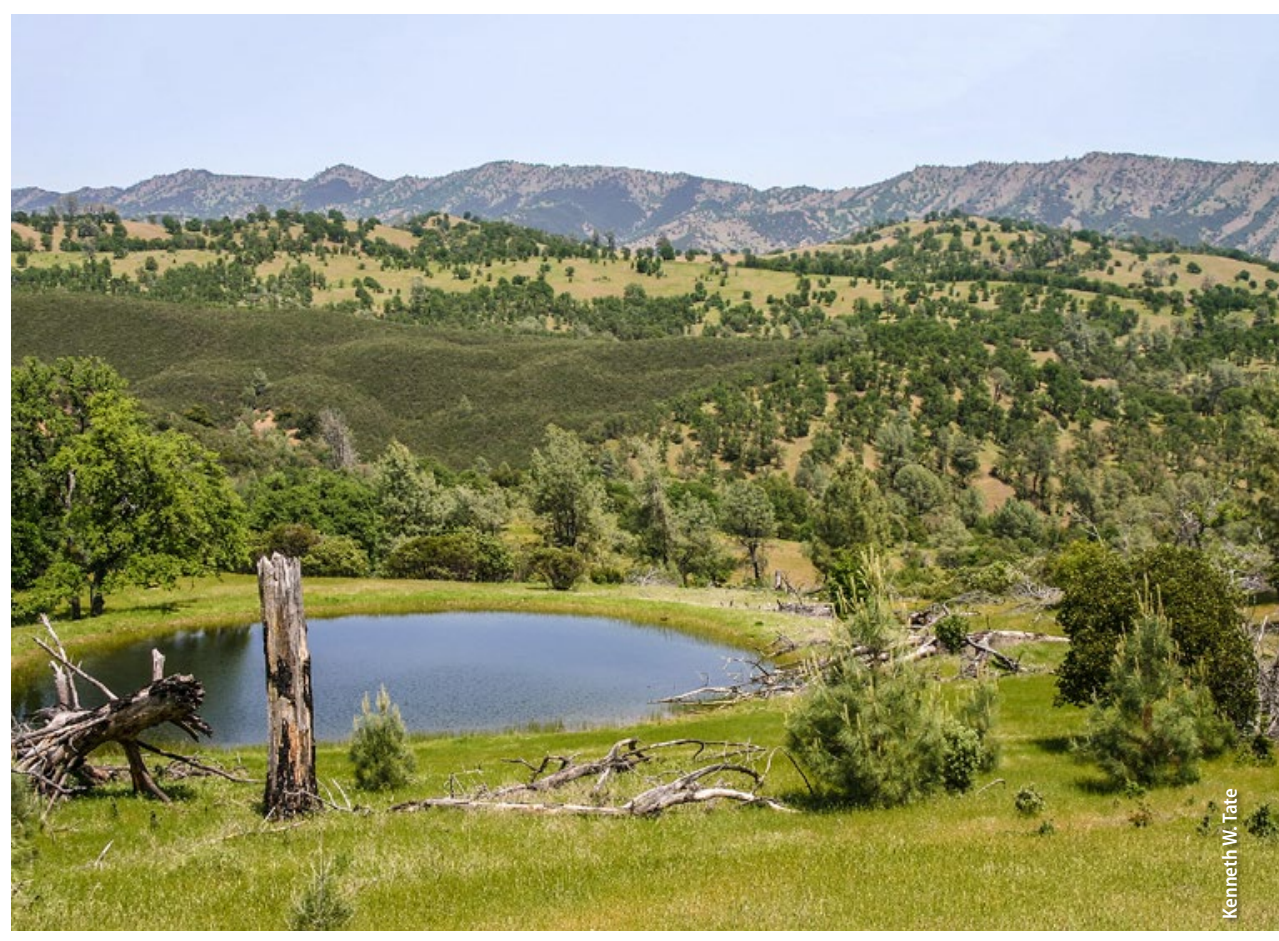


FIG. 3. Modeled erosion potential in tons/acre/year for Northern California (A) under the medium RDM scenario. Yellow box identifies the area of the finer scale map (B) near Redding, California. While erosion potential appears uniformly low at broad scale, areas of high erosion potential exist when visualized at fine scales. potential below $T$ for the low RDM scenario. However, the small portion of rangeland exceeding $T$ values does indicate potential areas in which soils should be managed carefully to maintain productivity.

The relevance of soil loss tolerance values should be considered cautiously. Low soil loss tolerance values fail to recognize the resilience of soil to management and can lead to unnecessary and expensive soil conservation strategies. In contrast, high $T$ values can lead to productivity loss since they may unduly discourage managers from considering erosion protection
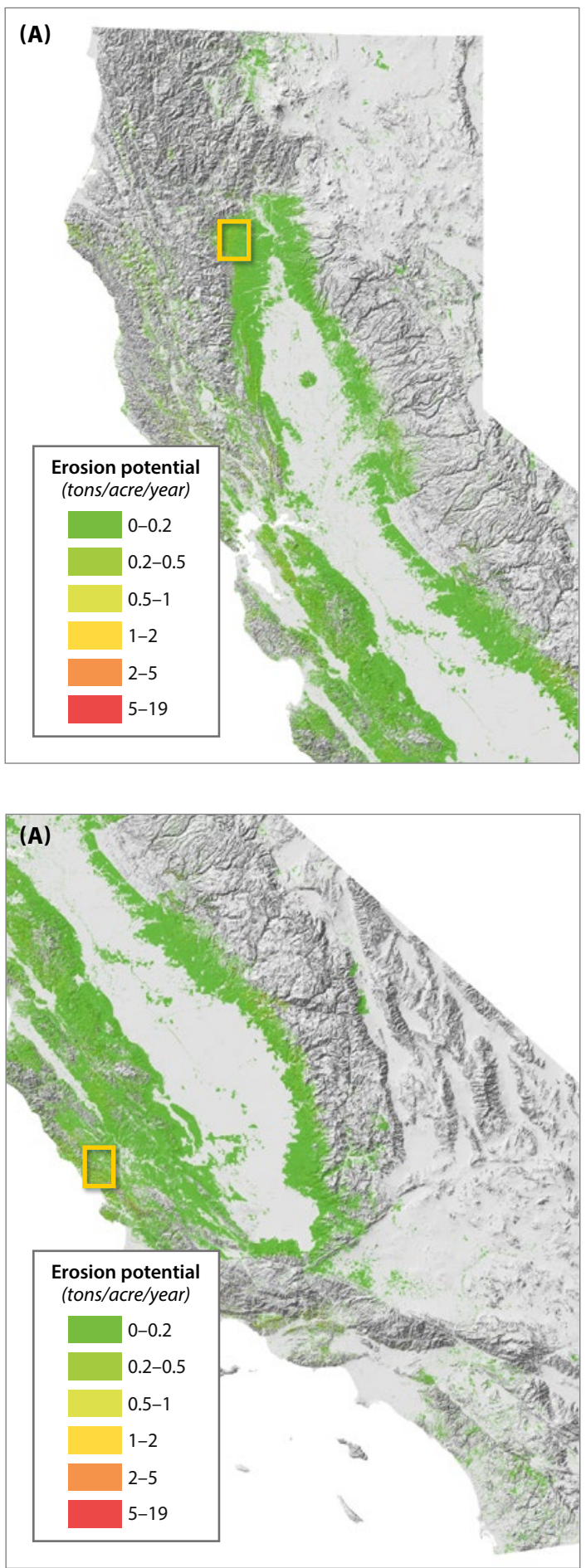

measures (Li et al. 2009). Some believe that $T$ values are not accurate benchmarks of sustainability because they are based on overestimated soil formation rates and fail to consider environmental costs associated with erosion (Amundson et al. 2015).

\section{Influence of grazing recommendations on erosion potential}

Moderate RDM is typically recommended to optimize livestock performance and rangeland protection (Bartolome et al. 2006). Our modeling results suggest that
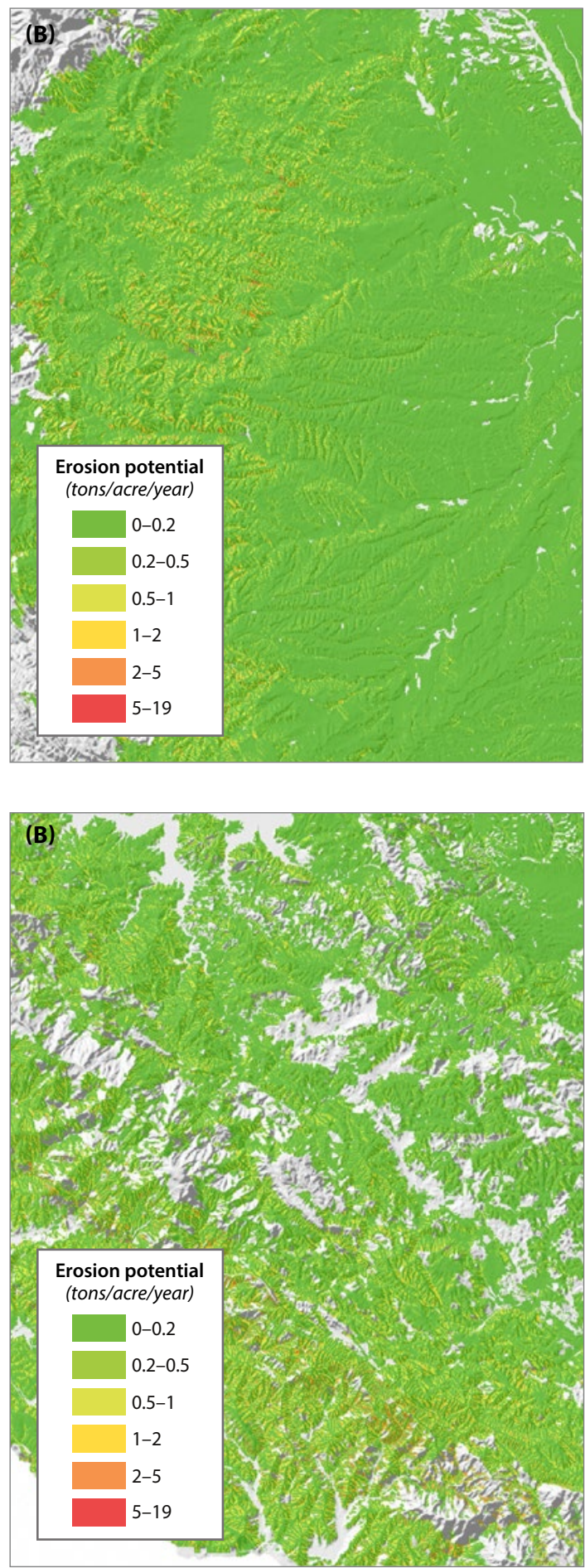

FIG. 4. Modeled erosion potential in tons per acre per year for Southern California $(A)$ under the medium RDM scenario. Yellow box identifies the area of the finer scale map (B) near San Luis Obispo. While erosion potential appears uniformly low at broad scale, areas of high erosion potential exist when visualized at fine scales. 
this recommendation is most important in regions that are more prone to erosion, such as RPZ 4 and 5 , and to a lesser extent RPZ 2. Zone 6 may also benefit from moderate RDM, but erosion potential is low throughout.

It is important to note that all other factors being constant, the relationship between surface cover and erosion potential is not linear; a reduction of surface cover in areas where cover was low increased erosion potential more than reduction by the same percentage in areas where cover was high. This implies that erosion is most effectively reduced by carefully managing areas with low cover (i.e., areas with high amounts of bare soil).

While more cover reduces erosion potential, there are trade-offs between cover and other rangeland management objectives, including forage production, forage quality and plant species diversity. To maximize rangeland forage production as well as erosion protection, optimal RDM levels have been proposed. In California annual grasslands receiving annual rainfall between 15 and 40 inches (38 and 102 centimeters), maximum productivity was found to occur with 840 kilograms per hectare (750 pounds per acre) of RDM (Bartolome et al. 1980). Another study suggested that the RDM range to optimize forage production and species richness was 672 to 1,344 kilograms per hectare (600 to 1,200 pounds per acre) (Bartolome and Betts 2005). These RDM levels both coincided with the moderate RDM scenario modeled here, though the upper range identified by Bartolome and Betts (2005) extended into the high RDM class. Productivity has been observed to be higher with more RDM, but low RDM may increase plant species diversity in the form of forbs and clovers (Bartolome et al. 2007), which are considered higher quality forage. Additionally, as suggested by RDM guidelines, these relationships vary spatially (Bartolome et al. 2006), suggesting that our uniform extrapolation of RDM classes at regional scales is speculative.

\section{Medium RDM scenario statewide}

Figures 3 and 4 depict patterns in erosion potential using the medium RDM cover scenario. At the state scale (figs. 3A and 4A), erosion potential appears uniformly low. At finer scales, however (figs. $3 \mathrm{~B}$ and $4 \mathrm{~B})$, erosion potential appears more variable where portions of the hillslope are depicted, which cannot be seen at the statewide scale. Some broad-scale trends are evident. High erosion potential values were common along the eastern edge of the Sierra Foothills, more so toward the south. A large swath of rangeland skirting the north end of the Central Valley near Redding showed elevated erosion potential as well (fig. $3 \mathrm{~B})$. Erosion potential was higher in the northern Coast Range (figs. 3A, 4A and 4B). Many of these areas coincide with relatively high rainfall intensity and steep slopes. Areas of low erosion potential include well-vegetated areas in the Sierra Foothills and the

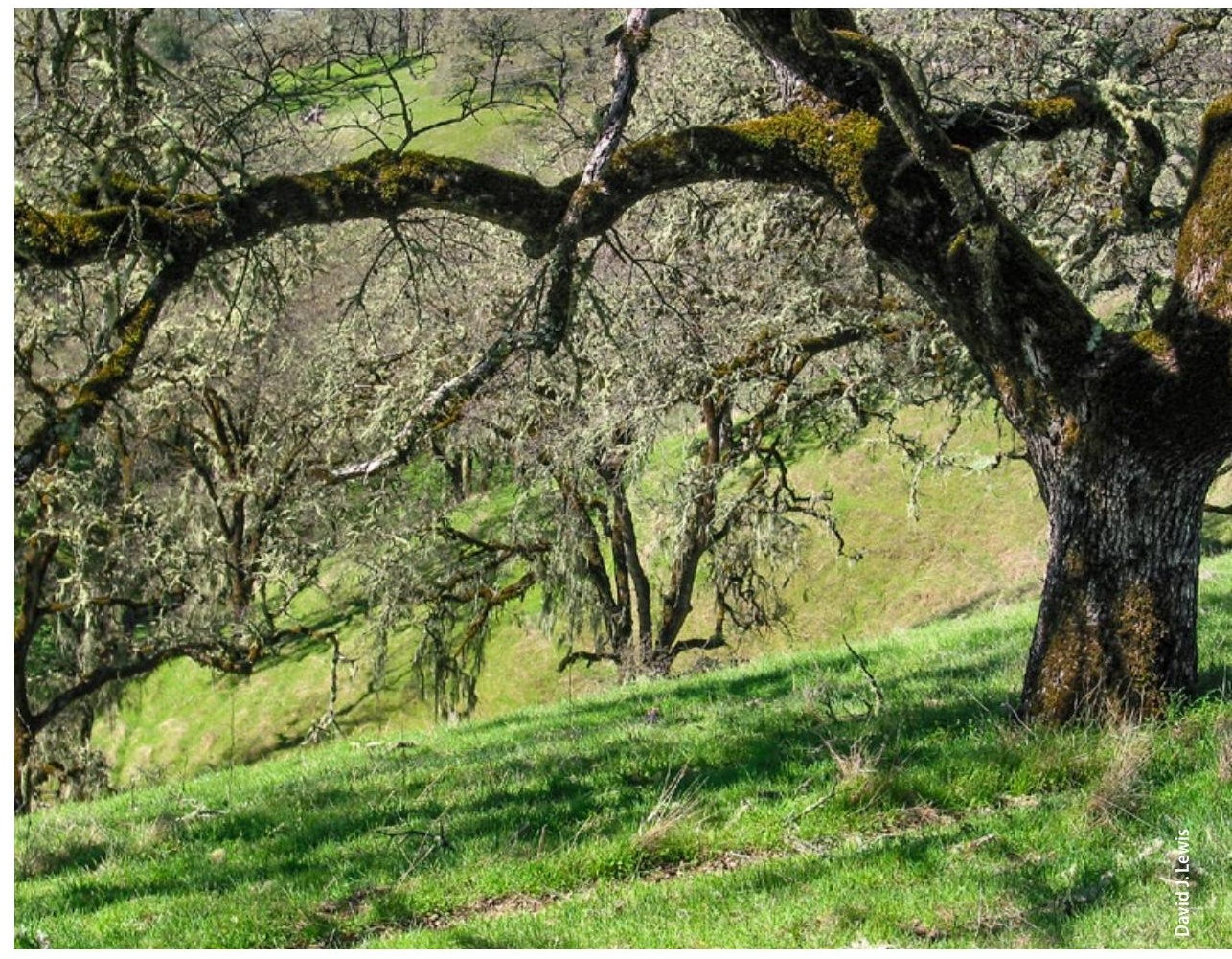

interior central and southern Coast Range, low slope angles in and around the Central Valley, and soils derived from metavolcanic rocks in the northern Sierra Foothills that are resistant to erosion because of low $K$ factors (Salls 2016; Singer et al 1980).

\section{Comparison of modeled and measured values}

To assess model performance, modeled erosion potential values were compared to field data collected from three different locations. The first location was in the Central Coast Range near Paso Robles, where we measured erosion in three plots for each of two treatments: planted with a cover crop of the oilseed Camelina sativa, and bare soil. In addition, we used data from existing studies in two locations, each of which monitored sediment discharge into a California rangeland stream. Average annual sediment flux from each stream was used to calculate a sediment flux per area (in tons per acre per year) based on the size of each watershed. Though sediment flux values are not directly comparable to erosion soil loss rates (see explanation below), they provide a rare opportunity to test the model against watershed-scale assessments. One stream, Stemple Creek, originates in Sonoma County and drains from the Marin County coast (Lewis et al. 2008). The Stemple Creek study reflects monitoring of creek discharge after major storm events over two seasons (2004 to 2006). The other stream drains the Schubert watershed in the northern Sierra Foothills (Lewis et al. 2006). The Schubert study uses a 20 -year data set (1981 to 2000) where stream flow was monitored continuously and suspended sediment was measured intensively during storms and occasionally during storm-free periods.
Erosion potential was higher in the northern Coast Range. Many of these areas coincide with relatively high rainfall intensity and steep slopes. 


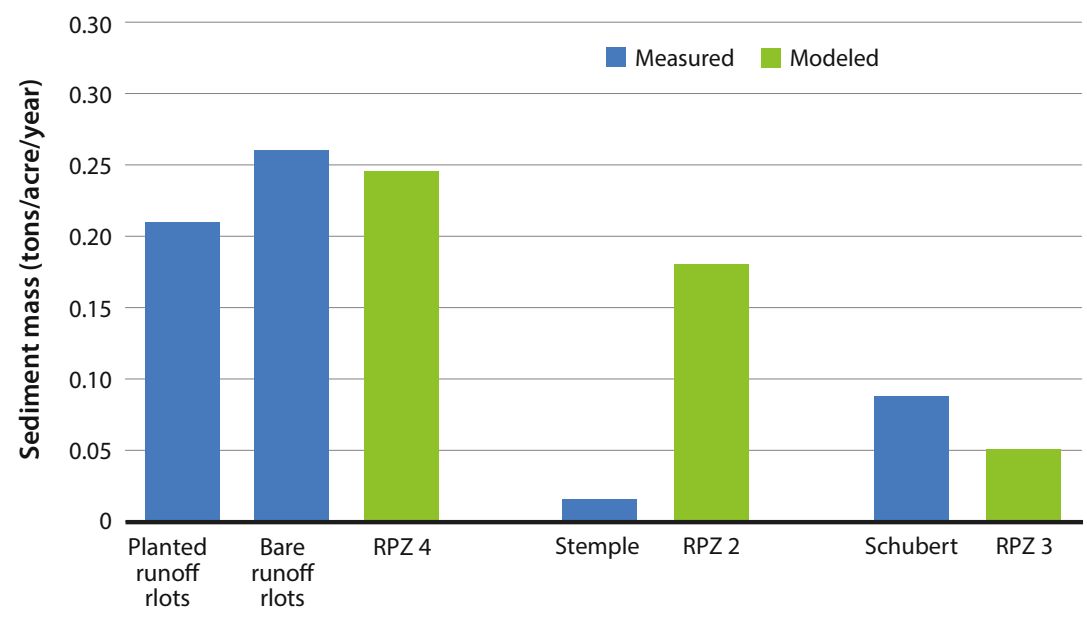

FIG. 5. Comparison of measured soil loss at three locations with average erosion potential modeled for the site's associated rangeland productivity zone (RPZ) using the low RDM scenario. Stemple Creek and Schubert Watershed values correspond to suspended sediment in streams, not directly to soil loss, and runoff plots did not have a rangeland cover type. Evidence suggests that the RUSLE model produces estimates of erosion that are comparable to field measurements despite the fact that sediment in streams (Stemple and Schubert) is not a direct measurement of soil erosion. While modeled versus measured erosion at Stemple creek and RPZ 2 appear different, they are both low.

Rain falling in late fall and early winter, when protective cover is lowest, can have a disproportionate impact on soil erosion compared to rain falling in the spring, when annual grass cover begins to emerge.

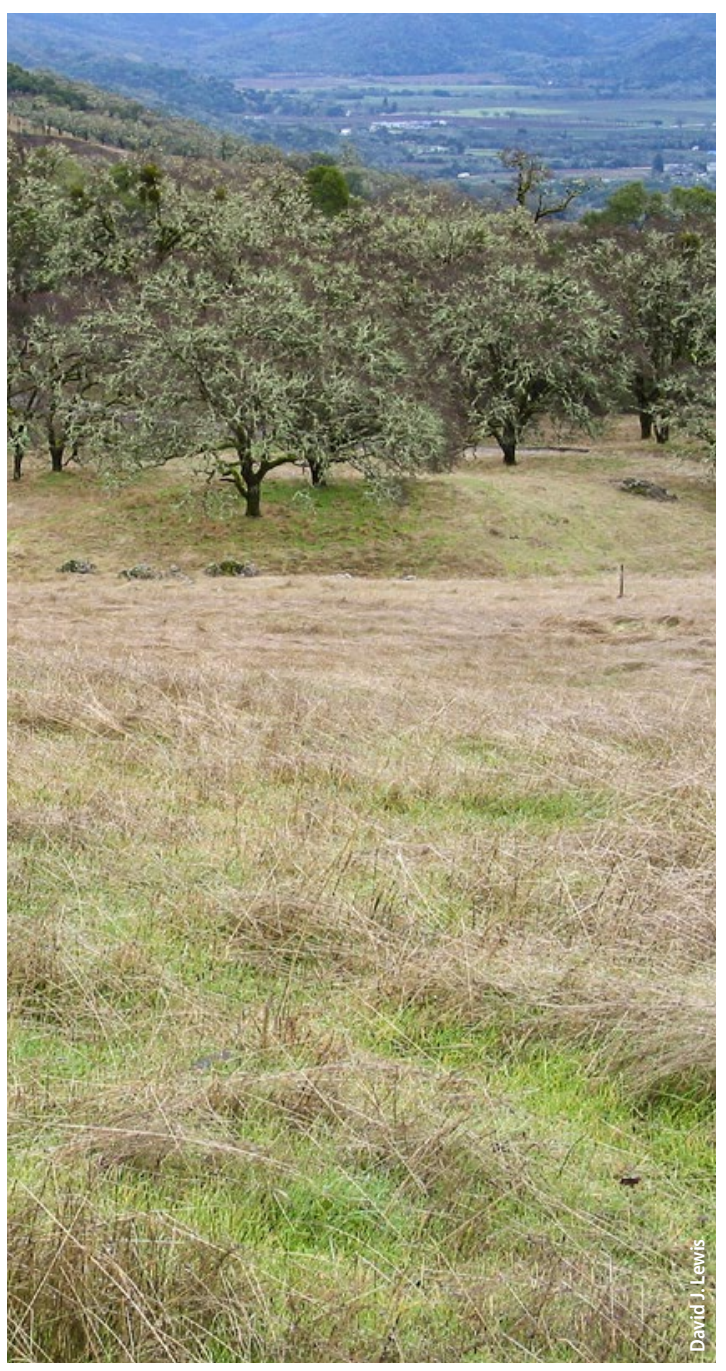

Measured erosion and sediment flux values at the three locations were low and were surprisingly (given the differences in scale) similar to average modeled erosion potential values based on the low RDM scenario (fig. 5).

Erosion rates measured at the planted and bare runoff plots in Paso Robles were similar to modeled erosion potential for zone 4, the RPZ where this site is located. Measured sediment flux from the Schubert Creek study was 0.088 ton per acre per year ( 0.20 megagram per hectare per year), relatively close to the average modeled erosion potential based on the lower RDM scenario in RPZ 3, in which Schubert is located: 0.05 ton per acre per year ( 0.11 megagram per hectare per year).

Measured sediment flux averaged across the Stemple Creek watershed was 0.015 ton per acre per year $(0.03$ megagram per hectare per year). This value was much lower than the modeled erosion potential in its associated RPZ (2), where average erosion potential ranged from 0.18 ton per acre per year $(0.4$ megagram per hectare per year) under low RDM to 0.13 ton per acre per year (0.29 megagram per hectare per year) with high RDM.

Some of the difference between measured and modeled values at the Stemple Creek site may be explained by the fact that, as mentioned above, the sediment flux measurements generated by watershed discharge studies are not directly comparable to RUSLE modeled values. Sediment flux is an imperfect proxy for erosion as it reflects sediment transported to waterways; it does not account for all on-site soil loss, some of which may be deposited on land before reaching a waterway (Renard and Stone 1982; Walling 1983). Therefore, sediment yield to waterways can be lower than erosion at the catchment scale. Another implication is that the findings of this study do not provide information about sediment flux to streams in rangeland areas.

\section{Model limitations}

There are many limitations to our analysis. Modeling at a statewide scale diminishes precision. Generalizations, often unrealistic, must be applied to larger areas. RUSLE models rill and sheet erosion, but does not include channelized gully erosion. Erosion from cattle trails has been shown to be significantly higher than the surrounding grazed landscape (George et al. 2004). Our modeling could not account for this fine scale occurrence and is a possible explanation of why our results were so low. While RUSLE was originally designed and tested in both rangelands and croplands (Renard et al. 1997; Spaeth et al. 2003), USDA-NRCS now limits its application primarily to cropland. Inconsistences in erosion predictions from RUSLE have been identified. In general, soil erosion models have a bias against extreme values, whether high or low. This limited modeling of variability leads to overprediction of low values and underprediction of high values (Nearing 1998). Moreover, results do not reflect erosion 
from roads or cattle trails, which may be significant contributors to erosion (George et al. 2002; George et al. 2004; Lewis et al. 2001). In other studies, infiltration rate has been shown to increase in the presence of blue oak trees (Dahlgren et al. 1997) and decrease due to soil disturbance from intensive grazing (Thurow et al. 1988; Warren et al. 1986), effects not directly considered here.

We chose to use an older version of RUSLE1 (Reynard et al. 1997) even though a more recent version exists (RUSLE2), because the latter calculates erosion on daily time steps. Statewide data on seasonal changes in rainfall intensity and vegetation cover do not exist for California, thus we decided a simplified approach was needed for our statewide assessment. We acknowledge that RUSLE1 erosion output can vary from RUSLE2 by as much as $20 \%$ (Foster et al. 2003). For example, RUSLE1 models the average rainfall intensity and does not consider extreme events, which could be responsible for a bulk of the runoff. Despite this discrepancy, our field validation suggests that RUSLE1 produces reliable estimates of erosion.

The model could be improved through better definition of the $C$ factor by establishing more relationships between cover and RDM across a wider array of physiographic conditions. This relationship varies spatially with a variety of factors including temperature, precipitation, light, soil depth and fertility, slope, and aspect. Moreover, this study did not address temporal variability of cover, neither within nor between years. Cover and rainfall vary throughout the year, particularly in California's Mediterranean climate zones (Becchetti et al. 2016; George et al. 2010). Unlike perennial systems, the annual grass and forb cover of California's annual rangelands is seasonally dynamic in response to grazing and the timing of precipitation. Cover generally increases as the rainy season progresses and peaks in mid- to late spring. After excessive grazing, cover remains low until the rainy season resumes the following growing season. Rain falling in late fall and early winter when protective cover is lowest can have a disproportionate impact on erosion. Our assumption likely overestimates erosion since cover often regenerates during the rainy season, depending on timing of temperature and precipitation (Becchetti et al. 2016). Variability between years is more problematic. Rainfall varies substantially each year, but this is not captured in the empirical structure of RUSLE. Cover RDM relationships and rangeland productivity also vary year to year depending on amount and timing of rainfall, temperature and sunlight (Becchetti et al. 2016). For example, in the Central Coast Range, RDM has been observed to decrease $7 \%$ to $11 \%$ each month during the dry season due to natural decomposition (R. Larson, personal communication 2017). If fall rains fail to arrive and RDM levels continue to decrease, cover can diminish substantially, resulting in a landscape highly vulnerable to erosion in winter months when rainfall intensity is high. These issues demonstrate that modeling provides information about scenarios modeled,

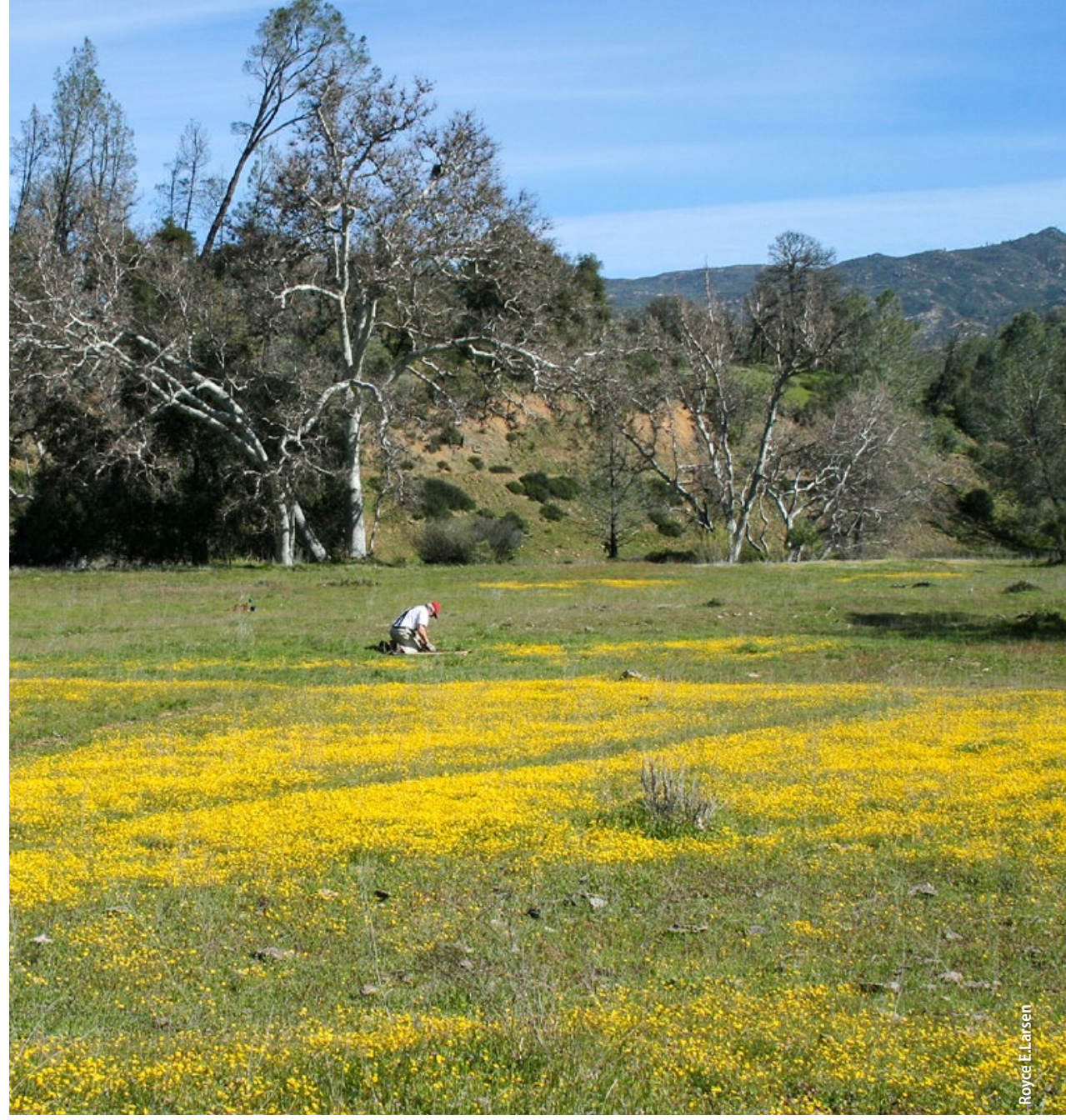

Unlike perennial systems, the annual grass and forb cover of California's annual rangelands is seasonally dynamic in response to grazing and the timing of precipitation. but may not accurately simulate real-world conditions. Ultimately better models are needed that address the complexity of range landscapes (Nearing et al. 2011).

Other geospatial erosion models are available (see Borah and Bera 2003 and Merritt et al. 2003 for extended reviews of models), but are generally intended for modeling individual watersheds. A few other models such as N-SPECT and SedNet are intended for larger scales (Álvarez-Romero et al. 2014). Though RUSLE was developed at the field scale, its simple multiplicative factor approach is well suited to broad scale GIS based modeling in rangelands (Blaszczynski 1992) and elsewhere (Demirci and Karaburun 2012; Erdogan et al. 2007).

\section{Implications}

Modeled erosion potential in California's rangelands was remarkably low (mean well below 1 ton per acre per year), and less than for most land uses in most states reported in the 2012 National Resources Inventory (USDA 2015). Actual erosion in a given area could be much higher. Areas with high erosion potential exist throughout the state. Such hot spots where erosion potential was especially high represent instances where a combination of some or all factors $(R, K, L S)$ creates an environment favorable for substantial soil loss. These locations must be managed carefully. 


\section{References}

Álvarez-Romero JG, Wilkinson SN, Pressey RL, et al. 2014. Modeling catchment nutrients and sediment loads to inform regional management of water quality in coastal-marine ecosystems: A comparison of two approaches. J Environ Manage 146:164-78.

Amundson R, Berhe AA, Hopmans J, et al. 2015. Soil and human security in the 21st century. Science 348(6235). https://doi.org/10.1126/sci ence.1261071.

Bartolome JW, Allen-Diaz BH, Barry S, et al. 2014. Grazing for biodiversity in California Mediterranean grasslands. Rangelands 36(5):36-43.

Bartolome J, Betts A. 2005. Residual dry matter impacts on water quality and biomass production. Proceedings of UC Sierra Foothill Research and Extension Center Field Day, April 21, 2005.

Bartolome JW, Frost W, McDougald N. 2006. Rangeland Monitoring Series: Guidelines for Residual Dry Matter on Coastal and Foothill Rangelands in California. UC ANR Pub 8092. Oakland, CA

Bartolome JW, Jackson RD, Betts ADK, et al. 2007. Effects of residual dry matter on net primary production and plant functional groups in Californian annual grasslands. Grass Forage Sci 62(4):445-52.

Bartolome JW, Stroud MC, Head HF. 1980. Influence of natural mulch on forage production on differing California annual range sites. J Range Manage 33(1):4-8. Becchetti T, George M, McDougald N, et al. 2016. Rangeland Management Series: Annual Range Forage Production. UC ANR Pub 8018. Oakland, CA

Beckmann G, Smith K. 1974.

Micromorphological changes in surface soils following wetting, drying and trampling. In: Soil Microscopy Proceedings of the Fourth International Working Meeting on Soil Micromorphology. Rutherford GK (ed.). Ontario, Canada: Limestone Press.

Blaszczynskl J. 1992. Regional soil loss prediction utilizing the RUSLE/GIS interface. In: Geographic Information Systems (GIS) and Mapping - Practices and

Standards, ASTM STP 1126. Johnson Al, Pettersson CB, Fulton JL (eds.). Philadelphia: American Society for Testing and Materials. p 122-31.

Borah DK, Bera M. 2003.

Watershed-scale hydrologic and nonpoint-source pollution models: Review of mathematical bases. T Am Soc Agr Eng 46(6):1553-66.
Briske DD, Sayre NF, Huntsinger $L$, et al. 2011. Origin, persistence, and resolution of the rotational grazing debate: Integrating human dimensions into rangeland research. Rangeland Ecol Manag 64(4):325-34.

[Cal Fire] California Department of Forestry and Fire Protection. 2015. Fire and Resource Assessment Program (FRAP) Vegetation: FVEG15_1. http://frap.fire. ca.gov/data/frapgisdata-swfveg_download (accessed February 2016).

Dahlgren RA, Singer MJ, Huang X. 1997. Oak tree and grazing impacts on soil properties and nutrients in a California oak woodland. Biogeochemistry 39(1):45-64.

Demirci A, Karaburun A. 2012 Estimation of soil erosion using RUSLE in a GIS framework: A case study in the Buyukcekmece Lake watershed, northwest Turkey. Environ Earth Sci 66(3):903-13.

De Ploey J. 1982. A stemflow equation for grasses and similar vegetation. Catena 9(12):139-52.

Dunne T, Zhang W, Aubry BF. 1991. Effects of rainfall, vegetation, and microtopography on infiltration and runoff. Water Resour Res 27(9):2271-85.

Ehlschlaeger C. 2015. r.watershed Raster Module for GRASS GIS. US Army Construction Engineering Research

Laboratory.

Erdogan EH, Erpul G, Bayramin I. 2007. Use of USLE/GIS methodology for predicting soil loss in a semiarid agricultural watershed. Environ Monit Assess 131(1-

3):153-61.

Foster GR, Toy TE, Renard KG. 2003. Comparison of the USLE, RUSLE1.06c, and RUSLE2 for application to highly disturbed lands. In: Renard KG, McElroy SA, Gburek WJ, et al. (eds.). First Interagency Conference on Research in the Watersheds, Oct. 27-30, 2003. US Department of Agriculture Agricultural Research Service.

George M, Larsen R, McDougald $\mathrm{N}$, et al. 2004. Cattle grazing has varying impacts on streamchannel erosion in oak woodlands. Calif Agr 58(3):138-43. https://doi.org/10.3733/ ca.v058n03p138

George M, Larsen R, McDougald N, et al. 2010. Determining drought on California's Mediterranean-type rangelands: The noninsured crop disaster assistance program. Rangelands 32(3):16-20.
George MR, McDougald NK, Tate KW, Larsen RE. 2002. Sediment dynamics and sources in a grazed hardwood rangeland watershed. In: Standiford RB, McCreary D, Purcell KL (eds.) Proc 5th Symposium on Oak Woodlands: Oaks in California's Changing Landscape. USDA Gen Tech PSW-184. p 65-73.

Hodgkinson K. 1993. Tactical grazing can help maintain stability of semi-arid wooded grasslands. Proc XVII International Grasslands Congress. p. 75-6.

Jasiewicz J, Stepinski TF. 2013. Geomorphons-a pattern recognition approach to classification and mapping of landforms. Geomorphology 182:147-56.

Knoll G, Hopkins HH. 1959. The effects of grazing and trampling upon certain soil properties. Trans Kansas Acad Sci (1903-) 62(4):221-31.

Lewis D, Harper J, Price J. 2001. Survey identifies sediment sources in North Coast rangelands. Calif Agr 55(4):32-8.

http://calag.ucanr.edu/

Archive/?article $=$ ca.v055n04p32

Lewis DJ, Singer MJ, Dahlgren

RA, Tate KW. 2006. Nitrate and sediment fluxes from a California rangeland watershed. Environ Qual 35(6):2202-11.

Lewis DJ, Tate KW, Huerta M, et al. 2008. Stemple Creek Watershed Water Quality Analysis. Report to USDA Conservation Effectiveness Assessment Program.

Li L, Du S, Wu L, Liu G. 2009. An overview of soil loss tolerance. Catena 78(2):93-9.

Menke J, Bradford EG. 1992 Rangelands. Agr Ecosyst Environ 42(1-2):141-63.

Merritt WS, Letcher RA, Jakeman AJ. 2003. A review of erosion and sediment transport models. Environ Modell Softw 18(8-9):761-99.

Milchunas DG, Lauenroth WK 1993. Quantitative effects of grazing on vegetation and soils over a global range of environments. Ecol Monogr 63(4):327-66.

Nearing MA. 1998. Why soil erosion models over-predict small soil losses and underpredict large soil losses. Catena 32(1):15-22.

Nearing MA, Wei H, Stone JJ, et al. 2011. A rangeland hydrology and erosion model. Trans ASABE 54(3):901-8

[OSTP] White House Office of Science and Technology Policy. 2016. A call to action to save one of America's most important natural resources. https:// obamawhitehouse archives. gov/blog/2016/08/01/call-ac tion-save-one-americas-mostimportant-natural-resources (accessed Dec. 20, 2017).

[OTA] Office of Technical Assessment 1982. Impacts of Technology on US Cropland and Rangeland Productivity. Government Printing Office.

Pellant M, Shaver P, Pyke DA Herrick JE. 2005. Interpreting Indicators of Rangeland Health, Vol. 4. Bureau of Land Management Technical Reference

1734-6.

Pimentel D, Harvey C, Resosudarmo P, et al. 1995. Environmental and economic costs of soil erosion and conservation benefits. Science 267:1117-23.

Renard KG, Foster GR, Weesies GA et al. 1997. Predicting Soil Erosion by Water: A Guide to Conservation Planning with the Revised Universal Soil Loss Equation (RUSLE). Agriculture Handbook No. 703. USDA ARS. 404 p.

Renard KG, Stone JJ. 1982. Sediment yield from small semiarid rangeland watersheds. Proc Workshop on Estimating Erosion and Sediment Yield on Rangelands, ARM-W-26.

Salls WB. 2016. Grazing the Surface: Estimating Erosion Potential across California's Rangelands. Masters thesis, in Dept. of Land, Air and Water Resources, UC Davis. 50 p.

Schuman GE, Janzen $\mathrm{HH}$ Herrick JE. 2002. Soil carbon dynamics and potential carbon sequestration by rangelands. Environ Pollut 116(3):391-6.

Singer M, Blackard J, Huntington G. 1980. Plant cover helps control rangeland soil erosion. Calif Agr 34(10):8-10. http://calag. ucanr.edu/archive/?article=ca. v034n10p8

Ditzler C, Scheffe K, Monger HC (eds). 2017. Soil Survey Manual. USDA Handbook No. 18. Government Printing Office, Washington, DC. Spaeth KE Jr, Pierson FB Jr. Weltz MA, Blackburn WH. 2003. Evaluation of USLE and RUSLE estimated soil loss on rangeland. J Range Manage 56(3):234-46.

[SWRCB] California State Water Resource Control Board. 2012 Isoerodent $R$ value. www. waterboards.ca.gov/water_is sues/programs/stormwater/ 


\section{University of California}

Agriculture and Natural Resources

\section{California Agriculture}

2801 Second Street

Room 181A

Davis, CA 95618-7779

Phone: (530) 750-1223

Fax: (530) 756-1079

\section{Visit us online:}

calag.ucanr.edu

twitter3 @Cal_Ag

www.facebook.com/CaliforniaAgriculture

\section{Upcoming UC and UC ANR events}

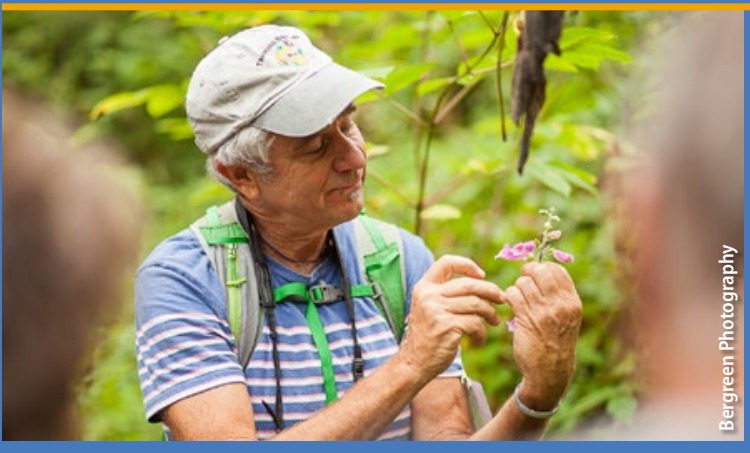

Point Reyes National Seashore Association CalNat Course

http://calnat.ucanr.edu/Take_a_class/PRNSA/

Date: $\quad$ September 22-October 20, 2018

Time: $\quad$ 9:00 a.m. to 5:00 p.m.

Location: Morgan Horse Ranch, Point Reyes National Seashore

Contact: fieldinstitute@ptreyes.org

Firewise Practices for Home Landscape - Sonoma

http://ucanr.edu/?calitem $=420897$

Date: October 6, 2018

Time: $\quad 8: 30$ a.m. to $12: 30$ p.m.

Location: Sonoma Community Center

Contact: Stan Pawlak stan.pawlak@gmail.com
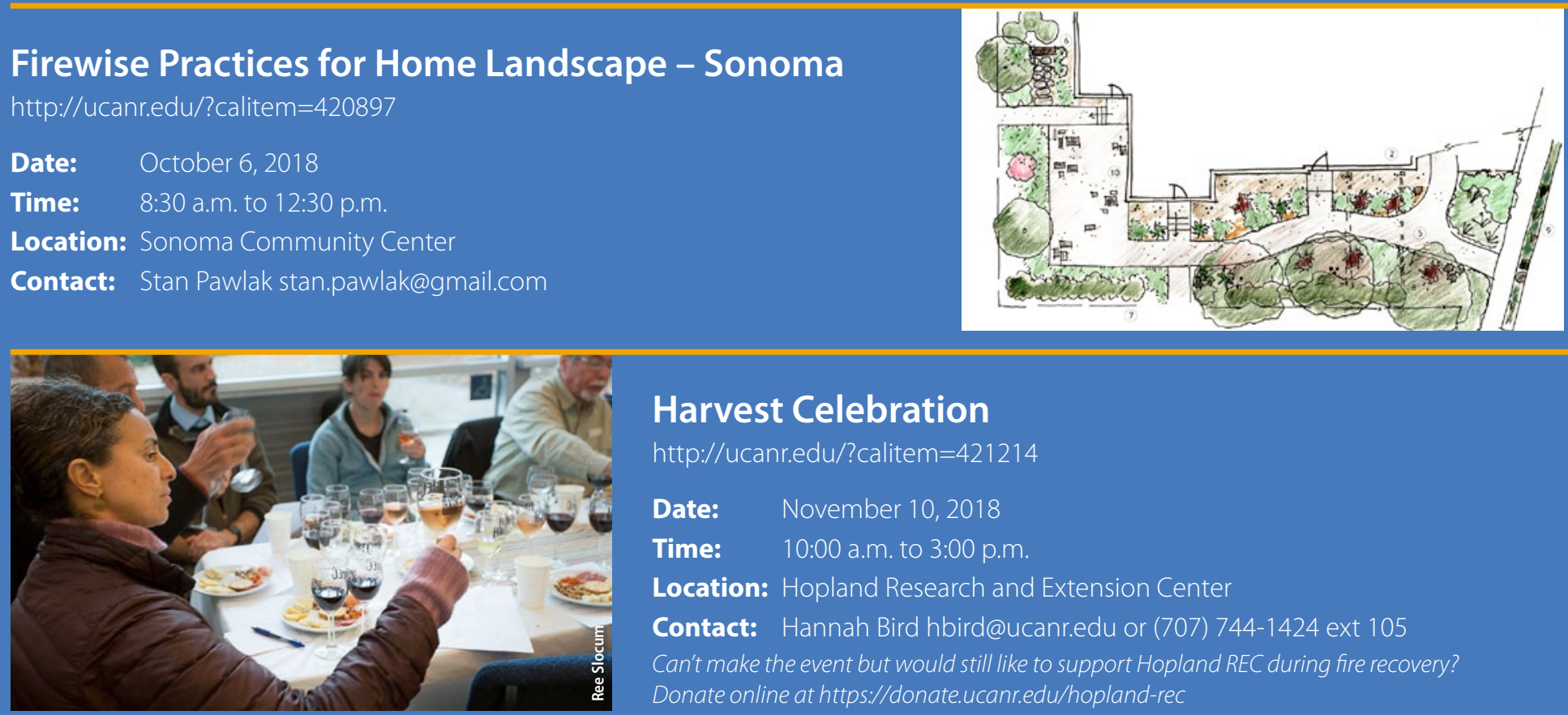

Harvest Celebration

http://ucanr.edu/?calitem=421214

Date: $\quad$ November 10, 2018

Time: $\quad$ 10:00 a.m. to 3:00 p.m.

Location: Hopland Research and Extension Center

Contact: Hannah Bird hbird@ucanr.edu or (707) 744-1424 ext 105

Can't make the event but would still like to support Hopland REC during fire recovery?

Donate online at https://donate.ucanr.edu/hopland-rec 